\title{
Examining predictors of marital satisfaction among age-similar and age-discrepant older couples
}

Kristi A. Barnes

West Virginia University

Follow this and additional works at: https://researchrepository.wvu.edu/etd

\section{Recommended Citation}

Barnes, Kristi A., "Examining predictors of marital satisfaction among age-similar and age-discrepant older couples" (2003). Graduate Theses, Dissertations, and Problem Reports. 1915.

https://researchrepository.wvu.edu/etd/1915

This Dissertation is protected by copyright and/or related rights. It has been brought to you by the The Research Repository @ WVU with permission from the rights-holder(s). You are free to use this Dissertation in any way that is permitted by the copyright and related rights legislation that applies to your use. For other uses you must obtain permission from the rights-holder(s) directly, unless additional rights are indicated by a Creative Commons license in the record and/ or on the work itself. This Dissertation has been accepted for inclusion in WVU Graduate Theses, Dissertations, and Problem Reports collection by an authorized administrator of The Research Repository @ WVU.

For more information, please contact researchrepository@mail.wvu.edu. 
Examining predictors of marital satisfaction among age similar and age discrepant older couples

\author{
Kristi A. Barnes \\ Dissertation submitted to the \\ Eberly College of Arts and Sciences \\ at West Virginia University \\ in partial fulfillment of the requirements \\ for the degree of \\ Doctor of Philosophy \\ in \\ Developmental Psychology
}

\author{
Julie H. Patrick, Ph.D., chair \\ Rick Briggs, Ph.D. \\ Stanley H. Cohen, Ph.D. \\ Barry A. Edelstein, Ph. D. \\ Jennifer A. Margrett, Ph. D. \\ Department of Psychology
}

Morgantown, WV 2003

Keywords: Marital Satisfaction, Age-discrepancy, Gender, Household Tasks, Sex Roles, Psychological well-being 


\begin{abstract}
Examining predictors of marital satisfaction among age similar and age discrepant older couples.
\end{abstract}

\title{
Kristi A. Barnes
}

Sociocultural and demographic trends suggest the importance of examining the marital experience among older adults, and those who are in non-traditional marriages in particular. The current study examined the marital experiences of middle-aged and older individuals who are involved in long-term $(15$ yrs. or longer $)$ age-similar $(n=35)$ and age-discrepant marriages $(n=$ 35). All information was gathered through telephone interviews. Analysis of variance tests examined mean differences as a function of type of marriage (2; ADM and AS) and gender (2). These analyses revealed no differences between marriage types on a number of measures of marital satisfaction. However, gender differences, consistent with the literature, emerged on most measures. Given the growing percentage of older adults and the link between marital satisfaction and well being, the results of this study suggest the importance of additional research examining gender-based differences in marital satisfaction. 


\section{Acknowledgements}

I would like to thank Dr. Julie Patrick for the guidance that she gave me throughout each phase of this study. I also would like to thank Amber Barse, Kelly Littlehale, Stephanie Maloney, Erin Mullins, Tricia Thames, and Jennifer Wiles who served as research assistants on this investigation. Their hard work and conscientiousness helped to expedite data collection. I am indebted to several colleagues, friends, and family members who provided me with support, encouragement, and referrals. I also would like to thank my committee members: Dr. Rick Briggs, Dr. Stan Cohen, Dr. Barry Edelstein, and Dr. Jennifer Margrett. I am grateful to them for the time that they invested in helping to shape this research study and the written document. I am thankful to all of these people because their efforts made it possible for me to complete this project successfully. 


\section{Table of Contents}

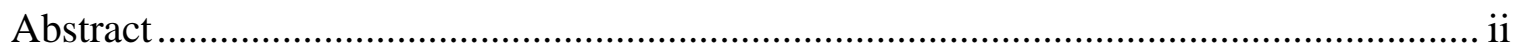

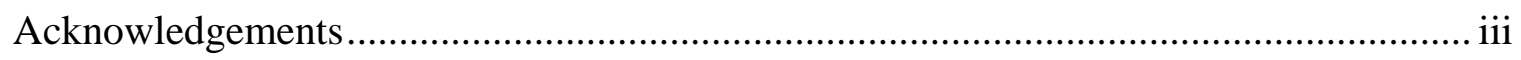

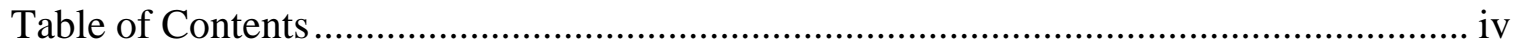

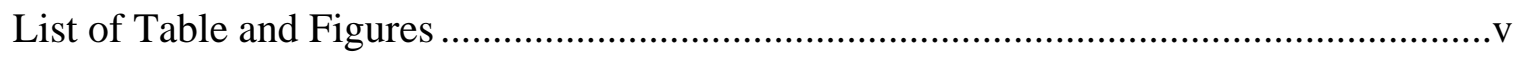

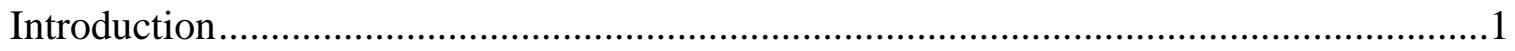

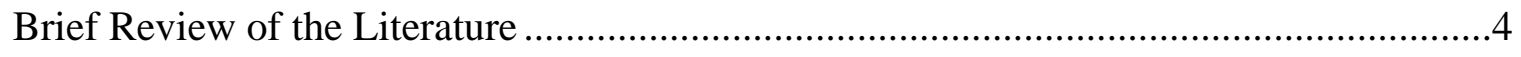

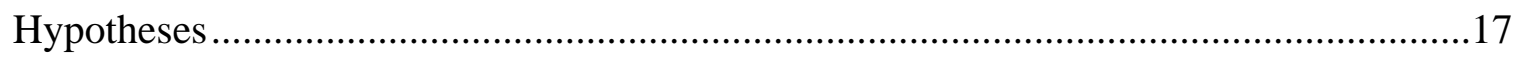

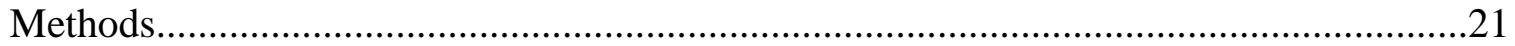

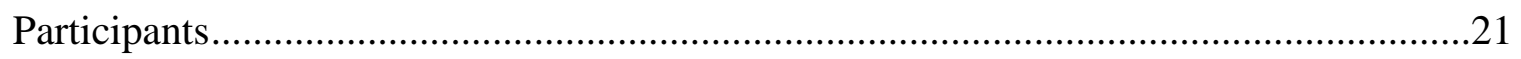

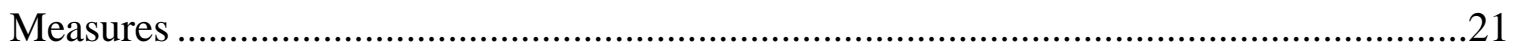

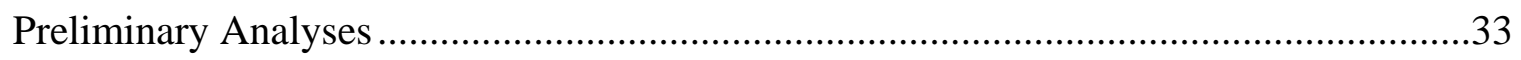

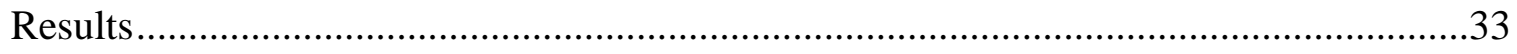

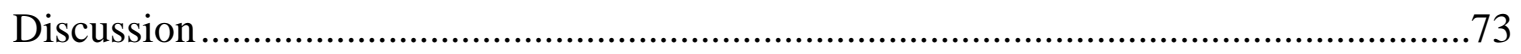

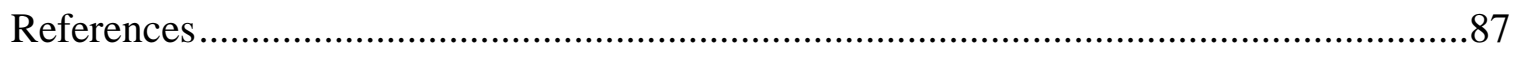

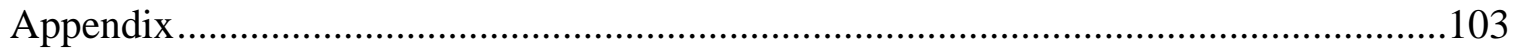


List of Tables and Figures

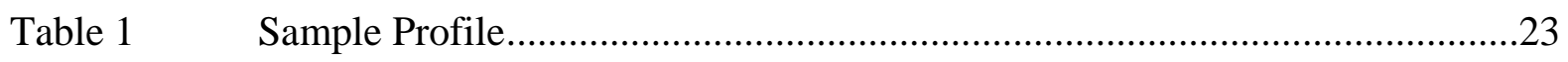

Table 2 Profile of sample outcomes by gender and marriage type............................24

Table 3 Correlations Among EE and Marital Satisfaction Scales ........................ 35-36

Table 4 Correlations Among Demographic Variables and Outcome Measures..... 40-44

Table 5 Marriage Type as a Predictor of DAS Satisfaction Subscale Scores...............52

Table $6 \quad$ Marriage Type as a Predictor of DAS Consensus Subscale Scores.................53

Table $7 \quad$ Marriage Type as a Predictor of DAS Composite Scores...............................55

Table $8 \quad$ Marriage Type as a Predictor of Conflict Scores .........................................56

Table 9 Marriage Type as a Predictor of Ambivalence Scores...................................57

Table $10 \quad$ Marriage Type as a Predictor of Maintenance Scores ..................................58

Table 11 Examining the Relation Among the Correlates of Marital Satisfaction and Psychological Well-Being ....................................................................61

Table 12 Profile of marital satisfaction among individuals in marriages that include an employed wife ............................................................................. 72

Figure 1 Path Model of the Correlates of Marital Satisfaction and their Relation to Psychological Well-Being ....................................................................60 


\section{Chapter 1}

\section{Statement of the Problem}

Socioemotional selectivity theory (SST; Fredrickson \& Carstensen, 1990) suggests that with advanced age, close interpersonal relationships become more valued. Therefore, the spouse becomes increasingly important as a source of support and satisfaction (Carstensen, Isaacowitz, \& Charles, 1999; Frederickson \& Carstensen; Lang \& Carstensen, 1994). Thus, a better understanding of the factors affecting marital satisfaction among older adults is important. A limitation to the current knowledge base regarding late-life marital satisfaction is that most of it is derived from studies in which both partners are in late-life. However, Census data indicate that age-discrepant marriages (ADM) account for nearly one quarter of all marriages (U.S. Bureau of the Census, 2001). ADMs will likely become more prominent in light of increased life expectancy and other changing sociocultural trends (Winston \& Klepfer, 2000). Yet, the literature does not reflect this growing population of married couples. It is important to examine marital quality among partners who are at different life stages because the demands and resources available at different points of the adult life span may directly and indirectly affect marital satisfaction and global well-being (Carstensen et al.; Frederickson \& Carstensen).

Sustaining a marriage poses multiple challenges across the lifespan. However, marital partners of different generational cohorts may face additional and unique challenges. Three areas, demonstrated to be challenging to most marriages, may pose especially powerful threats to marital satisfaction among age-discrepant couples. These include the division of household tasks, social needs and goals, and gender role ideologies.

Research indicates that there is a change in the division of household labor that accompanies retirement (e.g., Kulik, 1999; 2001) and that perceptions regarding the fairness of 
this division relate to marital satisfaction among women (Ward, 1993). According to Pina and Bengston (1995), wives view a lack of domestic assistance as a lack of support. Cohort differences in gender role ideologies (Amato, Johnson, Booth, \& Rogers, 2003), coupled with the link between traditional attitudes and a gender segregated division of labor (e.g., Kurdek, 1998), suggest that wives married to men who are significantly older may experience particularly low levels of support from their husbands. However, this pattern may reverse for males as they transition into retirement earlier than their spouses do; upon retirement, men’s domestic contributions potentially increase. Also, as SST states, emotional needs become more prominent with age. Therefore, gender-based differences in perceptions of spousal support may be reversed during the cycle of marriage for age-discrepant couples as differences in life-stage become more salient.

In addition to the effects of age and gender, the division of household tasks and social goals may be influenced by gender role ideologies. Research confirms a link between gender role ideologies and men’s contributions to household tasks (e.g., Kurdek, 1998). Older adults may have more traditional attitudes regarding gender roles (Byrne \& Murnen, 1988), although there is evidence of a progression toward more egalitarian roles among successive generations of adults (e.g., Amato et al., 2003). Whether individuals in ADMs hold incongruent gender role ideologies is an empirical question that remains unanswered.

Another area that may pose challenges to late-life couples, but especially to couples in ADMs, concerns the extent to which their social needs and goals are congruent. In essence, SST indicates that older and middle-aged adults have different motivations for continued social interactions. Older adults are motivated to maintain and increase the positive emotional consequences of familiar relationships, whereas middle-aged adults tend to seek out multiple 
relationships for their informational resources (Carstensen et al., 1999; Fredrickson \& Carstensen, 1990). Empirical evidence indicates that retirement coincides with a greater emphasis on family-related issues for men (e.g., Kulik, 1999). Thus, ADM couples may not share common social needs and goals.

Examining the experiences of this emerging, but overlooked population of married adults may provide useful insights regarding how the components of a relationship affect marital satisfaction (Acitelli \& Antonucci, 1994; Levenson, Carstensen, \& Gottman, 1993). Thus the goals of the proposed study are:

1. To compare the marital satisfaction of age-discrepant couples, who are in long-term marriages, to their middle-aged and older counterparts who are age-similar;

2. To compare gender differences in marital satisfaction, within and across marriage type;

3. To examine the division of household tasks between partners in age-similar and agediscrepant couples;

4. To explore gender-role ideologies between partners in age-similar and age-discrepant marriages; and

5. To test the ways in which gender and marriage type interact with the division of household tasks, social needs and goals, and attitudes toward sex roles to explain variance in marital satisfaction and psychological well-being. 


\section{Chapter 2}

Review of the Literature

\section{Overview of Socioemotional Selectivity Theory (SST)}

According to socioemotional selectivity theory (SST), the nature and frequency of interactions among people vary as a function of life stage (Carstensen, et al., 1999; Fredrickson \& Carstensen, 1990; Lang \& Carstensen, 1994). More specifically, as individuals age, there is a greater emphasis on maximizing those relationships associated with positive interactions (Carstensen et al., 1999; Fredrickson \& Carstensen, 1990). The social interactions of younger adults are motivated by a concern for information. Therefore, children, younger- and middleaged adults typically have numerous relationships. However, not all of these relationships are especially meaningful.

Older adults are motivated by emotional "connectedness." These adults are less interested in investing their time on relationships that may not have the opportunity to develop; nor are they interested in the potentially negative interactions associated with less familiar partners. Consequently, older adults often prefer to interact with familiar partners with whom they have had positive contact (Carstensen et al., 1999; Fredrickson \& Carstensen, 1990).

Studies examining preferences for social partners provide further evidence of changing emotional needs across the life span (Lang \& Carstensen, 1994). Specifically, research indicates that the social networks of older adults are comprised of family members to a greater extent than those of younger adults. This suggests that as people age, and parents and siblings die, the spouse becomes an increasingly important source for potential support. It is important to recognize that the significance of the spouse as a potential source of social support may not be equal for men and women. The literature provides empirical support for gender differences in the structure and 
function of social support (Patrick, Cottrell, \& Barnes, 2001; Stokes \& Wilson, 1984); men depend more heavily on family members for support, while women are more dependent upon friends. Therefore, examining marital satisfaction among older men and women is of particular importance.

Overview of Late-Life Marriage Patterns

Over the last three decades there have been significant changes in patterns of marital status and family structure (Amato et al., 2003; Bytheway, 1981; Klinger-Vartabedian \& Wispe, 1989; Merriam \& Hyer, 1984; U.S. Bureau of the Census, 2001). Specifically, both men and women are delaying first marriages (U.S. Bureau of the Census). Compared to statistics from 1970, the median age of first marriage for women has increased from 20.8 years to 25.1 years. The median age at first marriage for men has increased to26.8 years. This is an increase of more than 3.5 years.

These demographic shifts have been precipitated by changing cultural norms that have moved away from "traditional" conceptions of gender identities to more "modern" conceptualizations of men’s and women's roles (Burke \& Cast, 1997; Bytheway, 1981; Levenson, et al., 1993; Snyder, Valasquez \& Clark, \& Means-Christensen, 1997). Demographic shifts have not only affected age at first marriage, but have also contributed to an emerging group of age-discrepant marriages (ADMs; Bonds \& Nicks, 1999; Davis, 1998; KlingerVartabedian \& Wispe, 1989; U.S. Bureau of the Census, 2001), with marital partners often belonging to different generational cohorts. ADMs are expected to become more common given the high divorce rate and the number of women in less traditional roles; these non-traditional women typically delay the onset of first marriage and child-bearing, and thereby constrain their pool of potential marriage partners to older men who have likely been divorced (Bonds \& Nick, 
1999; Davis, 1998; U.S. Bureau of the Census, 2001). A review of the data by Winston and Klepfer (2000), further substantiates the link between divorce and male-older marriages. Winston and Klepfer also contend that as people delay marriage, they continue to constrain the availability of potential marriage partners who share characteristics common to theirs. Although the percentage of ADMs constitute one quarter of all marriages, and sociocultural trends suggest that ADMs will become more prominent, the interactions between younger and older partners in long-term marriages have received little empirical attention. Examining these relationships, which typically consist of an older man and a comparatively younger woman would allow researchers to extend the existing literature on marital satisfaction to include the potential impact of age-related changes in life stage on the interactions between partners (Bonds \& Nick; Davis).

To date, empirical research is limited by a lack of consensus regarding the operationalization of ADMs (Bonds \& Nicks, 1999). For example, some studies have examined age differences as minimal as one year, while others have examined discrepancies in excess of eighteen years. As a result, it is difficult to establish any meaningful conclusions based on the existing literature (for a review see, Berardo, Appel, \& Berardo, 1993; Shehan, Berardo, Vera, \& Carley, 1991).

According to Berardo et al. (1993) some investigators have defined age discrepant couples to include those who differ in age by as little as one year. Shehan et al. (1991) have indicated a wide variety of definitions in the literature: 3 yrs. (Cramer, 1993), 4 yrs., 5 yrs., or 10 years and greater. Cowan (1984) distinguished between moderately (7 yrs.) and highly (18 yrs. or more) age discrepant couples. The lack of a systematic definition for age discrepancy makes it difficult to examine differences in age-discrepant couples. Also, differences between same-age 
couples and couples who differ in age by 3 years could be significantly fewer than comparisons to couples who have an 18 year age difference.

In spite of these inconsistencies, a bulk of the research on couples who are dissimilar in age does indicate that male-older marriages are more common than female-older marriages (Berardo et al., 1993; Bonds \& Nick, 1999; Davis, 1998; Klinger-Vartabedian, \& Wispe, 1989; Shehan et al., 1991; U.S. Bureau of the Census, 2001). Specifically, recent Census data indicate that $19.6 \%$ of all marriages are comprised of husbands who are 6 or more years older than their wives; whereas, only 3.3\% of all marriages are comprised of women who are 6 or more years older than their husbands. A majority of these couples involve a man who is marrying for the second time and a woman who is marrying for the first. Despite these statistics, there are no known studies that have explicitly compared long-term marriages of older and middle-aged adults who are age similar to those who are age-discrepant.

\section{Marital Satisfaction}

Current statistics indicate that the rate of divorce declined only slightly in 2001 (47.06\%) in comparison to 49\% in 1999 (National Center for Health Statistics, 2002). Despite high divorce rates and changing marital patterns, there is substantial evidence of the potential physical and psychological benefits of having a satisfied marriage (e.g., Klinger-Vartabedian \& Wispe, 1989). Marital satisfaction has been traditionally conceptualized according to socially defined standards of happiness and stability (Hicks \& Platt, 1970). Happiness, satisfaction, success and adjustment are commonly used indices of marital satisfaction. The "individual's feelings" approach and "marital adjustment" are the two major perspectives of marital satisfaction (Glenn, 1998). Therefore, marital quality is measured according to the individual's sentiments regarding the marriage and the nature of the dyad, respectively. 
There have been various perspectives regarding the pattern of marital satisfaction across the marital relationship (Gagnon, Hersen, \& Kabacoff, 1999; Glenn, 1998; Hicks \& Platt, 1970). These perspectives underscore the dynamic nature of the marital relationship and imply several normative and non-normative changes that may be linked to marital quality over time. One of the most widely accepted perspectives on marital quality suggests that there is a curvilinear relationship between marital satisfaction and the number of years married (Gagnon et al.; Orbuch, House, Mero, \& Webster, 1996). More specifically, studies examining long-term marital success suggest that marital satisfaction is highest during the first years of marriage, after which point satisfaction begins to decrease. This reflects the concept of "goodness of fit" (Pineo, 1961). Byrne \& Murnen (1988) note in an overview of the research, that compatibility is one of the key factors related to the survival of a relationship. According to the literature, couples who have congruent attitudes, values, education, religious beliefs, and who are similar in age should be more likely to maintain their relationships when compared to couples who differ from each other on these characteristics. Differences in these domains present a potential source of conflict.

Age differences are particularly detrimental because the attitudes of younger adults are influx as they mature; whereas the attitudes of mature adults are more firmly established and less likely to be significantly altered by experience (e.g., Norris et al., 1997). "Goodness of fit" suggests that with time, couples realize that they are "mismatched" and divorce. For those couples who remain married, satisfaction is said to improve during middle age and continues to improve throughout adulthood. Although there may be inconsistencies regarding the specific pattern of marital satisfaction, there is obvious support for the underlying concept of change across the marriage among partners who are age similar (Hicks \& Platt, 1970). Yet there is relatively little research that extends what is known about patterns of change to the growing 
percentage of older adults who are involved in long-term or multiple marriages (Acitelli \& Antonucci, 1994; Levenson et al., 1993). The lack of research pertaining to couples involved in ADMs is particularly evident.

It is important to recognize that numerous factors influence the quality of interactions between marital partners (Gagnon et al., 1999; Gilford, 1984; Glenn, 1998; Hicks \& Platt, 1970; Orbuch et al., 1996; Wright \& Aquilino, 1998). In fact, a bulk of the literature implies that many of the factors that influence marital quality are consistent with those changes associated with stages of maturation (Gagnon et al.; Glenn; Hicks \& Platt; Orbuch et al.). First, there is evidence that children may affect marital satisfaction (Gagnon et al.; Hicks \& Platt; Orbuch et al.), with issues related to child rearing creating a potential source of conflict (Gagnon et al., 1999). Another potential source of stress arises when children leave the home (Orbuch et al.). The absence of children often involves redefining the respective roles of husband and wife.

Second, career demands stress the relationship during the early years of the marriage as individuals strive to achieve their professional goals (Orbuch et al., 1996). Another career-related stress concerns the transition into retirement (e.g., Kulik, 2001). Although the onset of retirement may initially strain the relationship, research among age-similar partners indicates a positive relation between the opportunity for interaction associated with retirement and marital satisfaction (Orbuch et al.; Szinovacz, 1996). More specifically, the increased frequency and higher quality of marital interactions among retired couples have been associated with higher marital satisfaction (Gagnon et al., 1999). Increased financial stability linked to retirement and age is also positively correlated with marital quality (e.g., Orbuch et al.).

The potential impact of children leaving the home and retirement suggests that the "goodness of fit" between partners is challenged throughout adulthood (Pineo, 1961). However, 
age-discrepant couples face different issues as one partner enters a different life stage. This is an issue that becomes increasingly salient as one partner enters or nears the last stage of life because couples who are at different life stages may experience greater conflict and strain associated with incompatible attitudes and goals.

Kulik (2001) compared employed couples to those who were synchronous and asynchronous for retirement. The results of this comparison suggest that gender may have implications for those couples who are at similar life stages versus those who are not. Kulik noted that retirement synchrony and marital roles affected division of household labor, a potential source of conflict among many couples (e.g., Brooks, 2000; Thompson \& Walker, 1989). Kulik’s findings suggested that the division of household labor was more egalitarian among retired couples versus those couples who were not retired. Couples in which the husband was retired and the wife was still employed demonstrated a pattern of labor division similar to that of retired couples. However, couples in which the wife was retired and the husband was employed demonstrated a pattern of labor division more consistent to that of employed couples. Thus, wives were disproportionately responsible for more tasks than husbands. These findings are consistent with previous research (Kulik, 1999) indicating that husbands who are married to working women have more modern gender role ideologies and less traditional attitudes regarding the division of labor.

Several potential explanations for a gendered division of household labor have been posited (Blair \& Lichter, 1991). One explanation suggests that household responsibilities continue to be shouldered by women because women are socialized to adopt this as part of their identity as a woman. Therefore, many women may discourage help from their husbands because this challenges their self-identity. Recognizing that husbands contribute more to household duties 
upon retirement (Atchley, 1992), regardless of their wife’s employment status, may suggest a potential source of conflict as men encroach upon what has traditionally been accepted as a “woman’s domain.” This may be an issue that is more pronounced for ADMs who transition into retirement at different times. Although Kulik's (1999; 2001) results do not suggest that age discrepancy may exacerbate potential sources of conflict that couples in age-similar marriages have already confronted and resolved, it is important to recognize that no specific data regarding age similarity between partners was provided. Moreover, Kulik's (2001) study focused on Israeli couples who were in dual-earner marriages. As a result, the potential impact of culture may fail to extend to American couples.

Kurdek (1998) provides further support for the link between gendered divisions of household labor and gender socialization. Kurdek examined the relation among division of household labor, gender role orientation, and marital satisfaction. The link between gender role orientation and division of household labor were consistent with Kulik’s (1999; 2001) findings. Although the women in Kulik's sample shouldered more of the household responsibilities than men, the division of household labor was not significantly related to marital satisfaction. According to Kulik, this may be because an inequitable division of household labor is consistent with traditional views regarding the roles of men and women and is therefore congruent with the expectations of both husbands and wives.

Ward’s (1993) study provides additional insight regarding the relation between marital satisfaction and the division of household labor. Unlike Kurdek (1998), Ward's study provided evidence supporting the link between the division of household labor and marital satisfaction for wives, but not husbands. These findings have been replicated in several studies (e.g., Grote and Clark, 2003; Pina \& Bengston, 1995 ). According to Ward, unequal divisions of household labor 
are not responsible for gender differences in marital satisfaction. Rather, the link to marital satisfaction is based on whether wives consider these labor divisions to be fair. Pina and Bengston suggest that marital satisfaction may diminish for wives because they view help with domestic tasks as a form of support from their spouses. Although research indicates a consensus between husbands' and wives’ views regarding the fairness of labor divisions, marital satisfaction among men remains unaffected by this imbalance because existing labor divisions spare them additional domestic responsibilities (Amato et al., 2003; Grote and Clark; Ward).

Several studies have linked gender role ideologies to the division of household labor (e.g., Kurdek, 1998), yet the impact of aging on attitudes toward sex roles remains unclear (e.g., Kulik, 1999; Norris, Snyder, \& Rice, 1997). Norris et al. found evidence that younger adults displayed more modern gender role ideologies when compared to older adults. Norris et al. note that the differences between younger and older couples may reflect differences in socialization related to cohort. As a result couples who are age discrepant may be more likely to experience conflicts related to the impact of cohort differences on attitudes toward sex roles. However, Burke and Cast (1997) note that newlyweds who have a newborn during the first year of marriage experience changes in gender identity that accompany gender role taking. According to Burke and Cast, gender-role-taking yields more congruency between partners in regards to gender identity. The implications of Burke and Cast's study indicate that retirement may present the same opportunity for gender role taking among ADMs that the birth of a child does for newlyweds. These are issues that have yet to be examined among older couples and ADMs in particular. 


\section{$\underline{\text { Marital satisfaction and Gender }}$}

Fowers (1991) noted that a number of factors may contribute to gender-based differences in perceptions of marital quality. Indeed, SST specifies this trend as well. Levenson and colleagues (1993) note that a review of related research suggests that men evaluate marriage favorably, regardless of marital quality. Gender differences in perceptions of marital satisfaction provide support for the concept of "his and her" marriages. In fact, there is evidence that marital satisfaction is greater among men across the lifespan and in a variety of domains relevant to the relationship (Fowers, 1991; Levenson et al., 1993; Rhyne, 1981). This is of particular importance given the inverse relation between marital quality and mortality (e.g., Klinger-Vartabedian \& Wispe, 1989).

Although both men and women benefit from satisfying marriages, Levenson et al. (1993) note that a bulk of the literature suggests that dissatisfying marriages appear to be more detrimental to women. One issue that impacts the goodness of fit is the potentially unequal benefits of marriage that have been widely documented in the empirical literature (e.g., Acitelli \& Antonucci, 1994; Fowers, 1991; Klinger-Vartabedian \& Wispe, 1989; Kiecolt-Glaser \& Newton, 2001). Research indicates that married men report greater life satisfaction than married women; this finding parallels previous research suggesting that husband characteristics and behaviors are more salient to marital satisfaction among women than characteristics of the wife are to satisfaction among men (Bollman, Schumm, \& Jurich, 1997; Fowers, 1991; Levenson et al., 1993). These trends suggest that the marital experience may be associated with genderdifferentiated psychological and physical outcomes that favor men.

As in the division of household labor, these differences may also be related to gender-role orientations that reflect gender biases that favor men (Martin, 1985). Gender role orientations 
(i.e., "traditionals" versus "moderns") are believed to influence expectations of marital interactions in relation to outputs and rewards. In fact, reward expectations of "moderns" are significantly higher than those for "traditionals.” The relation between gender role orientations and marital satisfaction is of growing importance given changing sociodemographic trends that challenge traditional gender roles that portray men as more powerful than women (Merriam \& Hyer, 1984; Rogers \& Amato, 2000; U.S. Bureau of the Census, 2001). A recent review of marital interactions and gender supports the notion that gender role ideologies are becoming less traditional (Rogers \& Amato) and that marriages adopting traditional power systems demonstrate lower marital quality (Amato et al., 2003). Yet, research supports the link between modern gender role ideologies and marital satisfaction, particularly for women. Specifically, wives are more likely to reinforce modern gender role ideologies among their spouses because this promotes a more egalitarian division of domestic power and labor; however, the reverse is true for husbands (Amato et al.).

Recent studies suggest that although the gap between attitudes and behaviors is still large, it is narrowing (e.g., Rogers \& Amato, 2000). Specifically, there are more wives and mothers in the workforce, and more favorable attitudes among husbands and fathers regarding women in the workplace. Moreover, on average, men are providing more assistance with household tasks and wives contribute more to family/household decision making than in previous years. Despite more pronounced male participation in the family domain, housework and childcare duties predominantly remain the woman’s responsibility (Kurdek, 1998; Thompson \& Walker, 1989). Changing attitudes are still not consistent with egalitarian arrangements for household and family related responsibilities (Brooks, 2000). This lack of balance in family-related tasks is a major source of conflict for many couples. 
Many have suggested that the prevalence of less-traditional gender role attitudes does not preclude marital dissatisfaction (e.g. Baker, Kiger, \& Riley, 1996; Merriam \& Hyer, 1984). More specifically, gender roles are not clearly defined according to egalitarian perspectives. Therefore, both men and women must define these roles together, presenting the threat of disagreement and conflict. Rogers and Amato (1984) note that family-work conflicts are a significant threat to marital satisfaction. Baker et al. further contend that division of household tasks is particularly detrimental to the marital satisfaction of women, who are displeased with their husbands' minimal contributions. Baker and colleagues suggest that role strain or individual beliefs regarding fairness is more detrimental to the marital quality of women than men.

According to Fowers (1991), incompatible behaviors and expectations are at the core of marital dissatisfaction. Therefore, it is imperative to explore the influence of gender role orientations on marital satisfaction. This is of particular importance given continued changing sociodemographic trends and high divorce rates (U.S. Bureau of the Census, 2001). More specifically, the literature suggests that marital satisfaction may be influenced by maturational changes, as well as gender role orientations (Acitelli, 1992; Baker et al., 1996; Fowers; Gagnon et al., 1999; Glenn, 1989; Hicks \& Platt, 1970; Martin, 1985; Merriam \& Hyer, 1984; Orbuch et al., 1996; Rogers \& Amato, 2000). As gender role orientations become less rigid, and women continue to assume non-traditional roles, traditional roles will be delayed or placed aside (e.g., Merriam \& Hyer).

\section{$\underline{\text { Summary }}$}

Given that cultural and demographic shifts have combined to create a larger population of married older adults and a growth in age-discrepant marriages, and in light of the potential impact of continued cultural shifts on gender role orientations and subsequent marital satisfaction 
(Merriam \& Hyer, 1984; Shehan et al., 1991; U.S. Bureau of the Census, 2001), comparisons among age-discrepant couples in long-term marriages to age similar older and middle-aged couples in long-term marriages would provide useful insights regarding the relation between gender roles and marital satisfaction. Comparisons based on marital satisfaction and attitudes toward sex roles would provide a thorough understanding of how age congruency affects perceptions and interactions in marital partnerships.

The proposed comparisons would provide a better understanding of the predictors of marital satisfaction among older and middle-aged couples whose developmental tasks become more congruent over time (Carstensen et al., 1995) versus those older and middle-aged adults who are married to a significantly younger partner. It is imperative to examine these long-term relationships in order to provide a better understanding of those factors that have contributed to the success of these couples (Mackey \& O'Brien, 1999). Closer examination of couples in longterm age-similar and age-discrepant marriages will provide a more comprehensive understanding of the developmental factors that affect marital interactions among partners as the "types" marital relationships continue to change in accordance with cultural shifts. 
Hypotheses

Hypothesis 1: Research has identified similarity between partners as key to marital success (Byrne \& Murnen, 1988). SST also suggests that the motivation for maintaining social relationships becomes driven by a greater focus on satisfying emotional goals with age (Carstensen et al., 1999; Frederickson \& Carstensen, 1990; Lang \& Carstensen, 1994). These findings imply that age differences between partners may threaten marital satisfaction by introducing potential conflicts linked to age-related differences in the emphasis on emotional needs. Therefore, it is expected that age-similar couples will report greater marital satisfaction than age-discrepant couples.

Hypothesis 2: A bulk of the literature provides evidence of gender-based differences in the evaluation of marital satisfaction indicating that marital quality is less significant to the marital satisfaction of men than women (Fowers, 1991; Levenson et al., 1993). Based on these findings, it is hypothesized that women will demonstrate lower marital satisfaction than men, regardless of marriage type.

Hypothesis 3: Despite the visibility of women in the labor force, research indicates that household tasks are primarily the responsibility of women (e.g., Brooks, 2000; Kulik, 1999). Research further indicates that women may perceive help with domestic tasks as a form of social support (Pina \& Bengston, 1995). Therefore, it is expected that women will be responsible for a bulk of the household tasks and will be less satisfied with their household responsibilities than men, regardless of employment status.

Hypothesis 4: Previous research has linked marital roles to attitudes regarding sex-roles (e.g., Amato et al., 2003). This is important to note because evidence supports the notion that genderrole ideologies are becoming less traditional (Rogers \& Amato, 2000). Moreover, research 
indicates that more modern attitudes towards sex roles are linked to more equitable power systems on the homefront (e.g., Kurdek, 1998). According to research by Norris and colleagues (1997) younger cohorts have been socialized to adopt more modern attitudes. Therefore, it is expected that age-similar couples will have a more equitable division of household tasks and that each partner will be satisfied with their household duties.

Hypothesis 5: Atchley (1992) notes that husbands contribute more to household duties upon retirement. This additional assistance may present a potential source of conflict for couples because women may view this help as undermining their identity as a women (Blair \& Lichter, 1991). Given that individuals in ADMs may retire at different times, it is expected that individuals in age-similar marriages will demonstrate less discrepancy on the division of household tasks than individuals in age-discrepant couples.

Hypothesis 6: The literature has supported gender differences in marital satisfaction that favor men (Bollman et al., 1997; Fowers, 1991; Levenson et al., 1993). There is also evidence that satisfaction with the division of household labor influences marital satisfaction (Grote \& Clark, 2003; Pina \& Bengston, 1995; Ward, 1993). Couples who are at different life stages may face unique challenges that could affect marital satisfaction. Therefore, it is expected that marriage type may account for additional variance in marital satisfaction beyond that accounted for by gender and satisfaction with the division of household labor.

Hypothesis 7: Research suggests that age impacts positive and negative affect (Mroczek \& Kolarz, 1998). Research also suggests that the impact of marital quality on well being is more pronounced for women than men(Levenson et al., 1993). Klinger-Vartabedian and Wispe (1989) provide evidence that marital satisfaction influences psychological well-being. Recognizing that the spouse becomes an increasingly important potential source for social support according to 
SST (Carstensen et al., 1999; Frederickson \& Carstensen,1990 ; Lang \& Carstensen, 1994), the spouse and the marriage are influential to well being. In fact, there is evidence that suggests that wives perceive domestic assistance from their spouse as one form of support and that these perceptions may be detrimental to their marital satisfaction (Pina \& Bengston, 1995). Based on these findings, it is expected that age, gender, and marital satisfaction will exert direct effects on psychological well-being. Satisfaction with the division of household tasks is expected to exert indirect effects on well being through the construct of marital satisfaction.

Hypothesis 8: Research highlights the importance of socialization in shaping attitudes toward sex-roles (Norris et al., 1997). Specifically, Norris et al. note that younger adults demonstrate more modern attitudes than do older adults. Therefore, it is expected that individuals in agediscrepant marriages, who are from different generational cohorts will demonstrate greater discrepancy on attitudes toward sex roles than individuals in age-similar couples.

Hypothesis 9: Amato et al. (1993) note that women benefit more from less traditional attitudes regarding sex roles than do men. According to Amato et al., women are more likely to encourage these behaviors from their husbands than men are responsive to nontraditional from their wives. Therefore, it is expected that men will have more traditional attitudes toward sex roles than women.

Hypothesis 10: SST argues that the spouse becomes increasingly more important as social networks shrink with age (Carstensen et al., 1999; Frederickson \& Carstensen,1990 ; Lang \& Carstensen, 1994). Recognizing that the selection criteria for the present study is likely to yield a sample of husbands in age-discrepant marriages that are older than men married to women who are of similar age, it is expected that age-discrepant husbands will have smaller personal networks than age-similar husbands and wives in general. Consistent with research suggesting 
gender differences in the structure and function of social support networks (Stokes \& Wilson, 1984), it is expected that women will have larger networks than men.

Hypothesis 11: Given that age-discrepant husbands are likely to be older than age-similar husbands because of the criteria used to define the sample, it is also expected that age-discrepant wives will require more social support than age-similar wives because they are dealing with the issues associated with their husbands growing older. These stressors may relate to caregiving roles (Wright \& Aquilino, 1998). Therefore, it is expected that age-discrepant wives will report significantly more total people in their personal networks than all other participants.

Hypothesis 12: SST states that emotional needs become more important motivators as individuals grow older (Carstensen et al., 1999; Frederickson \& Carstensen, 1990; Lang \& Carstensen, 1994). Therefore, it is expected that age-discrepant husbands in the current sample will have more emotional goals than age-similar husbands and wives, in general.

Hypothesis 13: Likewise, it is expected that age-discrepant husbands in the current sample, who are likely older than the other participants due to the selection criteria, will report fewer individual goals than age-similar husbands and wives, in general. 


\section{Chapter 3}

\section{Methodology}

\section{$\underline{\text { Participants }}$}

Participants included couples who were married for at least 15 years. Age-similar couples were defined as couples who were within 5 years of one another in age. Age-discrepant couples were between 10 and 25 years age-discrepant. A total of 35 age-similar couples and 35 agediscrepant couples were included in this study. Participants were successfully recruited via personal referrals (34\%), participant referrals (9\%), and student referrals from West Virginia University (31\%), Ohio University and Dennison College (26\%). Recruitment announcements available to students adhered to a standardized script to minimize confounds. All undergraduate students who provided a "successful" referral were eligible for course extra credit, as designated appropriate by instructors. Newspaper advertisements and press releases were also used for recruitment; however, no participants were recruited using these strategies. Participants were mailed a summary of the findings and mailed a "thank you" note for their participation. Winners for the cash lottery were drawn and prizes were awarded to those selected.

The 140 individuals interviewed were an average age of 57.4 years, with a range of 40-90 years. The average age difference between age-discrepant partners was 14 years. Sixty-nine percent of the 35 age-discrepant couples had an age difference of 14 years or less between them and their partner. The sample reported an average of 15 years education (range $=5-20$ years). The couples reported an average annual household income in the $\$ 65,000-\$ 70,000$ range. Approximately $98.6 \%$ of the couples interviewed were Caucasian. Couples in the sample reported an average of nearly 29 years of marriage. About half of the couples interviewed (54\%) indicated that there were individuals other than their spouse living in the family home. Among 
those who reported a co-resident, approximately $94 \%$ indicated that this person was a son or daughter. More specifically, nearly 31\% of the sample reported that a son was residing in the home compared to approximately $63 \%$ who reported that a daughter lived in the family home. Less than $2 \%$ of the sample reported that a grandchild lived with them and their spouse. Approximately 54\% of the sample indicated that someone other than their spouse lived in the home. In fact, nearly 3\% of the sample reported the presence of at least four other co-residents. A majority of the sample (66\%) was employed; nearly $69 \%$ of the women in age-similar and $69 \%$ of the women in age-discrepant marriages were employed at the time of assessment. Sample characteristics are listed in Table 1.

\section{$\underline{\text { Measures }}$}

All measures of demographic information, well being, marital satisfaction, expressed emotion, and division of household labor are listed in the Appendix. All proprietary measures have been excluded. Table 2 provides means for all of the independent and dependent variables of interest.

\section{Demographics:}

Participants were asked to complete a brief demographics survey. Questions related to date of birth, marriage number (e.g., first, second, third, etc.), religion, race, employment status, type of employment, education, finances, place of residence, and the presence of others currently residing in the participants' home.

\section{Well Being:}

The PGC Positive and Negative Affect Scales were used to index well being (Lawton, Kleban, Dean, Rajagopal, \& Parmelee, 1992). The 5-item PGC Positive Affect Scale asks respondents to indicate how often in the past week (Never, Rarely, Sometimes, Frequently, and Very Frequently) they felt: Happy; Interested; Energetic; Warm-hearted; and Content. Scores on 
Marital Satisfaction 23

Table 1. Sample Profile

\begin{tabular}{|c|c|c|c|c|c|c|c|c|c|}
\hline & \multicolumn{4}{|c|}{ WIVES } & \multicolumn{4}{|c|}{ HUSBANDS } & \\
\hline & \multicolumn{2}{|c|}{ Similar $=(\mathrm{A})$} & \multicolumn{2}{|c|}{ Discrepant $=(B)$} & \multicolumn{2}{|c|}{ Similar $=(C)$} & \multicolumn{2}{|c|}{ Discrepant=(D) } & 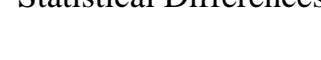 \\
\hline & $\underline{\mathrm{M}}$ & $\underline{\mathrm{SD}}$ & $\underline{\mathrm{M}}$ & $\underline{\mathrm{SD}}$ & $\underline{\mathrm{M}}$ & $\underline{\mathrm{SD}}$ & $\underline{\mathrm{M}}$ & $\underline{\mathrm{SD}}$ & \\
\hline Age & 54.75 & 7.01 & 52.56 & 8.85 & 55.83 & 6.66 & 66.49 & 9.97 & $\begin{array}{l}\underline{F}(3,136)=19.90^{* * *} \\
\text { A, B }<\text { C, D } \\
\text { A, C }<\text { B, D }\end{array}$ \\
\hline $\begin{array}{l}\text { Length } \\
\text { Married }\end{array}$ & 32.66 & 7.42 & 24.67 & 7.83 & 32.66 & 7.42 & 24.67 & 7.83 & $\begin{array}{l}\underline{\mathrm{t}}(66)=4.32^{* * *} \\
\mathrm{~A}, \mathrm{C}>\mathrm{B}, \mathrm{D}\end{array}$ \\
\hline Education & 14.23 & 2.02 & 15.80 & 2.52 & 14.11 & 2.39 & 15.66 & 3.29 & $\begin{array}{l}\underline{F}(3,136)=4.23^{* *} \\
\mathrm{~A}, \mathrm{C}<\mathrm{B}, \mathrm{D}\end{array}$ \\
\hline $\begin{array}{l}\text { Other } \\
\text { Residents }\end{array}$ & 1.34 & 0.48 & 1.60 & 0.50 & 1.34 & 0.48 & 1.60 & 0.50 & $\begin{array}{l}\underline{t}(68)=-2.198^{*} \\
A, C<B, D\end{array}$ \\
\hline $\begin{array}{l}\text { No. of } \\
\text { Marriages }\end{array}$ & 1.03 & 0.17 & 1.46 & 0.51 & 1.09 & 0.28 & 1.69 & 0.53 & $\begin{array}{l}\underline{F}(3,135)=20.78^{* * *} \\
\text { A, B }<\text { C, D }\end{array}$ \\
\hline Annual & 12.52 & 3.12 & 12.72 & 3.81 & 12.52 & 3.12 & 12.72 & 3.81 & $\begin{array}{l}\mathrm{A}, \mathrm{C}<\mathrm{B}, \mathrm{D} \\
\underline{\mathrm{t}}(54)=-0.22\end{array}$ \\
\hline Income & & & & & & & & & \\
\hline
\end{tabular}

Note. Annual income is based on husbands' reports only. Length of marriage is based on wives' reports only.

${ }^{*} \mathrm{p} \leq 0.05,{ }^{* *} \mathrm{p} \leq 0.01,{ }^{* * *} \mathrm{p} \leq 0.001$. 
Marital Satisfaction 24

Table 2. Profile of sample outcomes by gender and marriage type.

\begin{tabular}{|c|c|c|c|c|c|c|c|c|}
\hline & \multicolumn{4}{|c|}{ Men } & \multicolumn{4}{|c|}{ Women } \\
\hline & \multicolumn{2}{|c|}{ Age-Similar } & \multicolumn{2}{|c|}{ Age-Discrepant } & \multicolumn{2}{|c|}{ Age-Similar } & \multicolumn{2}{|c|}{ Age-Discrepant } \\
\hline & $\underline{\mathrm{M}}$ & $\underline{\mathrm{SD}}$ & $\underline{\mathrm{M}}$ & $\underline{\mathrm{SD}}$ & $\underline{\mathrm{M}}$ & $\underline{\mathrm{SD}}$ & $\underline{\mathrm{M}}$ & $\underline{\mathrm{SD}}$ \\
\hline Positive Affect & 19.63 & 2.68 & 19.81 & 2.60 & 19.20 & 2.64 & 20.51 & 2.25 \\
\hline Negative Affect & 11.69 & 2.72 & 12.41 & 3.19 & 12.80 & 2.68 & 13.17 & 4.00 \\
\hline Femininity & 97.8 & 12.30 & 101.86 & 11.67 & 103.26 & 11.77 & 107.35 & 11.05 \\
\hline Masculinity & 109.31 & 13.53 & 103.08 & 16.58 & 93.60 & 16.85 & 99.35 & 16.29 \\
\hline Androgyny & 37.75 & 30.17 & 36.22 & 27.22 & 33.04 & 26.84 & 38.93 & 28.53 \\
\hline Conflict & 13.94 & 5.23 & 15.92 & 5.88 & 16.60 & 5.83 & 17.37 & 5.14 \\
\hline Ambivalence & 7.89 & 5.76 & 8.18 & 4.84 & 8.66 & 4.96 & 8.57 & 4.39 \\
\hline Maintenance & 28.20 & 8.47 & 27.74 & 7.67 & 26.57 & 6.43 & 28.37 & 8.53 \\
\hline Satisfaction & 41.91 & 3.67 & 40.95 & 4.13 & 40.49 & 4.85 & 39.63 & 3.89 \\
\hline Consensus & 52.46 & 6.21 & 52.32 & 5.23 & 50.74 & 4.20 & 51.77 & 4.75 \\
\hline DAS Composite & 94.26 & 8.97 & 93.24 & 8.29 & 91.14 & 8.08 & 91.46 & 7.41 \\
\hline Functional & 3.69 & 4.52 & 3.19 & 4.15 & 3.34 & 3.90 & 3.71 & 5.17 \\
\hline Household Tasks & 11.20 & 2.40 & 12.11 & 2.49 & 13.63 & 1.75 & 12.54 & 2.36 \\
\hline Household Satisfaction & 2.26 & 2.69 & 2.43 & 2.69 & 2.60 & 2.44 & 3.14 & 3.38 \\
\hline Family in Network & 7.74 & 3.91 & 9.26 & 5.81 & 9.34 & 5.30 & 12.03 & 7.27 \\
\hline Friends in Network & 1.17 & 1.60 & 2.54 & 3.87 & 2.09 & 3.36 & 3.32 & 3.69 \\
\hline Total in Network & 8.91 & 4.67 & 11.80 & 7.29 & 11.43 & 6.21 & 15.38 & 8.45 \\
\hline Individual Goals & 3.76 & 0.82 & 3.72 & 1.23 & 3.79 & 1.04 & 3.74 & 1.31 \\
\hline Couple Goals & 3.79 & 0.95 & 3.49 & 1.32 & 3.44 & 1.26 & 3.26 & 1.48 \\
\hline Emotional Goals & 0.21 & 0.54 & 0.22 & 0.55 & 0.26 & 0.57 & 0.14 & 0.49 \\
\hline Family Goals & 1.35 & 1.23 & 1.12 & 1.06 & 1.32 & 0.88 & 0.94 & 1.06 \\
\hline Health Goals & 0.47 & 0.66 & 0.63 & 0.76 & 0.71 & 0.68 & 0.74 & 0.92 \\
\hline
\end{tabular}


this scale can range from 5 to 25 . Higher scores are reflective of more positive affect. The mean score for this sample was 19.81 with a standard deviation of 2.60. Scores for this sample ranged from 14 to 25. Coefficient alpha was .67 in the current sample. The PGC Negative Affect Scale was used as an index of negative well-being. Participants were asked how frequently (Never to Very Frequently) they felt: Sad, Annoyed, Worried, Irritated, and Depressed during the past week. Scores can range from 5 to 25 . Lower scores are reflective of less negative affect. The sample mean was 12.41 with a standard deviation of 3.19. Scores for this sample ranged from 5 to 23, and coefficient alpha was .72.

\section{Funtional Ability:}

Functional ability was assessed using a 10-item scale adapted from the 20-Item ShortForm Health Survey (SF-20; Ware, Sherbourne, \& Davies, 1992). Respondents were asked to indicate the extent (no difficulty, some difficulty, much difficulty, or unable) that their physical capabilities interfere with performing various tasks involving walking, standing, stooping, lifting, or sitting. Sample questions include, "How much difficulty do you have lifting or carrying something as heavy as 25 lbs. (such as two full grocery bags)?” Scores can range from 0-30. Higher scores are reflective of greater functional impairment. Scores for this sample ranged from 0-20; the sample mean was 3.19 with a standard deviation of 4.15 .

\section{Marital Satisfaction:}

Multiple indicators of marital satisfaction were used: the satisfaction and consensus subscales of the Dyadic Adjustment Scale (DAS; Spanier, 1976), the maintenance, ambivalence, and conflict subscales of the Couples' Questionnaire (Braiker \& Kelley, 1979), and the Five Minute Speech Sample of Expressed Emotion (FMSS-EE; Magana, Goldstein, Karno, Miklowitz, Jenkins, \& Falloon, 1986). 
The DAS (Spanier, 1976) is a commonly used measure that consists of four subscales that tap "dyadic satisfaction," "cohesion," "consensus," and "affectional expression.” The scale was designed for use with married couples and couples who live together. The DAS is a global measure and therefore does not provide participants with a specific time frame as a point of reference for assessing their marriage. One of the advantages of the DAS is that it recognizes that that adjustment is not a rigid construct, but an ongoing condition. In light of time concerns, only the dyadic satisfaction and consensus subscales were included in the interview.

The dyadic satisfaction subscale includes 10 items (Spanier, 1976). Items reflect the level of happiness in the relationship and the desire to continue in the relationship. An example item is, "How often do you discuss or have you considered divorce, separation, or termination of your relationship?” The Likert-type response scales vary depending on the specific question. Response scales range from, "All the time" to "Never", "Extremely unhappy” to "Perfect," and "Every Day" to "Never." Participants were also asked to indicate their feelings regarding the future of their relationship from a list of provided statements. Scores on this subscale can range from 0-50. Higher scores reflect greater satisfaction. In this sample, scores ranged from 23-50. The sample reported a mean satisfaction score of $40.95(\underline{\mathrm{SD}}=4.13)$. This mean score is consistent with mean scores $(\underline{\mathrm{M}}=40.5)$ reported by married couples (Spanier). Although Spanier reports a coefficient alpha of .94 for this subscale, coefficient alpha for this sample was .72.

The consensus subscale consists of 13 items. Items included on this scale relate to the extent to which partners' attitudes regarding important decisions agree (Spanier, 1976). The underlying logic is that a lack of agreement may lead to conflict and interfere with adjustment. For example, respondents were asked to assess their level of agreement or disagreement on issues such as, "Aims, goals, and things believed important." Responses can range from "Always 
agree" to "Always Disagree." Scores on this subscale can range from 0-65. Higher scores reflect greater consensus. Sample scores ranged from 37-65 with a mean of $52.32(\underline{\mathrm{SD}}=5.23)$. These scores are higher than those reported by couples who divorced $(\underline{\mathrm{M}}=41.1$; Spanier, 1976). Although Spanier reports a coefficient alpha of .90 for the scale, coefficient alpha for this sample was .77. Composite scores for the satisfaction and consensus subscales were also computed. Composite scores can range from 0-115. Sample scores ranged from 68-115 with a mean of $93.24(\underline{\mathrm{SD}}=8.29)$. Coefficient alpha for this sample was .84.

Three subscales from the Couple’s Questionnaire (Braiker \& Kelley, 1979) were used to provide additional information related to couples' use of relational maintenance strategies, ambivalence, and conflict-negativity. It is based on the assumption that couples are interdependent and as such are susceptible to conflict. The data provided by the conflictnegativity subscale compliments the information provided by the consensus subscale of the DAS (Spanier, 1976). More specifically, the conflict-negativity subscale is intended to provide information about the emotional component of conflict (Braiker \& Kelley); whereas the consensus subscale of the DAS reflects the extent of agreement between partners' attitudes. These subscales also provide a more specific time frame for assessment that provides insights regarding recent interactions (during the last year). This information provides a more complete picture of how current interactions may differ from general perceptions of marital satisfaction as indicated by DAS data (Spanier, 1976).

Items are scored according to a Likert-type scale of 1 ("Not at all") to 9 ("Very Much"). Participants are asked to indicate how each item relates to their marriage according to their experiences with their partner during the preceding year. The maintenance subscale includes 5 items, such as: "To what extent do reveal or disclose very intimate things about yourself or 
personal feelings to your spouse?" Scores on this subscale can range from 5-45. Higher scores are reflective of greater use of maintenance strategies. Scores in this sample ranged from 11-45; the sample report a mean score of 27.47 with a standard deviation of 7.67. Coefficient alpha was 62.

The ambivalence subscale also consists of 5 items. A sample item includes, "To what extent do you feel "trapped" or pressured to continue in the relationship?” Scores can range from 5-45 with higher scores indicative of greater ambivalence. Sample scores ranged from 5-37; the sample reported a mean ambivalence score of 8.18 with a standard deviation of 4.84 . Coefficient alpha was .67.

The 5-item conflict-negativity subscale was also used. A sample item is, "How often do you and your spouse argue with each other?" Scores on this subscale can range from 1-45, with higher scores indicating more conflict-negativity. Sample scores ranged from 5-31 with a sample mean of $15.92(\underline{\mathrm{SD}}=5.88)$. This mean is significantly lower than scores $(\underline{\mathrm{M}}=24.00)$ used in other studies to differentiate couples experiencing significant conflict from other groups of couples (Helms-Erikson, Tanner, Crouter, \& McHale, 2000). Coefficient alpha was .46.

In order to more closely examine the emotional aspects of marital relationships and attitudes toward partners, the FMSS-EE (Magana, Goldstein, Karno, Miklowitz, Jenkins, \& Falloon, 1986) was also included in the present study. Although the FMSS-EE (Magana et al.) is a clinical measure, these data were used to provide qualitative information on partners' attitudes toward their partner. Respondents were informed that their speech samples would be recorded. The respondents were instructed to speak freely about their partner for five minutes. Sample instructions included telling participants to talk about their spouse as a person and their ability to get along with their partner. FMSS-EE (Magana et al.) has been used in a variety of samples and 
yields a global measure of relationship quality. Eight aspects are coded, including the number of positive remarks, the number of critical statements, and evidence of emotional over-involvement. Samples are then characterized as High or Low EE and categorized into the following subgroups: low, critical, emotionally over-involved, critical/emotionally over-involved, and borderline. Sixty-six percent of the sample were categorized as Low EE and evenly distributed across the subcategories.

\section{Division of Household Tasks:}

Division of household tasks was assessed using a modified version of the Instrumental Activities of Daily Living scale (IADL's; Lawton, Moss, Fulcomer, Kleban, 1982) and the measure used by Kulik (2001). The measure is designed to tap the most common household responsibilities of co-resident adults. The scale consists of 18 items related to areas such as housework, laundry, meal preparation, grocery shopping, paying bills, assistance with medications, travel/trips, daily transportation, yard work, household repairs and maintenance. Eleven of the areas tapped were modified from Lawton and colleagues' eight-item IADL scale. Seven of the areas tapped were adapted from Kulik's (2001) measure. Lawton et al. report a Cronbach's alpha of .96. Respondents were asked to indicate who is primarily responsible for each of the tasks listed. For each task, respondents were asked to indicate how often they give/receive help from their spouse on a Likert-type scale ranging from, "Never" to "Very frequently." Recognizing that assistance can be more of a nuisance than a favor, respondents were also asked to indicate whether they would like more or less help from their partner. This format is similar to that used by Kulik (2001) who reports a Cronbach's reliability coefficient of .83 for general responsibility for tasks. Respondents indicated that they were responsible, or shared responsibility, for anywhere from 5-17 tasks. Scores can range from 0-17; the sample 
mean was 12.12 tasks with a standard deviation of 2.49. Satisfaction with household tasks was conceptualized as not indicating a desire for more or less help. Respondents indicated being satisfied with an average of 2.43 out of 17 possible tasks $(\underline{\mathrm{SD}}=2.69)$.

\section{Attitudes Toward Sex Roles:}

The Bem Sex Role Inventory (BSRI; Bem, 1974) was used to measure masculinity and femininity. The scale conceptualizes masculinity and femininity as distinct constructs. The measure consists of a list of 60 adjectives; 20 adjectives are masculine, 20 are feminine, and 20 are filler items used as an index of social desirability. The BSRI is a widely used measure with sound psychometric properties; Bem (1974) reports a Cronbach's alpha of .86 and .84 for the masculinity and femininity subscales, respectively. Respondents were asked to indicate the extent to which each of the adjectives is true of themselves on a Likert-type scale. Responses can vary from 1 ("Never or almost never true") to 7 ("Always or almost always true") on each of the

items. Sample adjectives include: "self-reliant," "sympathetic," and "friendly." Masculinity and femininity were scored separately for each participant. Scores on each of these subscales can range from 1-140. Scores on the masculinity subscale ranged from 44-138 in this sample. The sample mean was 103.08 with a standard deviation of 16.58 . Scores on the femininity subscale ranged from 76-129 in this sample. The sample mean was 101.86 with a standard deviation of 11.67. Coefficient alpha for the masculinity and femininity subscales in this sample were .88 and .77, respectively. Androgyny scores were also computed as an index of traditional gender role attitudes. Androgyny scores were computed using Bem's equation: the absolute value of masculinity score-femininity score multiplied by 2.322. The average androgyny score for this sample was $36.22(\underline{\mathrm{SD}}=27.22)$. 


\section{Social Support:}

The social convoy model (Antonucci, 2001) was used to examine the size and structure of the sample’s personal networks. Respondents were asked to place people of importance in their lives in one of three concentric circles, with the core being the self. The innermost circle included people to whom the respondent was closest. Those individuals further from the core were of lesser importance than those in the inner circle. The network was examined for size and composition of family and non-relatives. The sample reported a range of 1-45 total people in their personal networks with a mean of $11.8(\underline{\mathrm{SD}}=7.29)$. The average number of family members respondents included in their personal network was 9.26 with a standard deviation of 5.81. The sample reported an average of 2.54 friends $(\underline{\mathrm{SD}}=3.89)$ in their networks.

\section{Goals:}

Respondents were asked to indicate four individual and four couple’s goals that they would like to accomplish in the next five years. Goals were coded as either an individual or couple goal. The goals were further coded for emotional, family, health, financial, household, retirement, work, leisure, religion, volunteer, and educational themes. The coding scheme used to code goals is consistent with one used by Strough, Patrick, Swenson, Cheng, and Barnes (2003). The total reported individual and emotional goals were of particular interest to the current investigation given the focus on life stage and SST. The sample reported an average of 3.72 individual goals with a standard deviation of .23. The sample reported an average of less than 1 total goal with emotional themes $(\underline{\mathrm{M}}=0.22, \underline{\mathrm{SD}}=0.55)$.

\section{Procedure}

All data were collected via telephone interviews in which partners were interviewed separately. Although all participants were interviewed separately via the telephone, participants 
were not required to complete the interview privately, so privacy was left to the individual participant's discretion. Participants were provided with various response cards to help clarify and expedite the interview process. The participants were instructed to refer to these cards when necessary. The interview began with the demographics questionnaire, well being indices, and goals. Participants were then asked to respond to questions from the Dyadic Adjustment Scale (DAS; Spanier, 1976). These questions were followed-up by questions from the Couples' Questionnaire (Braiker \& Kelley, 1979). The third_phase of the interview involved questions relating to the division of household tasks. Participants were then asked to provide a 5-minute speech sample in which they were instructed to speak freely about their partner, without interruptions or questions. Upon completing the FMSS-EE, participants were asked to list their personal networks and answer 10 follow-up questions related to their perceived social support. The Bem Sex Role Inventory (Bem, 1974) was the final portion of the interview. Participants were debriefed and thanked for their participation. 
Results

$\underline{\text { Power }}$

Preliminary power analyses indicated that a sample size of 70-80 couples would provide adequate power to detect moderate mean effects $\left(f^{2}=.18-.20\right.$; alpha $=.05$; power $\left.>.80\right)$. Additional analyses indicated that the sample size would provide adequate power to detect moderate effects in regression analyses with 3-4 predictors $\left(\mathrm{f}^{2}=.33\right.$; alpha $=.001$; power $\left.>.80\right)$. Psychometric Properties of the Proposed Indicators of Marital Satisfaction

Preliminary analyses were conducted on all indicators of marital satisfaction. These analyses indicated that several of the measures lacked sufficient reliability in this sample. Braiker and Kelley (1979) suggest that these scales represent a three-factor structure ${ }^{1}$. Coefficient alpha was less than .70 for each of the Couple’s Questionnaire subscales. The maintenance subscale yielded a coefficient alpha of .62. Coefficient alpha for the ambivalence subscale was equal to .67 in this sample. Reliability for the conflict subscale was particularly low; coefficient alpha was .46. Although the internal consistency of these subscales was low for this sample, the relations among the subscales of the Couple's Questionnaire and the subscales of the DAS were fairly moderate. Specifically, a significant inverse relation in excess of -.42 emerged among the conflict subscale and each of the subscales of the DAS, as well as the composite score. A significant inverse relation also emerged between the ambivalence subscale and the satisfaction subscale of the DAS and the composite score, $r=-.52$ and $-.29, \underline{p} \leq .001$, respectively. A modest significant inverse relation between the ambivalence and the consensus subscales also emerged, $\mathrm{r}$ $=-.29, \mathrm{p} \leq .001$. Also, a modest significant relation between the maintenance and satisfaction subscales was present, $\mathrm{r}=-.22, \mathrm{p} \leq .01$.

\footnotetext{
${ }^{1}$ Exploratory factor analyses using oblique and orthogonal rotations were conducted, showing five factors. Results were virtually identical for women and men. Specific details are available from the author.
} 
Expressed emotion, measured according to the FMSS-EE (Magana et al., 1986), was also used as an indicator of marital satisfaction. The speech samples were coded according to the standardized procedures outlined by Magana et al. A preliminary construct analysis indicated that there was a modest significant correlation between expressed emotion and the maintenance subscale of the Couple’s Questionnaire (Braiker \& Kelley, 1979), $\mathrm{r}=-.24, \mathrm{p} \leq .05$. Table 3 provides specific information. This was the only significant correlation between expressed emotion and the proposed indicators of marital satisfaction that emerged. No significant relations emerged among the subgroup classifications and the constructs tapping marital satisfaction. Furthermore, only two of the nine relevant subcomponents of expressed emotion were significantly correlated with the other proposed measures of marital satisfaction. Specifically, there were only modest negative correlations among number of critical statements, the presence of dissatisfaction, and the subscales of the DAS (Spanier, 1976).

Nine components were used to determine subgroup classifications. Initial statements were coded as positive (30.7\%), neutral (48.6\%), or negative (0.7\%). Relationship quality was classified as positive (52.9\%), neutral (26.4\%), and negative (0.7\%). Speech samples were coded as present (22.1\%) or absent (57.9\%). Emotional displays also were coded as present (2.1\%) or absent (77.9\%). Only 15\% of the speech samples demonstrated evidence of a lack of objectivity. Speech samples were also coded for the number of critical statements $(\underline{\mathrm{M}}=0.11, \underline{\mathrm{SD}}=0.41)$, number of positive remarks $(\underline{\mathrm{M}}=3.64, \underline{\mathrm{SD}}=2.96)$, excess detail $(\underline{\mathrm{M}}=0.12, \underline{\mathrm{SD}}=0.32)$, and statement of attitude $(\underline{\mathrm{M}}=0.50, \underline{\mathrm{SD}}=0.84)$. 
Marital Satisfaction 35

Table 3. Correlations among expressed emotion constructs and marital quality scales.

\begin{tabular}{|c|c|c|c|c|c|c|c|c|}
\hline & 1 & 2 & 3 & 4 & 5 & 6 & 7 & 8 \\
\hline 1. Critical & 1.00 & $.313^{* *}$ & -.045 & -.067 & -.080 & -.036 & -.040 & .152 \\
\hline 2. Dissatisfied & & & .020 & $-.225 *$ & -.042 & .085 & -.114 & .057 \\
\hline 3. Emotional display & & & & .036 & .064 & -.058 & -.143 & $.244 * *$ \\
\hline 4. Anger & & & & & $.375 * *$ & -.111 & .064 & $.517^{* *}$ \\
\hline 5. Lack of Objectivity & & & & & & -.098 & .007 & $.584 * *$ \\
\hline 6. Excess Detail & & & & & & & -.163 & .106 \\
\hline 7. Positive remarks & & & & & & & & $.316^{* *}$ \\
\hline 8. Subgroup & & & & & & & & \\
\hline 9. Expressed Emotion & & & & & & & & \\
\hline 10. Satisfaction & & & & & & & & \\
\hline 11. Consensus & & & & & & & & \\
\hline 12. DAS composite & & & & & & & & \\
\hline 13. Maintenance & & & & & & & & \\
\hline 14. Ambivalence & & & & & & & & \\
\hline 15. Conflict & & & & & & & & \\
\hline
\end{tabular}

Note. This table continues on the next page.

${ }^{*} \mathrm{p} \leq 0.05, * * \mathrm{p} \leq 0.01, * * * \mathrm{p} \leq 0.001$. 
Marital Satisfaction 36

Table 3(Continued) . Correlations among expressed emotion constructs and marital quality scales.

\begin{tabular}{|c|c|c|c|c|c|c|c|}
\hline & 9 & 10 & 11 & 12 & 13 & 14 & 15 \\
\hline 1. Critical & $.282 * *$ & $-.279 * *$ & $-.235^{*}$ & $-.294 * *$ & -.153 & $.261 * *$ & .113 \\
\hline 2. Dissatisfied & -.043 & $-.428 * *$ & $-.321^{* *}$ & $-.413^{* *}$ & -.075 & .175 & $.191 *$ \\
\hline 3. Emotional display & $.242 * *$ & .018 & -.087 & -.045 & .107 & .101 & .025 \\
\hline 4. Anger & $.464 * *$ & .105 & .143 & .146 & $.197 *$ & .180 & .114 \\
\hline 5. Lack of Objectivity & $.555^{* *}$ & -.136 & -.057 & -.101 & .161 & $.240^{*}$ & .182 \\
\hline 6. Excess Detail & -.004 & -.172 & -.094 & -.142 & .096 & -.116 & $.231^{*}$ \\
\hline 7. Positive remarks & $.212 *$ & .149 & .050 & .101 & .085 & -.060 & -.145 \\
\hline 8. Subgroup & $.906 * *$ & -.035 & -.043 & -.045 & .182 & .135 & .103 \\
\hline 9. Expressed Emotion & & .014 & -.027 & -.011 & $.206^{*}$ & .158 & .069 \\
\hline 10. Satisfaction & & & $.580 * *$ & $.848^{* *}$ & $.220 * *$ & $-.516^{* *}$ & $-.526 * *$ \\
\hline 11. Consensus & & & & $.923 * *$ & .000 & $-.288^{* *}$ & $-.417 * *$ \\
\hline 12. DAS composite & & & & & .107 & $-.428 * *$ & $-.519 * *$ \\
\hline 13. Maintenance & & & & & & .032 & $.273 * *$ \\
\hline 14. Ambivalence & & & & & & & $.364^{* *}$ \\
\hline 15. Conflict & & & & & & & 1.00 \\
\hline
\end{tabular}


Thirty-five participants were categorized as high on expressed emotion. Seventy-seven of the participants were categorized as low on expressed emotion. Separate chi-square analyses on the nine expressed emotion subgroup types were performed for marriage type and gender. These subgroups are: low (17.9\%), border critical (9.3\%), border emotionally overinvolved (20.7\%), border critical and border emotionally overinvolved (7.1\%), critical (2.1\%), critical and border emotionally overinvolved (0.7\%), emotionally overinvolved (17.9\%), emotionally overinvolved and border critical (2.9\%), and emotionally overinvolved and critical (1.4\%). No significant differences between marriage type and the subgroups of expressed emotion were present, $\left(\chi^{2}(8)\right.$ $=11.36, \mathrm{p}=.18, \mathrm{~ns})$. Significant gender differences in subgroup did not emerge, $\left(\chi^{2}(8)=11.36\right.$, $\mathrm{p}=.18, \mathrm{~ns})$.

Several differences emerged between individuals categorized as high versus low on expressed emotion. First, individuals categorized as high on expressed emotion reported higher maintenance subscale scores than individuals categorized low on expressed emotion, $\underline{\mathrm{t}}(110)=$ $2.21, \mathrm{p} \leq .05$. This was the only proposed indicator of marital satisfaction on which the two groups significantly differed. Those individuals categorized as high on expressed emotion also included more family members in their personal networks than did individuals categorized as low on expressed emotion, $\underline{\mathrm{t}}(110)=-2.92, \mathrm{p} \leq .05$. Finally, these individuals also included significantly more friends in their personal networks than did those categorized as low on expressed emotion, $\underline{\mathrm{t}}(44.17)=-2.24, \mathrm{p} \leq .05$; degrees of freedom were adjusted due to unequal variances between groups.

Differences among individuals in the various subgroups classified as low on expressed emotion were examined using several one-way ANOVAs. The data indicate that significant differences emerged among the subgroups on composite DAS scores, $\underline{\mathrm{F}}(3,73)=5.07, \underline{\mathrm{p}} \leq .01$. 
Post-hoc analyses indicate that individuals in the subgroups low and border emotionally overinvolved scored significantly higher on the DAS than did individuals categorized as border critical and border emotionally overinvolved, $(\underline{\mathrm{M}}=95.08$, 88.92, and 86.2, respectively). Significant differences among the subgroups also emerged on the satisfaction subscale of the DAS, $\underline{\mathrm{F}}(3,73)=5.53, \underline{\mathrm{p}} \leq .01$. According to post-hoc analyses, individuals categorized as border critical and border emotionally overinvolved scored significantly lower than individuals categorized as border critical, border emotionally overinvolved, and low, $(\underline{\mathrm{M}}=37.4,38.23,42.0$, and 42.24, respectively). The data indicate an overall effect for subgroup on consensus scores, but no two groups significantly differed, $\underline{\mathrm{F}}(3,73)=2.92, \mathrm{p} \leq .05$. Likewise, a significant overall effect for subgroup was present on conflict scores, but no two groups differed significantly ( $\underline{\text { F }}$ (3, $73)=3.01, \underline{p} \leq .05)$. No significant differences were detected on any of the other indices of marital satisfaction. The only other significant difference to emerge related to the total number of household tasks individuals shared or were responsible for themselves, $\underline{F}(3,73)=4.55, \underline{p} \leq .01$. According to post-hoc analyses, individuals categorized as border critical were responsible for significantly more tasks than individuals categorized as border emotionally overinvolved, $(\underline{\mathrm{M}}=$ 7.31 and 5.24, respectively).

These subgroup differences also were compared separately for women and men classified as low on expressed emotion. According to the data three significant differences effects emerged among these subgroups for women. First, the omnibus test indicates a significant effect for subgroups on composite DAS scores, $\underline{\mathrm{F}}(3,36)=4.36, \underline{\mathrm{p}} \leq .01$. Post-hoc analyses indicate that individuals categorized as border emotionally over-involved reported higher DAS scores than individuals categorized as border critical and border emotionally overinvolved, $(\underline{\mathrm{M}}=94.82$ and 82.8, respectively). A significant overall effect for subgroup was present on the satisfaction 
subscale of the DAS, $\underline{\mathrm{F}}(3,36)=3.27, \underline{\mathrm{p}} \leq .05$. However, no two groups differed significantly. Finally, the omnibus test examining differences on consensus scores was significant $(\underline{F}(3,36)=$ 3.30, $\mathrm{p} \leq .05$ ), but no two groups were significantly different from one another.

Only one significant difference emerged among men classified as low on expressed emotion. Specifically, the data indicate that subgroup had a significant overall effect on maintenance scores, $\underline{\mathrm{F}}(3,36)=3.67, \underline{\mathrm{p}} \leq .05$. However, no two groups differed significantly from one another on mean scores. Subgroups within the classification of high on expressed emotion were not conducted because there is no logical method for collapsing across the different subgroup types. Given the less than modest relation between this construct and the other proposed measures, coupled with the fact that it is typically used with families of the mentally ill and its interpretation for marital satisfaction is less than clear, the measure was excluded from the major analyses (Magana et al., 1986).

Preliminary analyses on both the satisfaction and consensus subscales of the DAS (Spanier, 1976) yielded adequate reliability in this sample (coefficient alpha was equal to .72 and .77, respectively). The data indicate a significant positive correlation between the two subscales, $r=.58, \underline{p} \leq .01$. Both subscales and a composite score (coefficient alpha $=.84$ ) were used as measures of marital satisfaction.

$\underline{\text { Examining the Link between Demographic Characteristics and Outcome Measures }}$

Refer to Table 4 for correlations between sample characteristics and the outcome measures. Gender was significantly associated with higher satisfaction, consensus, composite DAS, and conflict scores ( $\mathrm{r}=-.22,-.20,-.24, .18 \mathrm{p} \leq .05$; respectively). Marriage type was not significantly correlated with any of the indicators of marital satisfaction. 
Marital Satisfaction 40

Table 4. Correlations among demographic variables and outcome measures.

\begin{tabular}{|c|c|c|c|c|c|c|c|}
\hline & 1 & 2 & 3 & 4 & 5 & 6 & 7 \\
\hline \multicolumn{8}{|l|}{ 1. Gender } \\
\hline $1=$ Male & 1.000 & .000 & -.145 & .000 & $-.386 * * *$ & .000 & .000 \\
\hline $2=$ Female & & & & & & & \\
\hline \multicolumn{8}{|l|}{ 2. Marriage type } \\
\hline 1= Age-Similar & & & $.534^{* * *}$ & .006 & $.218^{* *}$ & $-.469 * * *$ & $-.287 * * *$ \\
\hline 2 = Age-Discrepant & & & & & & & \\
\hline 3. Marriage No. & & & & .032 & $.297 * * *$ & $-.348 * * *$ & -.112 \\
\hline 4. Income & & & & & $-.318 * * *$ & $-.408 * * *$ & .168 \\
\hline 5. Age & & & & & & $.462^{* * *}$ & $-.374 * * *$ \\
\hline 6. Yrs. Married & & & & & & & $-.248^{* *}$ \\
\hline 7. Co-residents & & & & & & & \\
\hline 8. Work Status & & & & & & & \\
\hline 9. Education & & & & & & & \\
\hline 10. Positive Affect & & & & & & & \\
\hline 11. Negative Affect & & & & & & & \\
\hline 12. Femininity & & & & & & & \\
\hline 13. Masculinity & & & & & & & \\
\hline 14. Androgyny & & & & & & & \\
\hline 15. Satisfaction & & & & & & & \\
\hline 16. Consensus & & & & & & & \\
\hline 17. DAS Composite & & & & & & & \\
\hline 18. Functional Well-Being & & & & & & & \\
\hline 19. Household Satisfaction & & & & & & & \\
\hline 20. Household Tasks & & & & & & & \\
\hline 21. People in Network & & & & & & & \\
\hline 22. Family in Network & & & & & & & \\
\hline 23. Friend in Network & & & & & & & \\
\hline 24. Emotional Goals & & & & & & & \\
\hline 25. Family Goals & & & & & & & \\
\hline 26. Individual Goals & & & & & & & \\
\hline 27. Couple Goals & & & & & & & \\
\hline 28. Expressed Emotion & & & & & & & \\
\hline
\end{tabular}

Note. This table continues on the next page. ${ }^{*} \mathrm{p} \leq 0.05,{ }^{* *} \mathrm{p} \leq 0.01,{ }^{* * *} \mathrm{p} \leq 0.001$. 
Marital Satisfaction 41

Table 4 (Continued). Correlations among demographic variables and outcome measures.

\begin{tabular}{|c|c|c|c|c|c|c|c|}
\hline & 8 & 9 & 10 & 11 & 12 & 13 & 14 \\
\hline \multicolumn{8}{|l|}{ 1. Gender } \\
\hline $1=$ Male & .060 & .024 & .019 & $.180 *$ & $.292^{* * *}$ & $-.399 * * *$ & -.010 \\
\hline $2=$ Female & & & & & & & \\
\hline \multicolumn{8}{|l|}{ 2. Marriage type } \\
\hline 1= Age-Similar & -.150 & $.291 * * *$ & .151 & .054 & .115 & .099 & .031 \\
\hline 2 = Age-Discrepant & & & & & & & \\
\hline 3. Marriage No. & $-.194 *$ & $.315^{* * *}$ & .099 & -.025 & .064 & .090 & -.017 \\
\hline 4. Income & $.329 * * *$ & $.398 * * *$ & -.099 & -.060 & -.109 & .142 & $.209 *$ \\
\hline 5. Age & $-.593 * * *$ & .045 & .071 & -.127 & .061 & .146 & -.120 \\
\hline 6. Yrs. Married & $-.318 * * *$ & $-.279 * * *$ & -.013 & -.022 & .141 & -.036 & -.099 \\
\hline 7. Co-residents & $.304^{* * *}$ & .020 & -.041 & .102 & -.139 & -.094 & .040 \\
\hline 8. Work Status & & .077 & -.042 & .023 & -.113 & .057 & .085 \\
\hline 9. Education & & & .043 & -.045 & -.101 & $.168^{*}$ & .060 \\
\hline 10. Positive Affect & & & & $-.214^{*}$ & $.233^{* *}$ & $.295^{* * *}$ & .019 \\
\hline 11. Negative Affect & & & & & .069 & -.011 & .014 \\
\hline 12. Femininity & & & & & & .078 & -.095 \\
\hline 13. Masculinity & & & & & & & .015 \\
\hline \multicolumn{8}{|l|}{ 14. Androgyny } \\
\hline \multicolumn{8}{|l|}{ 15. Satisfaction } \\
\hline \multicolumn{8}{|l|}{ 16. Consensus } \\
\hline \multicolumn{8}{|l|}{ 17. DAS Composite } \\
\hline \multicolumn{8}{|l|}{ 18. Functional Well-Being } \\
\hline \multicolumn{8}{|l|}{ 19. Household Satisfaction } \\
\hline \multicolumn{8}{|l|}{ 20. Household Tasks } \\
\hline \multicolumn{8}{|l|}{ 21. People in Network } \\
\hline \multicolumn{8}{|l|}{ 22. Family in Network } \\
\hline \multicolumn{8}{|l|}{ 23. Friend in Network } \\
\hline \multicolumn{8}{|l|}{ 24. Emotional Goals } \\
\hline \multicolumn{8}{|l|}{ 25. Family Goals } \\
\hline \multicolumn{8}{|l|}{ 26. Individual Goals } \\
\hline \multicolumn{8}{|l|}{ 27. Couple Goals } \\
\hline 28. Expressed Emotion & & & & & & & \\
\hline
\end{tabular}

Note. This table continues on the next page. ${ }^{*} \mathrm{p} \leq 0.05,{ }^{* *} \mathrm{p} \leq 0.01,{ }^{* * *} \mathrm{p} \leq 0.001$. 
Marital Satisfaction 42

Table 4 (Continued). Correlations among demographic variables and outcome measures.

\begin{tabular}{|c|c|c|c|c|c|c|c|}
\hline & 15 & 16 & 17 & 18 & 18 & 20 & 21 \\
\hline \multicolumn{8}{|l|}{ 1. Gender } \\
\hline $1=$ Male & $-.217(* *)$ & $-.204 *$ & $-.235 * *$ & .083 & .166 & $.395 * * *$ & $.216^{*}$ \\
\hline 2 = Female & & & & & & & \\
\hline \multicolumn{8}{|l|}{ 2. Marriage type } \\
\hline \multicolumn{8}{|l|}{2 = Age-Discrepant } \\
\hline 3. Marriage No. & .018 & .079 & .064 & -.039 & .022 & $-.167 *$ & .108 \\
\hline 4. Income & -.111 & $-.210 *$ & $-.185 *$ & -.109 & .098 & .087 & -.053 \\
\hline 5. Age & $.210^{*}$ & $.409 * * *$ & $.368 * * *$ & .116 & $-.202 *$ & $-.197 *$ & .020 \\
\hline 8. Work Status & -.100 & $-.293 * * *$ & $-.241 * *$ & $-.240 * *$ & .127 & .001 & -.126 \\
\hline 9. Education & -.152 & -.113 & -.141 & $-.173 *$ & .056 & $.210^{*}$ & -.062 \\
\hline 10. Positive Affect & $.349 * * *$ & $.372 * * *$ & $.405 * * *$ & $-.280 * * *$ & -.104 & -.046 & $.199 *$ \\
\hline 11. Negative Affect & $-.289 * * *$ & $-.343 * * *$ & $-.360 * * *$ & $.222 * *$ & $.283 * * *$ & .121 & .124 \\
\hline 12. Femininity & .144 & $.250^{* *}$ & $.233^{* *}$ & .119 & $.201 *$ & .080 & $.270 * * *$ \\
\hline 13. Masculinity & .131 & .154 & .163 & -.163 & .037 & -.079 & .024 \\
\hline 14. Androgyny & -.041 & -.102 & -.084 & .050 & -.056 & -.051 & -.009 \\
\hline 15. Satisfaction & & $.580 * * *$ & $.848 * * *$ & -.107 & $-.170 *$ & $-.182 *$ & -.059 \\
\hline 20. Household Tasks & & & & & & & .120 \\
\hline \multicolumn{8}{|l|}{ 21. People in Network } \\
\hline \multicolumn{8}{|l|}{ 22. Family in Network } \\
\hline \multicolumn{8}{|l|}{ 23. Friend in Network } \\
\hline \multicolumn{8}{|l|}{ 24. Emotional Goals } \\
\hline \multicolumn{8}{|l|}{ 25. Family Goals } \\
\hline \multicolumn{8}{|l|}{ 26. Individual Goals } \\
\hline \multicolumn{8}{|l|}{ 27. Couple Goals } \\
\hline 28. Expressed Emotion & & & & & & & \\
\hline
\end{tabular}

Note. This table continues on the next page. ${ }^{*} \mathrm{p} \leq 0.05,{ }^{* *} \mathrm{p} \leq 0.01, * * * \mathrm{p} \leq 0.001$. 
Marital Satisfaction 43

Table 4 (Continued). Correlations among demographic variables and outcome measures.

\begin{tabular}{|c|c|c|c|c|c|c|c|}
\hline & 22 & 23 & 24 & 25 & 26 & 27 & 28 \\
\hline \multicolumn{8}{|l|}{ 1. Gender } \\
\hline $1=$ Male & $.241 * *$ & .040 & -.026 & .007 & .041 & -.110 & -.005 \\
\hline $2=$ Female & & & & & & & \\
\hline \multicolumn{8}{|l|}{ 2. Marriage type } \\
\hline 1= Age-Similar & .125 & $.238 * *$ & -.032 & $-.200^{*}$ & -.050 & -.093 & $.215^{*}$ \\
\hline 2 = Age-Discrepant & & & & & & & \\
\hline 3. Marriage No. & .102 & .051 & .065 & $-.192(*)$ & -.056 & -.009 & .158 \\
\hline 4. Income & -.116 & .079 & .065 & .086 & .145 & $.211^{*}$ & -.015 \\
\hline 5. Age & .043 & -.025 & .128 & $-.175^{*}$ & $-.185^{*}$ & -.113 & -.028 \\
\hline 6. Yrs. Married & .029 & $-.197 *$ & -.004 & .079 & -.086 & -.010 & -.104 \\
\hline 7. Co-residents & -.086 & .006 & -.029 & $.245^{* *}$ & .117 & .160 & -.080 \\
\hline 8. Work Status & $-.252 * * *$ & .137 & -.016 & .128 & .154 & .111 & .036 \\
\hline 9. Education & -.161 & .126 & .123 & -.119 & $.234 * *$ & $.213^{*}$ & .005 \\
\hline 10. Positive Affect & $.210^{*}$ & .056 & .115 & -.040 & -.017 & -.007 & .060 \\
\hline 11. Negative Affect & .049 & .160 & -.026 & .114 & .070 & .053 & -.076 \\
\hline 12. Femininity & $.299 * * *$ & .057 & .062 & -.081 & -.099 & -.157 & .045 \\
\hline 13. Masculinity & -.033 & .094 & .130 & -.078 & .033 & .115 & .035 \\
\hline 14. Androgyny & .032 & -.064 & .013 & .124 & .061 & -.087 & .040 \\
\hline 15. Satisfaction & .010 & -.124 & .048 & -.054 & -.108 & -.034 & .014 \\
\hline 16. Consensus & .155 & -.119 & .004 & -.064 & $-.251^{* *}$ & $-.236^{* *}$ & -.027 \\
\hline 17. DAS Composite & .106 & -.139 & .021 & -.069 & $-.221 * *$ & $-.175^{*}$ & -.011 \\
\hline 18. Functional Well-Being & .052 & -.141 & .002 & -.011 & .003 & -.068 & .081 \\
\hline 19. Household Satisfaction & .055 & .025 & -.066 & .003 & .164 & .083 & -.027 \\
\hline 20. Household Tasks & .086 & .095 & -.001 & .036 & .053 & .010 & -.052 \\
\hline 21. People in Network & $.848^{* * *}$ & $.608^{* * *}$ & .054 & .023 & -.038 & .057 & $.284^{* *}$ \\
\hline 22. Family in Network & & .095 & -.071 & .081 & -.088 & -.002 & $.205^{*}$ \\
\hline 23. Friend in Network & & & $.209 *$ & -.077 & .060 & .112 & $.252^{* *}$ \\
\hline 24. Emotional Goals & & & & -.121 & .124 & .062 & .093 \\
\hline 25. Family Goals & & & & & $.283^{* * *}$ & $.252^{* *}$ & .113 \\
\hline 26. Individual Goals & & & & & & $.631^{* * *}$ & .000 \\
\hline 27. Couple Goals & & & & & & & .027 \\
\hline 28. Expressed Emotion & & & & & & & 1.000 \\
\hline
\end{tabular}

Note. ${ }^{*} \mathrm{p} \leq 0.05,{ }^{* *} \mathrm{p} \leq 0.01, * * * \mathrm{p} \leq 0.001$. 
Relations among composite scores of marital satisfaction and demographic variables emerged. First, higher annual incomes were associated with lower marital satisfaction and greater conflict, $\mathrm{r}=-.19 ; \mathrm{r}=.22, \mathrm{p} \leq .05$, respectively. Husbands' reported annual incomes were compared. Husbands' reports were used because wives frequently indicated that they did not handle the finances. Cases in which husbands and wives differed by greater than 2 financial brackets were excluded from these analyses. Analyses indicated that there were no significant differences between the 35 age-similar and 35 age-discrepant couples on reported annual income, (average income is approximately $\$ 65,000 ; \underline{t}(54)=-0.22, \underline{p}=.83$, ns).

Age also was positively correlated with marital satisfaction, $r=.37, \mathrm{p} \leq .001$. Life-stage differences, linked to age, were expected to impact marital satisfaction; therefore, a 2 x 2 univariate ANOVA was performed to determine whether age varied as a function of marriage type and gender. Due to unequal variance, degrees of freedom were adjusted. The omnibus test indicated that the overall model was significant, $\underline{F}(3,136)=19.895, \underline{p} \leq .001$. The men were significantly older than the women, $(\underline{\mathrm{M}}=61.2,53.7$ respectively; $\underline{\mathrm{F}}(3,136)=29.12, \mathrm{p} \leq .001)$. People in ADMs were significantly older than age-similar couples, $(\underline{\mathrm{M}}=$ 59.5, 55.3 respectively; $\underline{F}(3,136)=9.27, \underline{p} \leq .01)$. A significant interaction was present, $(\underline{F}(3,136)=21.31, \underline{\mathrm{p}} \leq .001)$. Men in age-discrepant marriages were approximately 11 yrs. older than men in age-similar marriages. It is important to recognize that age differences between groups were precipitated by sampling strategies. Although these age differences were related to the sampling strategies employed, it should be noted that these differences are consistent with real world differences between partners in ADMs and therefore are not considered to be a confound.

Consistent with expectations, length of marriage was positively correlated with marital satisfaction, $\mathrm{r}=.27, \mathrm{p} \leq .001$. Group differences on length of marriage were compared using an 
independent samples $t$-test. Wives' responses were used to compare group differences. The decision to use wives' reports was made on the basis that many men indicated that their wives would be more likely to be accurate. Cases where extreme deviations between husband and wife reports were present were excluded from these analyses. The data indicate that individuals in age-similar marriages were married for nearly 8 years longer than age-discrepant couples, $(\underline{\mathrm{M}}=$ 32.66, 24.67 respectively; $\underline{\mathrm{t}}(66)=0.485, \mathrm{p} \leq .001)$.

A negative relation between employment status and marital satisfaction emerged, $r=-.24$, $\mathrm{p} \leq .01$. Specifically, employment was associated with lower marital satisfaction. A $2 \times 2$ univariate ANOVA was conducted to examine whether employment status varied across groups. Degrees of freedom vary in the present analyses due to unequal variances. The omnibus test indicates that the overall model was not significant, $\underline{F}(3,136)=2.33$, $\underline{p}=.08$, ns.

The presence of co-residents and functional well-being were not significantly related to marital satisfaction. The presence of other individuals co-residing with the couple is another factor that has been linked to marital satisfaction. For the purpose of these comparisons, all categories of individuals living with the couple were collapsed. Wives' reports also were used for these analyses. The results indicate that individuals in ADMs more frequently reported the presence of individuals other than their spouse living in their home, $\underline{\underline{M}}=1.6,1.34$ respectively; $\underline{t}$ $(68)=-2.198, \mathrm{p} \leq .05)$. Preliminary analyses were performed to determine whether there was a significant correlation between marital satisfaction and the presence of others in the home after controlling for the impact of gender. The data indicate that the association between composite DAS scores and the presence of others in the home was not significant after controlling for the effects of gender, $\mathrm{r}=-.15, \mathrm{p}=.07$. Therefore, additional analyses did not control for the presence of others in the home. Analyses examining the impact of co-residents on the division of 
household labor indicate that individuals who reported co-residents reported sharing or being responsible for significantly more household tasks than those individuals who did not report coresidents, $(\underline{\mathrm{M}}=13.92,12.09$ respectively; $\underline{\mathrm{t}}(68)=3.93, \mathrm{p} \leq .001)$. Despite this pattern, no significant differences in the satisfaction with the division of household labor failed to emerge, $(\underline{\mathrm{M}}=3.39$ for co-residents, 2.25 for individuals without co-residents; $\underline{\mathrm{t}}(68)=1.64, \underline{\mathrm{p}}=.15)$

Although higher scores on the femininity subscale of the BSRI (Bem, 1979) were associated with greater marital satisfaction and more maintenance $(r=.23, \underline{p} \leq .01 ; \mathrm{r}=.3, \underline{\mathrm{p}} \leq$ .001 , respectively), femininity scores were not significantly related to the division of household labor or satisfaction with household duties. A modest inverse relation between the total number of household tasks assumed or shared and marital satisfaction emerged, $r=-.17, \underline{p} \leq .05$. Lower marital satisfaction was linked to greater dissatisfaction with the division of household duties, $\mathrm{r}=$ $-.21, \mathrm{p} \leq .05$. Conflict was significantly associated with greater dissatisfaction with household labor divisions, $\mathrm{r}=.22, \mathrm{p} \leq .01$. The division of household labor and satisfaction with household responsibilities was not significantly related to marriage type.

A 2 x 2 univariate analysis was performed to examine whether number of marriages varied as a function of gender and marriage type. Due to unequal variances, degrees of freedom for these analyses vary. The omnibus test indicated that the overall model was significant, $\underline{F}$ ( 3 , $135)=20.775, \mathrm{p} \leq .001$. Consistent with Census (2001) reports, men reported significantly more previous marriages than women, $(\underline{\mathrm{M}}=1.39,1.25$ respectively; $\underline{\mathrm{F}}(3,135)=4.337, \mathrm{p} \leq .05)$. Also consistent with projected trends, individuals in ADMs reported significantly more previous marriages, $(\underline{M}=1.57,1.06$ respectively; $\underline{F}(3,135)=56.447, \underline{\mathrm{p}} \leq .001)$; significant interaction effects were not observed. 
A 2 x 2 univariate ANOVA was conducted to determine whether level of education varied as a function of gender or marriage type. Degrees of freedom were adjusted because of unequal variance. The omnibus test indicates the overall model was significant, $\underline{F}(3,136)=$ 4.233, $\mathrm{p} \leq .01$. The data indicated that individuals in age-discrepant marriages had completed significantly more years of educational training, $(\underline{\mathrm{M}}=15.7,14.2$, respectively; $\underline{\mathrm{F}}(3,136)=$ 12.61, $\mathrm{p} \leq .001)$. No significant main effects for gender or interaction effects emerged.

Positive affect was significantly associated with higher satisfaction, consensus, composite DAS, and maintenance scores, $\mathrm{r}=.35, .37, .41, .18, \mathrm{p} \leq .05$, respectively. Greater ambivalence and conflict were significantly associated with lower positive affect, $\mathrm{r}=-.21$ and -.22 , $\mathrm{p} \leq .05$, respectively. Higher satisfaction, consensus, and DAS composite scores were significantly associated with greater negative affect, $\mathrm{r}=-.29,-.34,-.36, \mathrm{p} \leq .001$, respectively. Also, conflict was significantly related to greater negative affect, $\mathrm{r}=.31, \mathrm{p} \leq .01$. In order to examine the link between marital satisfaction and psychological well-being as it applies to individuals involved in age-similar and age-different long-term marriages, positive and negative affect were examined. A 2 x 2 univariate ANOVA was performed to determine whether if affect varies as a function of gender and marriage type. The omnibus test indicates that the overall model was not significant, $\underline{F}(1,139)=1.58, \underline{p}=.20$, ns. Similar analyses indicated that the overall model examining negative affect also failed to reach significance, $\underline{F}(1,139)=1.66, \underline{p}=.18$, ns

Composite DAS marital satisfaction scores were inversely related to the total number of individual goals reported, $\mathrm{r}=-.22, \mathrm{p} \leq .01$. A similar relation emerged between the total number of couple goals and marital satisfaction, $\mathrm{r}=-.18, \mathrm{p} \leq .05$. This may be confounded by the average length of marriage for the couples in this sample. Maintenance scores were significantly related to the number of couple goals that were reported by participants, $r=.17, \mathrm{p} \leq .05$. 
A significant relation among emotional goals, personal network size, and marriage type failed to emerge. However, age-discrepant marriage type was associated with larger personal networks, $\mathrm{r}=.23, \underline{\mathrm{p}} \leq .01$. A significant inverse relation between age and individual goals also emerged, $\mathrm{r}=-.19, \mathrm{p} \leq .05$. Personal network size was not significantly associated with age. Marriage type and Marital Satisfaction

In order to test group differences in martial satisfaction, Hypotheses 1 and 2, a 2 x 2 MANOVA was performed using the satisfaction and consensus subscales of the DAS (Spanier, 1976) and the subscales of the Couple’s Questionnaire (Braiker \& Kelley, 1979). Main effects for marriage type were examined to determine if individuals in age-similar marriages reported greater marital satisfaction than individuals in ADMs (Hypothesis 1). The overall model for the consensus subscale was significant according to the omnibus test, $\underline{F}(3,136)=3.01, \underline{p} \leq .05$. No significant differences emerged on the consensus subscale between people in age-similar and age-discrepant marriages, $(\underline{\mathrm{M}}=51.6,53.0$ respectively; $\underline{\mathrm{F}}(1,139)=2.78, \underline{\mathrm{p}}=.10, \mathrm{~ns})$. According to the omnibus tests, the overall models for the satisfaction subscale of the DAS and the subscales of the Couple’s Questionnaire were not significant. Therefore, Hypothesis 1 was not supported.

Gender and Marital Satisfaction

A 2 x 2 univariate ANOVA using a composite score that combines scores on the satisfaction and consensus subscales yielded the same pattern of results. The omnibus test indicates that the overall model was significant, $\underline{\mathrm{F}}(3,136)=2.99, \mathrm{p} \leq .05$. The data indicated that women reported significantly lower marital satisfaction than men, $(\underline{M}=91.3,95.8$ respectively; $\underline{\mathrm{F}}(1,139)=8.02, \underline{\mathrm{p}} \leq .01)$. These results support Hypothesis 2 . No significant main effects for marriage type or interaction effects were present using the composite score. 
When determining whether women would report lower marital satisfaction than men (Hypothesis 2), women reported lower consensus than did men, $(\underline{M}=51.3,53.4$ respectively; $\underline{F}$ $(1,139)=6.04, \mathrm{p} \leq .05)$. A $2 \times 2$ univariate ANOVA confirmed main effects for gender on the consensus subscale. No significant main effects for marriage type or interaction effects were present in the data. Significant main effects for gender and interaction effects were not present on any of the other indicators of marital satisfaction. Although women reported significantly lower consensus than men, main effects for gender and marriage type did not emerge for satisfaction or the subscales of the Couple’s Questionnaire. Therefore, the data provide only partial support for Hypothesis 2.

The Division of Household Labor: Examining Gender and Marriage Type

A 2 x 2 MANCOVA was performed to determine whether satisfaction with household tasks and the total number of household tasks performed varied as a function of gender, marriage type, and employment status (see Hypotheses 3 \& 4). Employment status was controlled in these analyses. A satisfaction with household tasks score was calculated for each individual. All items that reflected a desire for more or less help were categorized as, “dissatisfied”. A 2 x 2 univariate ANOVA indicates that there are no main effects for employment status, $(\underline{F}(3,136)=2.31, \underline{p}=$ $.08, \mathrm{~ns})$. Degrees of freedom were adjusted for all analyses involving satisfaction with the division of household labor because of unequal variance. The omnibus test indicates that the overall model for division of household labor was significant $(\underline{F}(4,135)=20.55, \underline{p} \leq .001)$, but the overall model for satisfaction with household tasks was not, $(\underline{F}(4,135)=1.72, \underline{p}=.15)$.

The results indicate that women were responsible for significantly more tasks than the men, $(\underline{M}=13.09,11.13$ respectively; $\underline{F}(1,139)=76.86, \underline{p} \leq .001)$. These data are consistent with Hypothesis 3. However, the data indicate that satisfaction with the division of household 
labor does not vary as a function of gender, $(\underline{F}(3,136)=3.87, \underline{p}=.16$, ns). Therefore, the data provide only partial support for Hypothesis 3. No significant main effects for marriage type or interaction effect for satisfaction with the division of household labor emerged.

There were no significant differences between individuals in age-similar and agediscrepant marriages regarding the division of household labor, $(\underline{F}(1,139)=2.55, \underline{p}=.11$, ns $)$. The data indicate no significant interaction effect. Hypothesis 4 is not supported by the data. Discrepancies Over Division of Household Labor and Marriage Type

To examine differences within marriages, an independent samples $t$-test was conducted to determine whether individuals in age-similar marriages would demonstrate less discrepancy on the division of household tasks than individuals in ADMs (Hypothesis 5). Responsibility for household tasks was conceptualized as a continuous variable for these analyses. A total score on each of the items pertaining to responsibility was calculated for each partner. A simple difference score was computed based on each partner's individual score. The total number of tasks performed by the wife was subtracted from the total number of tasks performed by the husband. Therefore, a negative score indicates that the wife performs more total tasks than the husband. Contrary to Hypothesis 5, there were no significant differences between individuals in agesimilar and ADMs, $(\underline{\mathrm{M}}=-2.43,-1.49$ respectively; $\underline{\mathrm{t}}(68)=-1.131)$.

Predictors of Marital Satisfaction: Gender, Household Labor, and Marriage Type

Several separate hierarchical regression analyses, using each of the indicators of marital satisfaction, were performed to determine whether marriage type would account for additional variance in marital satisfaction beyond the variance accounted for by gender and satisfaction with household tasks (Hypothesis 6). 
The satisfaction subscale of the DAS (Spanier, 1976) was used as an index of marital satisfaction for the first regression analysis. Gender and satisfaction with household tasks were entered on the first step of the analysis. Marriage type was entered on the second step of the analysis. Results showed that gender and satisfaction with household tasks significantly account for $6.6 \%$ of the variance in scores on the satisfaction subscale, $\underline{F}(2,137)=4.81, \underline{p} \leq .01 ; \underline{R}^{2}=$ $0.066, \mathrm{p} \leq .01$. However, marriage type did not explain additional variance in satisfaction beyond that accounted for by gender and satisfaction with household tasks, $\underline{\mathrm{R}}^{2}$ change $=0.004, \underline{\mathrm{p}}=$ .46 , ns. The results indicate that the 3 predictor equation significantly explains the variance accounted for in marital satisfaction, $\underline{\mathrm{F}}(3,136)=3.379, \mathrm{p} \leq .05$. Gender, satisfaction with household tasks, and marriage type account for $4.9 \%$ of the variance in satisfaction scores. As shown in Table 5, only gender uniquely contributed to the explained variance in satisfaction.

A second regression analysis was conducted using the consensus subscale as an indicator of marital satisfaction. This regression analysis yielded a pattern of results similar to regression analyses examining satisfaction. Gender and satisfaction with household tasks accounted for $6.8 \%$ variance in scores on the consensus subscale, $\underline{\mathrm{F}}(2,137)=5.004, \underline{\mathrm{p}} \leq .01 ; \underline{\mathrm{R}}^{2}=0.068, \underline{\mathrm{p}} \leq$ .01. Marriage type did not add to the variance accounted for by gender and satisfaction with household tasks $\left(\underline{\mathrm{R}}^{2}\right.$ change $\left.=0.019, \underline{\mathrm{p}}=.09, \mathrm{~ns}\right)$. The 3-predictor model significantly accounted for variance in marital satisfaction, $\underline{\mathrm{F}}(3,136)=4.331, \mathrm{p} \leq .01$. Gender, satisfaction with household tasks, and marriage type account for $6.7 \%$ of the variance in consensus scores; however, only gender and satisfaction with household tasks uniquely contributed to the explained variance in consensus. Refer to Table 6. 
Table 5. Marriage type as a predictor of DAS satisfaction subscale scores.

Variable

Step 1

Gender

$($ Male $=1)$

$($ Female $=2)$

Satisfaction with

$-0.212$

0.129

$-0.138$

household tasks

Step 2

Gender

$($ Male $=1)$

$($ Female $=2)$

Satisfaction with

$-0.212$

0.129

$-0.138$

household tasks

Marriage type

$-0.500$

0.680

$-0.061$

$$
(\mathrm{AD}=2)
$$

Note. $\underline{\mathrm{R}}^{2}=.066$ for Step $1(\underline{\mathrm{F}}=4.81, \underline{\mathrm{p}} \leq .01) ; \Delta \underline{\mathrm{R}}^{2}=.00$ for Step $2(\mathrm{p} \leq .05), \underline{\mathrm{F}}=3.38, \underline{\mathrm{p}} \leq .05 ; \underline{\mathrm{F}}$ $=3.38(\mathrm{p} \leq .05)$ for overall model. ${ }^{*} \mathrm{p} \leq 0.05$. 
Table 6. Marriage type as a predictor of DAS consensus subscale scores.

Variable

Step 1

Gender

$($ Male $=1)$

$($ Female $=2)$

Satisfaction with

$-0.321$

0.163

$-0.165^{+}$

household tasks

Step 2

Gender

$-1.844$

0.867

$0.177^{*}$

$($ Male $=1)$

$($ Female $=2)$

Satisfaction with

$-0.321$

0.162

$-0.165 *$

household tasks

Marriage type

1.443

0.855

0.138

$(\mathrm{AD}=2)$

Note. $\underline{\mathrm{R}}^{2}=.068$ for Step $1(\underline{\mathrm{F}}=5.00, \mathrm{p} \leq .01) ; \Delta \underline{\mathrm{R}}^{2}=.00$ for Step $2(\mathrm{p} \leq .05), \underline{\mathrm{F}}=3.38, \mathrm{p} \leq .05$;

$\underline{\mathrm{F}}=4.33(\mathrm{p} \leq .01)$ for overall model. ${ }^{*} \mathrm{p} \leq 0.05,{ }^{+}$approaches $\mathrm{p} \leq 0.05$. 
A third regression analysis was conducted using the composite satisfaction and consensus score. These results are consistent with the other regression analyses reported. Gender and satisfaction with household tasks accounted for $8.4 \%$ variance in composite scores, $\underline{\mathrm{F}}(2,137)=$ 6.28, $\underline{\mathrm{p}} \leq .01 ; \underline{\mathrm{R}}^{2}=0.084, \mathrm{p} \leq .01$. Marriage type did not significantly add to the variance accounted for by gender and satisfaction with household tasks, $\underline{\mathrm{R}}^{2}$ change $=0.04, \underline{\mathrm{p}} \equiv .42$, ns. The data indicate that the model significantly predicts marital satisfaction, $\underline{\mathrm{F}}(3,136)=4.391, \underline{\mathrm{p}} \leq .01$; $\underline{\mathrm{R}}^{2}=0.068$. Only gender and satisfaction with household tasks uniquely account for the variance. Refer to Table 7.

Three separate regression analyses were also conducted to examine the subscales of the Couple’s Questionnaire (Braiker \& Kelley, 1979). First, a regression analysis was conducted using conflict subscale scores. These results are consistent with the other regression analyses reported. Gender and satisfaction with household tasks accounted for $7 \%$ of the variance in conflict scores, $\underline{\mathrm{F}}(2,137)=5.17, \underline{\mathrm{p}} \leq .01 ; \underline{\mathrm{R}}^{2}=0.07, \underline{\mathrm{p}} \leq .01$. Marriage type did not significantly add to the variance accounted for by gender and satisfaction with household tasks $\left(\underline{\mathrm{R}}^{2}\right.$ change $=$ 0.012, $\mathrm{p} \equiv .18$, ns). The model significantly predicted marital satisfaction, $\underline{\mathrm{F}}(3,136)=4.08, \mathrm{p} \leq$ $.01 ; \underline{\mathrm{R}}^{2}=0.06$. Only satisfaction with household tasks uniquely account for the variance. Refer to Table 8. Additional regression analyses using the maintenance and ambivalence subscales proved non-significant. Refer to Tables $9 \& 10$.

\section{Predicting Affect: Examining the Link to Marital Satisfaction}

A path analysis was used to examine the relation among age, gender, satisfaction with the division of household tasks, marital satisfaction, and psychological well-being (Hypothesis 7). Measures had to meet a minimum psychometric property of .70 to be included in a path model (Arbuckle, 1995). The composite DAS score was the only indicator of marital satisfaction 
Table 7. Marriage type as a predictor of composite DAS scores.

Variable

$\underline{\mathrm{B}}$

$-3.416$

1.370

$-0.207^{*}$

$($ Male $=1)$

$($ Female $=2)$

Satisfaction with

$-0.530$

0.256

$-0.172 *$

household tasks

Step 2

Gender

$-3.416$

1.372

$-0.207 *$

$($ Male = 1)

$($ Female $=2)$

Satisfaction with

$-0.530$

0.256

$-0.172 *$

household tasks

Marriage type

1.086

1.353

0.066

$(\mathrm{AS}=1)$

$\mathrm{ADM}=2$

Note. $\underline{\mathrm{R}}^{2}=.084$ for Step $1(\underline{\mathrm{F}}=6.28, \underline{\mathrm{p}} \leq .01) ; \Delta \underline{\mathrm{R}}^{2}=.00$ for Step $2(\mathrm{p} \leq .05), \underline{\mathrm{F}}=4.39, \mathrm{p} \leq .01$; $\underline{\mathrm{F}}=4.39(\mathrm{p} \leq .01) \cdot{ }^{*} \mathrm{p} \leq 0.05$. 
Table 8. Marriage type as a predictor of conflict scores.

Variable

Step 1

Gender

1.75

0.978

0.149

$($ Male $=1)$

$($ Female $=2)$

Satisfaction with

0.427

0.183

$0.195 *$

household tasks

Step 2

Gender

1.750

0.975

0.149

$($ Male = 1)

$($ Female $=2)$

Satisfaction with

0.427

0.182

0.195*

household tasks

Marriage type

1.30

0.962

0.111

$(\mathrm{AS}=1)$

$(\mathrm{AD}=2)$

Note. $\underline{\mathrm{R}}^{2}=.07$ for Step $1(\underline{\mathrm{F}}=5.17, \underline{\mathrm{p}} \leq .01) ; \Delta \underline{\mathrm{R}}^{2}=.00$ for Step $2(\mathrm{p} \leq .05), \underline{\mathrm{F}}=4.08, \mathrm{p} \leq .01$; $\underline{\mathrm{F}}=4.08(\mathrm{p} \leq .01)$ for overall model. ${ }^{*} \mathrm{p} \leq 0.05$. 
Table 9. Marriage type as a predictor of ambivalence scores.

Variable

Step 1

Gender

$($ Male $=1)$

$($ Female $=2)$

Satisfaction with

0.212

0.155

0.117

household tasks

Step 2

Gender

0.684

0.830

0.071

$($ Male = 1)

$($ Female $=2)$

Satisfaction with

0.212

0.155

0.117

household tasks

Marriage type

$-0.186$

0.819

$-0.019$

$(\mathrm{AD}=2)$

Note. $\underline{\mathrm{R}}^{2}=.022$ for Step $1(\underline{\mathrm{F}}=1.51, \underline{\mathrm{p}}=.23) ; \underline{\mathrm{R}}^{2}=.00$ for Step $2(\mathrm{p} \leq .05), \underline{\mathrm{F}}=1.02, \mathrm{p}=.39$;

$\underline{\mathrm{F}}=1.02(\mathrm{p}=.39, \mathrm{~ns})$ for overall model. 
Table 10. Marriage type as a predictor of maintenance scores.

Variable

$\underline{B}$

$\underline{\mathrm{SE}} \underline{\mathrm{B}}$

$\beta$

Step 1

$\begin{array}{lccc}\text { Gender } & -0.775 & 1.318 & -0.051 \\ (\text { Male }=1) & & & \\ (\text { Female }=2) & & & 0.092 \\ \text { Satisfaction with } & 0.262 & 0.246 & \\ \text { household tasks } & & & \end{array}$

Step 2

Gender

$($ Male $=1)$

$($ Female $=2)$

Satisfaction with

household tasks

Marriage type

$(\mathrm{AS}=1)$

$(\mathrm{AD}=2)$
$-0.775$

1.321

$-0.051$

0.262

0.247

0.092

0.714

1.303

0.047

Note. $\underline{\mathrm{R}}^{2}=.009$ for Step $1(\underline{\mathrm{F}}=0.65, \underline{\mathrm{p}}=.52) ; \Delta \underline{\mathrm{R}}^{2}=.00$ for Step $2(\mathrm{p} \leq .05), \underline{\mathrm{F}}=0.53, \underline{\mathrm{p}}=.66$; $\underline{F}=0.533(\underline{p}=.661)$ for overall model. 
to meet this criterion. Positive and negative affect were used as indicators of psychological wellbeing. The composite DAS score was used as an index of marital quality.

AMOS (Arbuckle, 1995) was used to test the hypothesized model in Figure 1. AMOS tests path models using the maximum likelihood estimates (MLE). Several fit indices are used, including an overall chi-square for which non-significant values are associated with better fitting models. Additional indices included goodness of fit index (GFDI) and the comparative fit index (CFI) for which values greater than .95 indicate good fit. Also, the root mean square error approximation (RMSEA) was used; values less than .08 indicate an adequate fit and values less than .05 indicate a good fit.

All paths were simultaneously tested. Table 11 lists the maximum likelihood estimates (MLE). Fit indices were mixed with regard to how well the data fit the model, $\left(\chi^{2}(3)=8.09, \mathrm{p}=\right.$ $.04 ; \mathrm{GFI}=.98 ; \mathrm{CFI}=.95 ; \mathrm{RMSEA}=.110)$. As hypothesized, the path between age and marital satisfaction was positive and significant. Older individuals were more satisfied with their marriages than younger individuals. The path from satisfaction with division of household labor and negative affect reached significance. Greater dissatisfaction was associated higher negative affect. The hypothesized paths from marital satisfaction to positive and negative affect also reached significance. Greater marital satisfaction was associated with higher positive affect and lower negative affect. The hypothesized covariance between age and gender reached significance.

Several hypothesized paths failed to reach significance. The hypothesized path between satisfaction with the division of household labor and marital satisfaction was not significant. The path from satisfaction with the division of household labor to positive affect was not significant. The paths from gender to both psychological well-being outcomes also failed to 
Figure 1. A path model examining the relation among the correlates of marital satisfaction and their impact on psychological well-being.

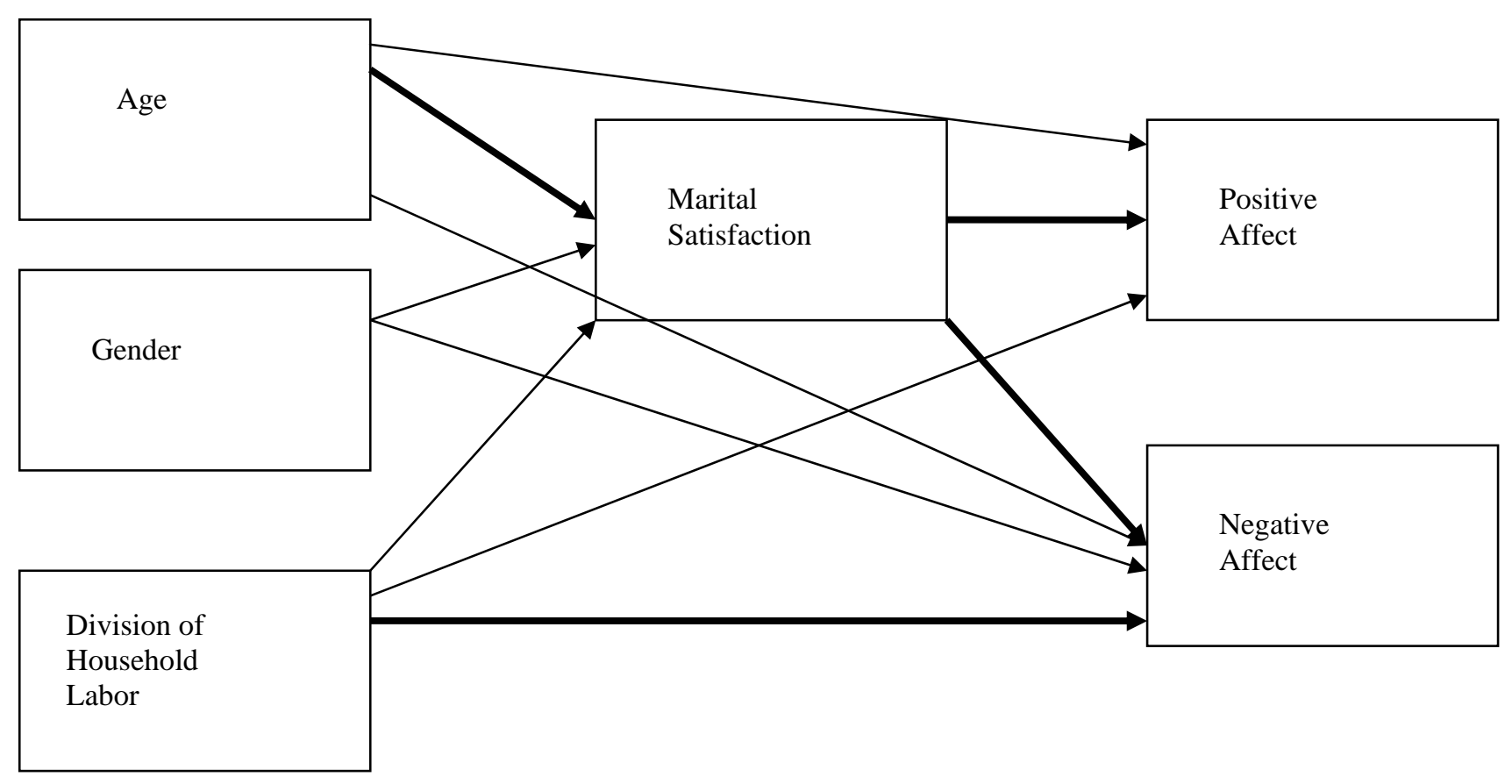


Marital Satisfaction 61

Table 11. Examining the relation among correlates of marital satisfaction and psychological well-being.

\begin{tabular}{|c|c|c|c|c|}
\hline Path & $\begin{array}{c}\text { Unstandardized } \\
\text { MLE }\end{array}$ & SE & $\begin{array}{c}\text { Standardized } \\
\text { MLE }\end{array}$ & CR \\
\hline DAS $\longleftarrow$ Age & 0.259 & 0.071 & 0.308 & $3.623^{* *}$ \\
\hline DAS $\longleftarrow$ Gender & -1.590 & 1.391 & -0.097 & -1.143 \\
\hline DAS $\longleftarrow$ Household Satisfaction & -0.397 & 0.240 & -0.130 & -1.656 \\
\hline Negative Household & 0.255 & 0.092 & 0.217 & $2.780^{* *}$ \\
\hline Satisfaction & & & & \\
\hline Negative $\longleftarrow$ Age & 0.023 & 0.028 & 0.071 & 0.811 \\
\hline \multicolumn{5}{|l|}{ Affect } \\
\hline Negative $\longleftarrow$ Gender & 0.613 & 0.530 & 0.097 & 1.157 \\
\hline \multicolumn{5}{|l|}{ Affect } \\
\hline Positive $\longleftarrow$ Household & -0.041 & 0.075 & -0.043 & -0.552 \\
\hline Satisfaction & & & & \\
\hline Positive $\longleftarrow$ Age & 0.560 & 0.433 & 0.108 & 1.292 \\
\hline \multicolumn{5}{|l|}{ Affect } \\
\hline Positive $\longleftarrow$ Gender & -0.016 & 0.023 & -0.059 & -0.676 \\
\hline \multicolumn{5}{|l|}{ Affect } \\
\hline Negative $\longleftarrow$ DAS & -0.123 & 0.032 & -0.318 & $-3.810 * *$ \\
\hline \multicolumn{5}{|l|}{ Affect } \\
\hline Positive $\longleftarrow$ DAS & 0.139 & 0.026 & 0.439 & $5.293 * *$ \\
\hline \multicolumn{5}{|l|}{ Affect } \\
\hline Covary Age and Gender & -1.877 & 0.442 & -0.386 & $-4.243 * *$ \\
\hline
\end{tabular}

Note. ${ }^{*} \mathrm{p} \leq 0.05, * * \mathrm{p} \leq 0.01, * * * \mathrm{p} \leq 0.001$. 
reach significance. Age was not directly associated with either psychological well-being outcomes.

In order to develop the most parsimonious model, all but one of the insignificant paths were deleted one at a time and model fit was re-evaluated after each modification. The only insignificant path that was not deleted was the path from gender to marital quality. This decision was based on an abundance of research indicating that men and women experience marriage differently. Removing the non-significant paths from the model resulted in a better fit, $\left(\chi^{2}(9)=\right.$ 15.19, $\mathrm{p}=.09 ; \mathrm{GFI}=.97 ; \mathrm{CFI}=.89 ; \mathrm{RMSEA}=.07)$. Significant paths from age to marital quality, from satisfaction with the division of household labor to negative affect, and from marital quality to both psychological well-being outcomes continued to be significant. Attitudes Toward Sex Roles: Gender and Marriage Type Differences

A 2 x 2 univariate ANOVA was conducted to determine whether attitudes toward sex roles differed as a function of marriage type (Hypothesis 8) and gender (Hypothesis 9). Bem (Bem, 1979) androgyny scores were used as an index of traditional attitudes toward sex roles. The omnibus test indicated that the overall model was not significant, $\underline{\mathrm{F}}(3,135)=0.32$, $\mathrm{p}=.81$. The results indicate that there were no significant effects for marriage type, $(\underline{\mathrm{M}}=35.39 ; 37.05$, AS and ADMs, respectively; $\underline{F}(1,138)=.131, \underline{p}=.72$, ns). Therefore, the findings do not support Hypothesis 8. The data also failed to support Hypothesis 9. Men and women did not significantly differ in their gender-role ideologies, $(\underline{\mathrm{M}}=36.49,35.94$ respectively; $\underline{\mathrm{F}}(1,138)=$ $.012, \underline{\mathrm{p}}=.91, \mathrm{~ns})$. 
Social Support and the Spouse: The Influence of Gender \& Age-Congruency

According to SST (Levenson, Carstensen, \& Gottman, 1994), the spouse becomes an increasingly more important potential source of social support as we grow older and our personal networks shrink. Most (96.4\%) of the 140 individuals interviewed placed their spouse in their personal networks. A total of $91.4 \%$ of the 140 individuals placed their spouse in their innermost circle. This location indicates that the respondent viewed their spouse as, "is so important to them that they can’t imagine life without them.” A total of eight individuals placed their spouse in their second circle. A chi-square analysis indicated that there were no significant gender effects for the presence of the spouse in the network, $\left(\chi^{2}(2)=5.89, \mathrm{p}=.30\right.$, ns). Moreover, no significant differences emerged between age-similar and age-discrepant couples, $\left(\chi^{2}(2)=2.397\right.$, $\mathrm{p}=.053, \mathrm{~ns})$ for the presence of the spouse in the network.

A 2 x 2 univariate ANOVA was performed to determine whether the total number of people in the personal network varied as a function of gender and marriage type. The omnibus test indicates that the overall model was significant, $\underline{\mathrm{F}}(3,135)=5.01, \mathrm{p} \leq .01$. Women included significantly more people in their personal networks than did men, $(\underline{\mathrm{M}}=13.38,10.24$ respectively; $\underline{\mathrm{F}}(1,138)=7.12, \mathrm{p} \leq .01)$. These results further substantiate differences between men and women in regards to personal network size, Hypothesis 10. People in ADMs reported more total people in their personal networks than people in age-similar marriages, $(\underline{\mathrm{M}}=13.45$, 10.17 respectively; $\underline{\mathrm{F}}(1,138)=7.77, \mathrm{p} \leq .01)$. Contrary to Hypothesis 11 , no significant interaction effect was present, $(\underline{\mathrm{F}}(1,138)=0.30, \underline{\mathrm{p}}=.59$, ns $)$. Individual and Emotional Goals within the Context of Marriage

In order to examine differences in emotional goals according to gender and marriage type, a 2 x 2 univariate ANOVA was performed. The omnibus test indicates that the overall model 
was not significant, $\underline{\mathrm{F}}(3,134)=0.36, \underline{\mathrm{p}}=.78$, ns. No significant main effects for gender or marriage type emerged. Contrary to expectation, age-discrepant husbands did not report more emotional goals than age-similar husbands or wives in general, $(\underline{\mathrm{F}}(1,137)=0.84, \mathrm{p}=.36$, ns); therefore, Hypothesis 12 was not supported by the data. Paired $t$-tests indicated that husbands and wives did not differ in the number of emotional goals reported, $(\underline{\mathrm{M}}=0.23$ and 0.20 , respectively; $\underline{\mathrm{t}}(69)=0.29, \underline{\mathrm{p}}=.78)$.

To determine whether people in age-similar marriages and age-discrepant wives report more individual goals than age-discrepant husbands (Hypothesis 13), a 2 x 2 univariate ANOVA was performed. Degrees of freedom were adjusted because of unequal variance between the groups. The omnibus test indicates that the overall model was not significant, $\underline{\mathrm{F}}(3,134)=0.23$, $\mathrm{p}=.88$, ns. No significant main effects for gender and marriage type emerged. Contrary to Hypothesis 13, a significant interaction effect was not present, $\underline{\mathrm{F}}(3,134)=0.11, \mathrm{p}=.74$, ns). Significant differences within couples also failed to emerge, $(\underline{\mathrm{M}}=3.67$ and 3.77, respectively; $\underline{\mathrm{t}}$ $(68)=-0.55, \mathrm{p}=.58)$.

\section{Post Hoc and Exploratory Analyses}

\section{Demographic Profiles and Predicting Marital Satisfaction}

The literature on marital satisfaction has linked several factors to marital satisfaction. Among these factors are gender, other individuals co-residing with the couple, education, and satisfaction with the division of household labor. An exploratory linear regression analysis was conducted including each of these variables. These variables were selected because of previous research indicating a relation to marital satisfaction and preliminary analyses suggesting significant group differences. The composite DAS score was used as an indicator of marital satisfaction. The overall model was significant, $(\underline{F}(4,135)=4.35, \underline{\mathrm{p}} \leq .01)$. Gender, satisfaction 
with household tasks, level of education completed, and the presence of other individuals living in the home account for $11.4 \%$ of the variance in composite scores.

A second exploratory linear regression analysis examined the association among gender, marriage type, satisfaction with the division of household labor, employment status, the presence of others in the family home, and marital satisfaction. The composite DAS score was used as an indicator of marital satisfaction. The overall model is significant, $(\underline{F}(6,133)=4.34, \underline{p} \leq .001)$. These five factors account for $16.4 \%$ of the variance in marital satisfaction. Age was the only factor that uniquely accounted for the variance in marital satisfaction. Refer to Table 11.

A follow-up hierarchical regression analysis was performed. Gender, marriage type, satisfaction with the division of household tasks, employment status, and the presence of coresidents were entered on Step 1. These four factors accounted for $13 \%$ of the variance in composite DAS scores, $\underline{\mathrm{F}}(5,134)=4.07, \underline{\mathrm{p}} \leq .01 ; \underline{\mathrm{R}}^{2}=0.13, \underline{\mathrm{p}} \leq .01$. Age was entered on Step 2. Age significantly added to the variance explained by the other four factors, $\underline{\mathrm{R}}^{2}$ change $=0.03, \underline{\mathrm{p}} \leq$ .05. The overall model significantly predicts marital satisfaction, $\underline{\mathrm{F}}(6,133)=4.34, \mathrm{p} \leq .001$. Gender, marriage type, satisfaction with household tasks, employment status, and the presence of co-residents accounted for $12.6 \%$ of the variance in marital satisfaction. Age is the only factor that uniquely accounts for the variance. Only the linear model was significant, $\underline{F}(1,138)=$ 21.62, $\mathrm{p} \leq .001$

\section{Gender, Marriage Type and Network Composition}

Hypotheses 10 and 11 examined network size. The following exploratory analyses examine network composition. According to the omnibus test, the overall model was significant, $\underline{F}(3,135)=4.19, \underline{p} \leq .01$. A $2 \times 2$ univariate ANOVA was performed examining group differences in the total number of family members included in the personal network. Women 
reported significantly more family members in their personal networks than men did, $(\underline{\mathrm{M}}=$ 10.67, 7.87 respectively; $\underline{\mathrm{F}}(1,138)=8.71, \underline{\mathrm{p}} \leq .01)$. No significant main effect for marriage type or interaction effect was present.

A 2 x 2 univariate ANOVA also was performed to examine group differences in the number of friends included in the personal network. Degrees of freedom were adjusted because of unequal variance. The omnibus test indicates that the overall model was significant, $\underline{\mathrm{F}}(3,135)$ $=3.10, \mathrm{p} \leq .05$. Although no significant main effect for gender or interaction effect were present, individuals in age-discrepant marriages reported more total friends in their personal networks than did age-similar couples, $(\underline{\mathrm{M}}=3.46,1.63$ respectively; $\underline{\mathrm{F}}(3,135)=8.17, \mathrm{p} \leq .01)$.

\section{A Closer Examination of Life Stage and Goals}

Although no significant interaction effect for marriage type and gender emerged in the number of reported emotional goals, a 2 × 2 univariate ANOVA was performed to examine whether the total number of couple's goals reported differed as a function of gender and marriage type. Degrees of freedom were adjusted because of unequal variance. The omnibus test indicates that the overall model was not significant, $\underline{\mathrm{F}}(3,134)=0.97, \mathrm{p}=.41$, ns). No significant main effects or interactions emerged.

The underlying premise for anticipated differences between age-similar couples and ADMs relates life stage differences between partners who are significantly mismatched by age. Two additional analyses were conducted to further explore the link between age-related changes in health and marriage. A $2 \times 2$ univariate ANOVA was conducted to determine whether the number of individual health goals reported varied as a function of gender and marriage type. The omnibus test indicates that the overall model was not significant, $\underline{F}(3,134)=0.90, \underline{p}=.45$, ns. Therefore, no significant main effects or interaction effect emerged. 
Recognizing that caregiving issues may be a serious concern for individuals married to a spouse who is significantly older than them, exploratory analyses were performed to examine differences in the number of individual goals reported that reflect themes of independence. A 2 x 2 univariate ANOVA was conducted to examine differences related to gender and marriage type. Degrees of freedom were adjusted due to unequal variance between groups. The omnibus test indicates that the overall model was not significant, $\underline{\mathrm{F}}(3,134)=0.75, \underline{p}=0.53$, ns. Therefore, no significant gender effects or differences according to marriage type emerged in the number of individual goals reported that had themes of independence. No significant interaction effect was present. $\underline{\text { Husbands and Wives: Marital Satisfaction and Satisfaction with Household Duties }}$

Paired $t$-tests were conducted to examine differences within dyads on outcome measures of interest. First, marital satisfaction within dyads was examined indicating that husbands and wives significantly differ in levels of reported marital satisfaction, $(\underline{M}=95.19$ and 91.3 , respectively; $\underline{\mathrm{t}}(69)=4.47, \mathrm{p} \leq .001)$. Husbands report greater marital satisfaction than do their wives. Marital satisfaction was examined more closely to determine whether husbands and wives differed on satisfaction or consensus. The data indicate that husbands report greater marital satisfaction than their wives, $(\underline{M}=41.84$ and 40.06, respectively; $\underline{\mathrm{t}}(69)=4.5, \underline{\mathrm{p}} \leq .001)$. Husbands also report significantly greater consensus than their wives, $(\underline{M}=53.39$ and 51.26 , respectively; $\underline{\mathrm{t}}(69)=3.19, \underline{\mathrm{p}} \leq .01)$.

Next husbands and wives were compared on the subscales of the Braiker-Kelley (1979). No significant differences between husbands and wives emerged on the maintenance or ambivalence subscales. However, wives did report significantly greater conflict than did their husbands, $(\underline{\mathrm{M}}=16.81$ and 14.86, respectively; $\underline{\mathrm{t}}(69)=-2.86, \underline{\mathrm{p}} \leq .01)$. 
Satisfaction with the division of labor also was compared within dyads. The data indicate no significant differences between husbands and wives, $(\underline{\mathrm{M}}=1.99$ and 2.87, respectively; $\underline{\mathrm{t}}$ (69) $=-1.913, \mathrm{p}=.06)$. This is of particular interest since wives are responsible for significantly more household tasks than their husbands, $(\underline{\mathrm{M}}=13.09$ and 11.13 , respectively; $\underline{\mathrm{t}}(69)=-4.69, \underline{\mathrm{p}} \leq$ $.001)$.

\section{Examining Indicators of "Goodness of Fit"}

Although Pineo’s (1961) concept of “goodness of fit” was not directly tested by the current study, the study did assess several factors that are consistent with this concept. More specifically, an overview by Byrne and Murnen (1988) discussed several potential factors that are crucial to relationship satisfaction. Inconsistencies between partners on these key characteristics may be source of conflict. Given the selection criteria used to define the two groups of marriages, age was not included in analyses of these indicators because differences were required for participation. Independent samples $t$-tests were conducted to determine whether partners differed significantly on race and religion. First the data for these two variables was examined to determine whether the individuals in each couple agreed or disagreed; similarity on race and religion was a dichotomous variable. Independent samples $t$-tests were then conducted to determine whether differences within dyads were present. A t value could not be computed for race because there was $100 \%$ agreement between partners on this characteristic. No significant religious differences between partners were present, $(\underline{M}=0.31$ and 0.31 , respectively; $\underline{\mathrm{t}}(138)=0, \underline{\mathrm{p}}=1.00, \mathrm{~ns})$. Finally, husbands and wives did not differ significantly on education, $(\underline{\mathrm{M}}=14.89$ and 15.01, respectively; $\underline{\mathrm{t}}(138)=-0.28, \underline{\mathrm{p}}=.78, \mathrm{~ns})$. 


\section{Examining The Role of Employment on Marital Satisfaction for Men and Women}

Several $2 \times 2 \times 2$ ANOVAs were performed using the six indicators of marital satisfaction to examine the impact of gender, marriage type, and employment status. Three of these analyses emerged as significant. The appropriate follow-up analyses were performed when appropriate.

First, a 2 x 2 x2 ANOVA examining the impact of gender, marriage type, and employment on composite DAS scores was conducted. The omnibus test was significant, $\underline{F}(7,132)=3.74, \underline{p}$ $\leq .001$. A significant 3-way interaction effect was present, $(\underline{\mathrm{F}}(1,139)=6.72, \underline{\mathrm{p}} \leq .05)$. Separate 2 x 2 univariate ANOVAs were conducted for men and women in order to examine this interaction more closely. First, a 2 x 2 univariate ANOVA was conducted to examine differences among employed and non-employed men in age-similar and age-discrepant marriages. The omnibus test indicates that the overall model was significant, $\underline{F}(3,66)=3.87, \underline{p} \leq .05$. A significant main effect for employment status was present, $\underline{\mathrm{F}}(1,69)=9.64, \underline{\mathrm{p}} \leq .01$. Men who were not employed reported greater marital satisfaction than men who were employed, $(\underline{M}=98.96,92.95$ respectively). Similar analyses were performed comparing women who were employed to those who were not. The omnibus test indicated that the overall model was not significant, $\underline{F}(3,66)=$ $1.84, \mathrm{p}=.15, \mathrm{~ns}$.

A similar 2 x 2 x 2 ANOVA was conducted using the consensus subscale of the DAS. The omnibus test was significant, $\underline{\mathrm{F}}(7,132)=4.64, \underline{\mathrm{p}} \leq .001$. A significant 3-way interaction effect emerged, $(\underline{F}(1,139)=8.67, \underline{p} \leq .01)$. Follow-up 2 x 2 univariate ANOVAs analyses were conducted separately for men and women to examine this interaction more closely. The omnibus test comparing men who were employed to those who were not indicates that the overall model was significant, $\underline{\mathrm{F}}(3,66)=4.14, \mathrm{p} \leq .01$. Although no significant main effect for marriage type 
or interaction effect was present, men who were not employed reported more consensus than those who were employed, $(\underline{M}=55.96,51.86$ respectively; $\underline{F}(1,69)=9.1, \underline{p} \leq .01)$.

Follow-up 2 x 2 univariate analyses that compared women who work to those who were not employed, indicates that the overall model was significant, $\underline{F}(3,66)=3.97, \underline{p} \leq .01$. No significant main effects were present. However, a significant interaction effect was present, $\underline{\mathrm{F}}$ (1, $69)=7.45, \underline{p} \leq .01$. Specifically, age-similar wives who were employed reported higher consensus scores than age-similar wives who were not employed, $\underline{\underline{M}}=50.21,55.18$, respectively). Age-discrepant wives who were employed reported less consensus than agediscrepant wives who were not employed, $(\underline{\mathrm{M}}=51.04,50.09$ respectively). The Tukey test performed on the interaction showed that age-discrepant wives who were not employed reported the highest consensus.

Finally, a 2 x 2 x2 ANOVA was conducted using maintenance scores. The overall model was significant, $\underline{\mathrm{F}}(7,132)=2.25, \underline{\mathrm{p}} \leq .05$. A significant 3 -way interaction effect was present, $\underline{\mathrm{F}}$ $(1,139)=4.04, \mathrm{p} \leq .05$. A follow-up $2 \times 2$ univariate ANOVA comparing men who were employed to those who were not indicates that the overall model was not significant, $\underline{\mathrm{F}}(3,66)=$ $1.67, \underline{p}=.18, \mathrm{~ns}$.

The 2 x 2 univariate ANOVA comparing women who were employed to those who were not employed indicates that the overall model was significant, $\underline{\mathrm{F}}(3,66)=3.67, \mathrm{p} \leq .05$. A significant main effect for marriage type was present, $\underline{\mathrm{F}}(1,69)=4.37, \underline{\mathrm{p}} \leq .05$. Specifically, agediscrepant wives reported higher maintenance scores than did age-similar wives $(\underline{M}=28.37$ and 26.57, respectively). No significant main effects for employment status were present, $\underline{F}(1,69)=$ 0.92, $\underline{p}=.34$, ns. However, a significant interaction effect emerged, $\underline{F}(1,69)=8.98, \underline{p} \leq .01$. Specifically, age-similar wives who were employed reported higher maintenance scores than 
age-similar wives who were not employed, $(\underline{\mathrm{M}}=27.75$, 24 respectively). Age-discrepant wives who were employed reported lower maintenance scores than age-discrepant wives who were not employed, $(\underline{\mathrm{M}}=26.08,33.36$ respectively). Post-hoc LSD analyses indicate that age-discrepant wives who were not employed reported the highest maintenance scores.

Wife's Employment Status and Marital Satisfaction

Separate 2 x 2 univariate ANOVAs using each of the indicators of marital satisfaction were also conducted to examine whether wives’ employment status affected husbands’ and wives’ perceptions of marital satisfaction. The overall omnibus test indicates that wives' employment status did not affect scores on the satisfaction subscale of the DAS, $\underline{F}(3,92)=2.27$, $\mathrm{p}=.09$, ns. Likewise, the overall model predicting consensus also failed to reach significance, $\underline{\mathrm{F}}$ $(3,92)=2.11, \underline{p}=.11$, ns. The same non-significant trend was present when examining composite DAS scores, $\underline{\mathrm{F}}(3,92)=2.04, \underline{\mathrm{p}}=.11$, ns. None of the models examining the subscales of the Couple’s Questionnaire reached significance. Refer to Table 12. 
Marital Satisfaction 72

Table 12. Profile of marital satisfaction among individuals in marriages that include an employed wife.

\begin{tabular}{|c|c|c|c|c|c|c|c|c|}
\hline & \multicolumn{4}{|c|}{ Men } & \multicolumn{4}{|c|}{ Women } \\
\hline & \multicolumn{2}{|c|}{ Age-Similar } & \multicolumn{2}{|c|}{ Age-Discrepant } & \multicolumn{2}{|c|}{ Age-Similar } & \multicolumn{2}{|c|}{ Age-Discrepant } \\
\hline & $\underline{\mathrm{M}}$ & $\underline{\mathrm{SD}}$ & $\underline{\mathrm{M}}$ & $\underline{\mathrm{SD}}$ & $\underline{\mathrm{M}}$ & $\underline{\mathrm{SD}}$ & $\underline{\mathrm{M}}$ & $\underline{\mathrm{SD}}$ \\
\hline Satisfaction & 42.04 & 2.87 & 41.04 & 3.85 & 41.04 & 3.78 & 39.29 & 4.24 \\
\hline Consensus & 51.46 & 4.47 & 53.38 & 5.17 & 51.04 & 4.07 & 50.21 & 4.32 \\
\hline DAS Composite & 93.29 & 5.82 & 94.46 & 8.11 & 91.92 & 7.08 & 89.58 & 7.53 \\
\hline Conflict & 14.21 & 6.29 & 17.08 & 5.07 & 16.29 & 5.22 & 17.38 & 5.03 \\
\hline Ambivalence & 6.58 & 2.17 & 8.50 & 4.82 & 7.92 & 3.98 & 9.13 & 4.68 \\
\hline Maintenance & 27.71 & 7.28 & 27.96 & 5.92 & 27.75 & 6.22 & 26.08 & 7.71 \\
\hline
\end{tabular}




\section{Discussion}

The objectives of this study were to examine the experiences of men and women in agesimilar and age-discrepant marriages. The focus of the investigation was to determine whether gender-role ideologies, and division of household labor differentially affected marital quality according to marriage type and gender. The existing research examining age-discrepant couples has been plagued with inconsistencies in the definition of age difference (Berardo et al., 1993; Bonds \& Nicks, 1999; Shehan et al., 1991). Demographic and cultural shifts suggest that agediscrepant couples will continue to become more visible as life expectancies increase and attitudes toward marriage continue to change (Amato et al., 2003; Rogers \& Amato, 2000; Winston \& Klepfer, 2000). The present study addresses limitations in the existing literature by comparing a well-defined population of age-similar and age-discrepant couples. Contrary to expectations, the general pattern of results suggests that age-discrepant couples are very similar to the traditional marriage type. Although the analyses failed to detect differences between marriage types, the findings do yield gender differences that are highly consistent with those reported in the literature (Brooks, 2000; Fowers, 1991; Levenson et al., 1993; Kurdek, 1998; Rhyne, 1981; Thompson \& Walker, 1989). The implications of these findings add to the developmental literature by providing a more comprehensive understanding of how age and length of marriage are related to the social identities of married partners via gender-role ideologies and division of labor (e.g., Garrido \& Acitelli, 1999; Kurdek, 1998).

\section{Marriage Type and Division of Household Labor}

The results of the present study suggest that division of household labor did not differ according to marriage type. Across marriage types, wives were responsible for more of the household tasks than husbands. Research does suggest that gender role ideologies are becoming 
less traditional over time (Amato et al., 2003; Rogers \& Amato, 2000); however, household tasks have traditionally been considered “women’s work” (Merriam \& Hyer, 1984; Rogers \& Amato) and as such may be an integral part of a wife's identity as a woman and a caregiver (Kurdek, 1998), particularly for the generation of wives examined in this study. Although partners in the age-discrepant group are from two different generational cohorts, all the wives examined were from the same generation. Therefore, it is possible that these trends reflect characteristics that are specific to women from this cohort.

It also should be recognized that nearly $66 \%$ of the sample were still employed, with nearly half of the age-discrepant husbands being employed. Therefore discrepancies in the division of household labor precipitated by incongruent retirements may not have emerged in these analyses because of the relatively young age (58 years) of the sample. Stricter age criteria for participation may have resulted in significant differences in employment status and group differences in the division of household labor being evident.

Marriage Type and Attitudes Toward Sex Roles

Discrepancy between partners on attitudes toward sex roles did not differ according to marriage type. The findings in this area are somewhat inconsistent. Some findings suggest that older adults have more traditional gender role ideologies and that their attitudes become less flexible with age (Byrne \& Murnen, 1988); whereas, others have argued that adults become less traditional in the roles that they assume as they grow older (Snell, 1993). The data not only indicate a lack of difference at the group level, but the data indicate that in general the sample is not particularly high in their masculine and feminine gender-role ideologies. The lack of extreme ideologies coupled with the average age of the sample (58 years) generally supports the idea that attitudes regarding masculinity and femininity are less traditional in midlife (Snell, 1993). The 
cross- sectional design of the current study makes it impossible to determine if the attitudes of the older men in age-discrepant marriages have attenuated over time becoming less extreme. According to Aube and Koestner (1995), attitudes toward gender roles may be malleable to partner influence over time. This is particularly relevant to the current findings given that the sample reported being married an average of approximately 29 years. It is also possible that the attitudes of the age-similar husbands may have been less extreme to begin with as a result of cohort differences that fostered less traditional attitudes (e.g., Norris et al., 1997). However, the cross-sectional nature of this study precludes explanation of this trend.

Marital Satisfaction and Marriage Type

The data indicate that the couples included in this study demonstrated fairly high satisfaction and consensus, the two indicators of marital satisfaction examined. No significant differences between marriage types were reported on either of these two measures. The lack of significant group differences may be a function of length of marriage. Specifically, age-similar couples were married an average of 33 years and the age-discrepant couples were married an average of 25 years. It is unlikely that couples who are dissatisfied would remain married for 25 years or longer. Rather, couples would have either resolved their conflicts at earlier periods or dissolved their marriages.

It was hypothesized that age-discrepant couples would demonstrate lower marital satisfaction because of incongruent developmental tasks linked to age-related differences in life stage. However, evidence of significant group differences in marital satisfaction did not emerge. Retirement is one of the major developmental tasks that individuals face as they grow older (Kim \& Moen, 2002). It was anticipated that husbands in the age-discrepant group would be dealing with retirement-related issues, but nearly half of these men were still employed despite an 
average age of approximately 66 years. As a result, incongruent retirements were not an issue for half of the couples in this group. The data do indicate that at least half of the age-discrepant husbands are retired while nearly $69 \%$ of their wives are still employed. It is possible that differences between marriage types may have emerged with a larger sample size; however, the age-difference between partners is an ongoing issue. In other words, incongruent developmental tasks may be an issue that these couples have overcome because of the extended time that they had to prepare for these types of challenges. Therefore, the issues that are unique to the marital satisfaction of couples in age-discrepant marriages may have been resolved over time for those couples who maintain successful long-term marriages.

Other developmental tasks are more difficult to prepare for in advance (e.g., caregiving, the death of a spouse). These are issues that are of potential concern to all couples as they grow older; however, the likelihood of facing these issues is greater for women who are married to men who are significantly older than them. Research has indicated that the stressors associated with the caregiving process pose a serious threat to marital satisfaction (Wright \& Aquilino, 1998). The relatively young average age of the age-discrepant husbands (66 yrs.), may suggest that the wives in this particular sample have not begun to address these concerns because they are not imminent. Although physical well-being was not directly assessed in this investigation, functional assessments indicate that ADM husbands are rather healthy. This further suggests that caregiving issues, although more typical of ADMs, are not of immediate concern to ADM wives. Therefore, the potential impact of caregiving concerns on marital quality may not have been captured by the current sample of ADMs. Future investigations may include a broader definition of age-discrepancy in order to increase the likelihood of capturing the impact of these concerns 
on marital quality. Increasing the minimum age for participation from 50 years for husbands to 65 years might also help to satisfy this specific aim.

Gender and Division of Household Labor

Although the analyses failed to reveal differences in marital satisfaction between agesimilar and age-discrepant couples, significant gender effects emerged that are consistent with previous research (e.g., Brooks, 2000; Fowers, 1991; Grote \& Clark, 2003 ). The current study provides additional support for a gendered division of labor that favors men (Grote \& Clark); women in this sample were responsible for significantly more household tasks than their husbands, regardless of marriage type and employment status. Division of household labor and satisfaction with household labor did not covary with employment status. However, there are no significant gender differences in satisfaction with household tasks. Women may consider housework to be a component of their identity as a woman and a wife (Kurdek, 1998; Garrido \& Acitelli, 1999), and therefore may not consider their additional household responsibilities to be a burden. In fact, some women may consider assistance from their spouses to be more frustrating than helpful (Ward, 1993). Thus, wives may not view this imbalance negatively because it is consistent with their expectations of "woman's work." If women expect that their domestic responsibilities should outweigh their husbands' and consider this a defining feature of their identity as a woman, then total household contributions shouldn't be inversely related to satisfaction with the household tasks.

Research on identity structure (Garrido \& Acitelli, 1999) provides an alternative explanation regarding the apparent inconsistencies between household responsibilities and satisfaction with the division of household labor. According to an overview of the literature on identity structure, Garrido and Acitelli adopted a classification system that combines ideas of 
interdependence and independence into high or low relational identities, respectively. Garrido and Acitelli found that satisfaction with the division of household labor operated at an individual rather than a couple level. Specifically, an individual's satisfaction with the division of household labor was determined according to their relational identity and their actual outputs. Individuals with high relational identities are motivated by a need for interdependence. In order to satisfy this need, these individuals are more likely to engage in household tasks that traditionally have been considered the responsibility of women because these tasks benefit more than just the individual who is performing them. Those individuals who are low in relational identity are motivated by a need for independence. These individuals would not be motivated to engage in tasks that have traditionally been labeled as "feminine” and "nurturing." Garrido and Acitelli (1999) argue that satisfaction with the division of household labor is determined by an individual's expectations and outputs. Expectations are directly linked to relational identity. Individuals are dissatisfied when their outputs are incompatible with their self-expectations. The lack of an inverse relation between division of household tasks and satisfaction with household tasks may be because wives are high in relational identity compared to their husbands. Therefore, women may not be dissatisfied with their disproportionate contributions to the home because their high outputs are consistent with their relational identities.

\section{Attitudes Toward Sex Roles}

There were no significant differences between men and women on gender role ideologies. These findings are contrary to research suggesting that men are more reluctant to adopt non-traditional gender role ideologies because doing so will diffuse the responsibility of these tasks to themselves (Grote \& Clark, 2003). The lack of extreme masculine and feminine attitudes toward sex roles may indicate that these couples are becoming less traditional as they 
age. It is important to note that the men are significantly older than the women (61 yrs. versus 54 yrs., respectively). The added effects of age may have helped to further offset once traditional attitudes among the husbands, thereby minimizing any preexisting gender differences in attitudes toward sex roles.

Previous findings have suggested a link between the division of household labor and gender-role ideologies (e.g., Burke \& Cast, 1997). Men with traditional ideologies contribute less, whereas women with traditional ideologies contribute more (Kulik, 1999; Kurdek, 1998). This is not consistent with the current findings. Women are responsible for more of the household tasks than their husbands, but there is no evidence of extreme attitudes toward sex roles or gender differences between the two groups. Perhaps the division of household labor is not a function of gender-role ideologies or attitudes toward sex roles, but a third factor that was not tested by the current study (e.g., relational identity).

Other studies have suggested that household responsibilities and satisfaction with the division of labor are related to time constraints (Amato et al., 2003; Baker et al., 1996). Although time constraints were not specifically tested in the current methodology, employment status may act as a rudimentary indicator of time constraints. No significant main effects for employment status emerged, but approximately $69 \%$ of the wives in this sample were employed. Consistent with previous findings (e.g., Brooks, 2000), these statistics suggest women continue to be responsible for a bulk of the household tasks despite work-related time constraints. Again, it is important to recognize that employment status was not significantly related to satisfaction with division of household labor. Therefore, responsibility for household duties and satisfaction with these household tasks appears to be unrelated to work-related time constraints in this sample. 


\section{$\underline{\text { Marital Satisfaction and Gender }}$}

Differences in the indicators of marital satisfaction emerged in the current sample of married couples. Although no significant differences on the satisfaction subscale emerged, women reported significantly less consensus and lower composite scores of marital satisfaction. These findings provide further support for the notion that men and women experience marriage differently (Fowers, 1991; Levenson et al., 1993; Rhyne, 1981). Gender and satisfaction with the division of household labor were significant predictors of marital satisfaction. Post-hoc analyses indicated that gender, the presence of others in the home, education, and satisfaction with the division of household labor accounted for significant variance in marital satisfaction among the participants in this sample. These findings are consistent with the existing literature and reflect the complex interaction among a variety of factors that combine to affect marital quality. However, it is important to recognize that the variance accounted for by these factors is modest, $11.4 \%$. This may suggest that factors that have not been identified and empirically tested in the current investigation impact marital quality.

\section{The Marital Experience and Psychological Well-Being}

Previous findings have linked marital satisfaction to physical and psychological wellbeing (e.g., Kiecolt-Glaser \& Newton, 2001; Levenson et al., 1993; Pina \& Bengston, 1995). The current study further substantiates the link between marital satisfaction and positive and negative affect. However, the present study challenges previous findings indicating that these outcomes are differentially related to gender (e.g., Kiecolt-Glaser \& Newton). Although marital satisfaction and satisfaction with the division of household labor were not significantly related, satisfaction with household duties was related to negative affect. This implies that inequities in the domestic realm are not innocuous. A gendered division of domestic labor may not impact 
marital quality, but it is related to psychological well-being. This indicates that there is a need to examine which factors determine the division of household duties, the subsequent satisfaction with household responsibilities, and well-being. Findings such as these may help to further delineate gender differences in well-being that favor married men.

Marital Satisfaction and Age

Post-hoc analyses also revealed that differences in marital quality may be better explained by age differences. Specifically, when considering age in addition to gender and other factors linked to marital quality, it is only age that explains unique variance in marital quality. Consistent with the literature, older individuals reported greater marital satisfaction than younger individuals (Carstensen et al., 1995; Kulik, 1999). Differences in marital quality may have emerged as gender differences because sampling procedures forced male participants to be significantly older than female participants. If age-discrepant couples defined by older femalemale unions were included in the sample, then differences in marital quality may have emerged as a function of marriage type rather than gender. Future studies should include this type of couple in order to more thoroughly examine marital quality within the context of relationships involving partners at different life stages.

Overall these findings suggest a great deal of similarity between marriage types, and confirm well-established gender differences in marital quality. The overall sample means reflected high marital quality. Post-hoc analyses provide additional support for the notion that the spouse becomes increasingly more important as a potential source of social support as married partners grow older (Acitelli \& Antonucci, 1994; Fredrickson \& Carstensen, 1990). Specifically, 96\% of the sample included their spouse in their personal networks. Nearly $94 \%$ of those individuals who placed their spouse in their personal network, indicated that they were so close 
to their spouse that, "it is difficult to imagine life without them.” Women reported larger networks than did men consistent with research suggesting gender differences in the size of personal networks (Stokes \& Wilson, 1984). Differences in network size may help to account for the lack of differences between age-similar and age-discrepant couples in marital satisfaction. Specifically, age-discrepant couples reported larger networks than age-similar couples. The larger network of social support may help to buffer potential threats to marital satisfaction that these couples could face.

Follow-up analyses failed to indicate any significant differences in the total number of friends or family members reported by the participants. The lack of differences in network composition, combined with a lack of significant differences in the types of goals reported, suggests that age-similar couples and ADMs were not motivated by different emotional and informational needs. Once again, it is important to recognize that the average age of ADM husbands was 66 years which may not be adequate for capturing differences in developmental tasks.

\section{$\underline{\text { Limitations }}$}

Perhaps the similarities between age-similar and age-discrepant couples are inflated by social desirability. Specifically, all data were collected via telephone interviews. The assessment instruments included in these interviews typically have been self-administered. The sense of privacy that accompanies self-administered surveys is not preserved in the current methodology. As a result, participants may feel uncomfortable sharing the less favorable details of their marriage thereby artificially inflating satisfaction scores. The current methodology may have exacerbated this potential confound. Specifically, privacy was not required during the interview process. Also, it is important to consider that the psychometric properties of these measures 
have not been validated for use in a structured interview. In order to help preserve the psychometric properties of the DAS (Spanier, 1976) and the Couples' Questionnaire (Braiker \&Kelley, 1979), which include different response scales, participants were provided with response cards. Participants were also instructed of changes in the response scale and directed to look at the appropriate scale on their cards. Response cards were implemented to help to expedite the interview and eliminate participant confusion.

Although social desirability provides an explanation for the lack of significant group differences, it is also important to recognize that the interactions between marriage partners are not exclusively private. Couples do not interact in a vacuum; their interactions with family, friends, and the public are revealing. Therefore, the extent to which social desirability directly impacted satisfaction in this sample is uncertain. It should also be noted that participant responses may have been affected by fatigue. The average interview time was approximately 1 hr.; however, interview times ranged from approximately 35 minutes to 2 hrs. and 30 mins. To help reduce participant burden, subscales of the DAS (Spanier, 1976) and the Couples' Questionnaire (Braiker \& Kelley, 1979) were used. Although the selected subscales compliment each other, they fail to provide a comprehensive picture of marital quality and may have impacted the results of the study. Low coefficient alphas were reported for the Couples' Questionnaire and were therefore eliminated from the major analyses. This may have further constrained the findings. A potential explanation for the low reliabilities in this sample may relate to the mode of assessment. Specifically, the questionnaire was developed as a paper and pencil measure. Administering the subscales in an interview format may have altered the psychometric properties of the measure. In fact, Pruchno and Hayden (2000) provide evidence that the psychometric properties of self-administered measures are sensitive to modes of 
assessment. Those individuals who responded to self-administered measures reported significantly lower well-being than those who were interviewed over the telephone. This suggests that data collected via telephone interviews may be particularly sensitive to issues of social desirability. Another issue to consider relates to potential gender-based differences in the meaning of maintenance, ambivalence, and conflict that alters the internal consistency of the measure at the dyadic level. Future studies should recruit a larger sample to yield the power to conduct factor analyses examining structural differences in the marital experiences of men and women.

Several studies have challenged the properties of the DAS (Spanier, 1976; e.g., Kurdek, 1992; Sabourin, Lussier, Lapante, \& Wright, 1990), questioning whether it fails to examine the hierarchical structure of dyadic qualities and the utility of each of the subscales. Despite these arguments, the DAS (Spanier) is still widely used and newer measurements have been validated against its psychometric properties. Although Spanier asserts that the DAS can be adapted for interview use, there are no known studies validating the scale for administration in an interview format. Perhaps a lack of differences between groups may be partially accounted for by a measure that does not precisely capture the construct of marital satisfaction.

Recruitment procedures also may have affected the results by yielding a biased sample of happily married couples. Participants were successfully recruited using word of mouth, student referrals, and participant referrals. It is unlikely that couples who are dissatisfied with their marriages would have been referred for participation. Interactions with referrals underscore the concern that couples who are less than satisfied with their marriages would be willing to consent to participation. Using an interview format for data collection may have magnified this issue. The extra credit that students received for providing successful referrals may have further 
contributed to a selective sample; students motivated by the incentive for extra credit may have influenced potential participants to participate in the study and may have even shaped participant's responses in a favorable manner. Moreover, dissatisfied couples may be underrepresented in this sample as a consequence of the selection criteria. Those couples who are dissatisfied are unlikely to have remained married long enough (15 yrs.) to have even been eligible for participation.

Certain characteristics of this sample do not necessarily extend to all married couples. Although, participants were recruited from across the country, the majority of those interviewed were from the tri-state area. These couples were predominantly Caucasian. The sample reported an average of 3 years post-secondary education and rather high annual incomes, \$65,000$\$ 70,000$. Research has indicated that finances significantly contribute to marital quality (Orbuch et al., 1996). Therefore, these couples may not be representative of all married couples. Future investigations should include a more diverse sample.

A repeated measures longitudinal research design would provide the ideal methodology to test fluctuations in marital satisfaction over the development course of a marriage. This type of research design would allow researchers to more closely identify changes in marital satisfaction that correspond to incongruent life stages between partners who are age-discrepant. A more time efficient alternative to this research design that would allow similar comparisons would be an age-stratified sample of husband-older marriages; analyses would control for length of marriage. This would force some of the differences in developmental tasks that were anticipated during the recruitment phase of the current study. 
It is important to recognize that the results of the current study do not necessarily generalize to those ADMs involving older women and younger men. It has been speculated that these couples are unique because they violate culturally defined negative stereotypes of female aging (Winston \& Klepfer, 2000). Therefore, future studies should include a comparison group of female-older ADMs.

Another critical issue pertains to the number of statistical analyses conducted in this investigation. Specifically, the number of statistically significant findings that emerged is consistent with the number of findings that would have emerged by chance given the numerous analyses performed. In other words, the number of statistical analyses conducted inflated the likelihood of Type I error.

Future investigations would include measures of physical and psychological well-being to provide a better understanding of how gender differences in marital quality impact global well-being among middle-aged and older adults involved in long-term marriages. In order to preserve the psychometric properties of existing measures and allow for a more complete assessment of marital quality with consideration for participant fatigue, future studies might implement a self-administered survey rather than a structured interview. Given the lower response rates associated with mail-back surveys, recruitment efforts might include soliciting participants based on marriage records to ensure an adequate sample size. Recruitment efforts of this nature, combined with the anonymity of a mail-back survey, would also help to yield a less biased sample by increasing the likelihood that individuals who are less satisfied with their marriages would participate. 


\section{References}

Acitelli, L. K., \& Antonucci, T. C. (1994). Gender differences in the link between marital support and satisfaction in older couples. Journal of Personality and Social Psychology, 67, 688-698.

Acitelli, L. K. (1992). Gender differences in relationship awareness and marital satisfaction among young married couples. Personality and Social Psychology Bulletin, 18, 102-110.

Amato, P. R., Johnson, D. R., Booth, A., \& Rogers, S. J. (2003). Continuity and change in marital quality between 1980 and 2000. Journal of Marriage and the Family, 65, 1-22.

Antonucci, T. L. (2001).Social Relations: An examination of social networks, social support, and sense of control. In the Handbook of Psychology \& Aging, ch.17. (pp. 427-453).

New York, N. Y. : Academic Press.

Atchely, R. (1993). Retirement and marital satisfaction. In M. Szinovacz, D. Ekerdt, \& B. Vinick (Eds.), Families and retirement (pp. 145-158). Newbury Park, CA: Sage.

Aube, J., \& Koestner, R. (1995). Gender characteristics and relationship adjustment: Another look at the similarity-complementarity hypotheses. Journal of Personality, 63, 879-904.

Baker, R., Kiger, G., \& Riley, P. J. (1996). Time, dirt, and money: The effects of gender, gender ideology, and type of earner marriage on time, household-task, and economic satisfaction among couples with children. Journal of Social Behavior and Personality, $11,161-177$.

Bem, S. L. (1974). The measurement of psychological androgyny. Journal of Consulting and Clinical Psychology, 42, 155-162.

Berardo, F. M., Appel, J., \& Berardo, D. H. Age dissimilar marriages: Review and assessment. Journal of Aging Studies, 7, 93-106. 
Blair, S. L., \& Lichter, D. T. (1991). Measuring the division of household labor. Journal of Family Issues, 12, 91-113.

Bollman, S. R., Schumm, W. R., \& Jurich, A. P. (1997). Predicting marital satisfaction from ideal and actual maternal roles. Psychological Reports, 80, 99-106.

Bonds, J. M., \& Nicks, S. D. (1999). Sex by age differences in couples applying for marriage. Psychological Reports, 84, 42-44.

Braiker, H. B., \& Kelley, H. H. (1979). Conflict in the development of close relationships. In R. L. Burgess \& T. L. Huston (Eds.), Social exchange in developing relationships (pp. 135168). New York: Academic Press.

Brooks, G. R. (2000). The role of gender in marital dysfunction. In R. M. Eisler \& M. Hersen (Eds.), Handbook of gender, culture, and health (pp. 449-470). Mahwah, NJ: Lawrence Erlbaum Associates, Inc.

Burke, P. J., \& Cast, A. D. (1997). Stability and change in the gender identities of newly married couples. Social Psychology Quarterly, 60, 277-290.

Byrne, D., \& Murnen, S. K. (1988). Maintaining loving relationships. In R. J. Sternberg \& M. L. Barnes (Eds.), The Psychology of Love (pp. 293-310). New Haven, Conn.: Yale University Press.

Bytheway, W. R. (1981). The variation with age of age differences in marriage. Journal of Marriage and the Family, 43, 923-927.

Carstensen, L. L., Gottman, J. M., \& Levenson, R. W. (1993). Emotional behavior in long-term marriage. Psychology and Aging, 10, 140-149.

Carstensen, L. L., Isaacowitz, D. M., \& Charles, S. T. (1999). Taking time seriously: A theory of socioemotional selectivity. American Psychologist, 54, 165-181. 
Cowan, G. (1984). The double standard in age-discrepant relationships. Sex Roles, 11, 17-23.

Cramer, D. (1993). Personality, socio-economic status and age disparity in marriage. Journal of Personality and Individual Differences, 15, 725-727.

Current Population Reports: America's Families and Living Arrangements. (June, 2001). U.S. Bureau of the Census [On-line]. Available: http://www.census.gov/prod/2001pubs/p20-537.pdf

Davis, A. (1998). Age differences in dating and marriage: Reproductive strategies or social preferences? Current Anthropology, 39, 375-380.

Doudna, C., \& McBride, F. (1981). Where are the men for the women at the top? In P. J. Stein (Ed.), Single life (pp. 21-34). New York: St. Martin's.

Fowers, B. J. (1991). His and her marriages: A multivariate study of gender and marital satisfaction. Sex Roles, 24, 209-221.

Frederickson, B. L., \& Carstensen, L. L. (1990). Choosing social partners: How old age and anticipated endings make people more selective. Psychology and Aging, 5, 335-347.

Gagnon, M. D., Hersen, M., Kabacoff, R. I., \& Van Hasselt, V. B. (1999). Interpersonal and psychological correlates of marital dissatisfaction in late life: A review. Clinical Psychology Review, 19, 359-378.

Garrido, E. F., \& Acitelli, L. K. (1999). Relational identity and the division of household labor. Journal of Social and Personal Relationships, 16, 619-637.

Gilford, R. (1984). Contrasts in marital satisfaction throughout old age: An exchange theory analysis. Journal of Gerontology, 39, 325-333.

Glenn, N. D. (1998). The course of marital success and failure in five American 10-year marriage cohorts. Journal of Marriage and the Family, 60, 569-576. 
Grote, N. K., \& Clark, M. S. (2001). Perceiving unfairness in the family: Cause or consequence of marital distress? Journal of Personality and Social Psychology, 80, 281-293.

Helms-Erikson, H., Tanner, J. L., Crouter, A. C., \& McHale, S. M. (2000). Do women’s provider-role attitudes moderate the links between work and family? Journal of Family Psychology, 14, 658-670.

Hicks, M W., \& Platt, M. (1970). Marital happiness and stability: A review of the research in the sixties. Journal of Marriage and the Family, 32, 553-574.

Jacobson, N. S. (1992). Change in marital adjustment following marital therapy: A comparison of two outcome measures. Psychological Assessment, 4, 219-223.

Kiecolt-Glaser, J. K., \& Newton, T. C. (2001). Marriage \& Health: His and Hers. Psychological Bulletin, 127, 472-503.

Kim, J. E., \& Moen, P. (2002) Retirement, transitions, gender, and psychological well-being. The Journals of Gerontology: Psychological and Social Sciences, 57, P212-P222.

Klinger-Vartabedian, L., \& Wispe, L. (1989). The influence of age difference in marriage on longevity. In J. F. Nussbaum (Ed.), Life-span communication: Normative processes. (pp.301-318). Hillsdale, NJ: Lawrence Erlbaum Associates, Inc.

Kulik, L. (1999). Continuity and discontinuity in marital life after retirement: Life orientations, gender role ideology, intimacy, and satisfaction. Families in Society: The Journal of Contemporary Human Services, May-June, 286-294.

Kulik, L. (2001). Marital relationships in late adulthood: Synchronous versus asynchronous couples. International Journal of Aging and Human Development, 52, 323-339.

Kurdek, L. A. (1998). The allocation of household labor in gay, lesbian, and heterosexual 
married couples. In D.L. Anselmi \& A. L. Law (Eds.), Questions of Gender: Perspectives and Paradoxes (pp. 582-591), Boston, M. A. : McGraw Hill.

Kurdek, L. A. (1992). Dimensionality of the dyadic adjustment scale: Evidence from Heterosexual and homosexual couples. Journal of Family Psychology, 6, 22-35.

Lang, F. R., \& Carstensen, L. L. (1994). Emotional relationships in late life: Further support for proactive aging in the social domain. Psychology and Aging, 9, 315-324.

Lawton, M. P., Kleban, M. H., Dean, J., Rajagopal, D., \& Parmelee, P. A. (1992). The factorial generality of brief positive and negative affect measures. Journal of Gerontology: Psychological Sciences, 47, P228-P237.

Lawton, M. P., Moss, M., Fulcomer, M., \& Kleban, M. H. (1982). A research and serviceoriented Multilevel Assessment Instrument. Journal of Gerontology, 37, 91-99.

Levenson, R. W., Carstensen, L. L., \& Gottman, J. M. (1993). Long-term marriages: Age, gender, and satisfaction. Psychology and Aging, 8, 301-313.

Mackey, R. A., \& O'Brien, B. A. (1999). Adaptation in lasting marriages. Families in Society, 80, 587-596.

Magana, A. B., Goldstein, M. J., Karno, M., Miklowitz, D. J., Jenkins, J., \& Falloon, I. R. H. (1986). A brief method for assessing expressed emotion in families of psychiatric patients. Psychiatry Research, 17, 203-212.

Martin, M. W. (1985). Satisfaction with intimate exchange: Gender-role differences and the impact of equity, equality, and rewards. Sex Roles, 13, 597-605.

Merriam, S. B., \& Hyer, P. (1984). Changing attitudes of women towards family-related tasks in young adulthood. Sex Roles, 10, 825-835. 
Mroczek, D. K., \& Kolarz, C. M. (1998). The effect of age on positive and negative affect: A developmental perspective on happiness. Journal of Personality and Social Psychology, 15, 1333-1349.

National Vital Statistics Reports: Births, Marriages, Divorces, and Deaths: Provisional Data for September 2001. (May, 2002). National Center for Health Statistics [On-line]. Available: http://www.cdc.gov/nchs

Norris, M. P., Snyder, D. E., \& Rice, J. L. (1997). Marital satisfaction in older adults: A comparison of community and clinic couples. Journal of Clinical Geropsychology, 3, 111-122.

Orbuch, T. L., House, J. S., \& Webster, P. S. (1996). Marital Quality over the life course. Social Psychology Quarterly, 59, 162-171.

Patrick, J. H., Epperly-Cottrell, L., \& Barnes, K. A. (2001). Gender, emotional support, and wellbeing among the rural elderly. Sex Roles, 45, 15-29.

Pina, D.L., \& Bengston, D. L. (1995). Division of household labor and the well-being of retirement-aged wives. The Gerontologist, 35, 308-317.

Pineo, P. C. (1961). Disengagement in the later years of marriage. Marriage and Family Living, 23, 3-11.

Pruchno, R. A., \& Hayden, J. M. (2000). Interview modality: Effects on costs and data quality in a sample of older women. Journal of Aging \& Health, 12, 22-24.

Rhyne, D. (1981). Bases of marital satisfaction among men and women. Journal of Marriage and the Family, 43, 941-955. 
Rogers, S. J., \& Amato, P. R. (2000). Have changes in gender relations affected marital quality? Social Forces, 79, 731-753.

Sabourin, S., Lussier, Y., Lapante, B., \& Wright, J. (1990). Unidimensional and multidimensional models of dyadic adjustment. Psychological Assessment, 2, 333-337.

Shehan, C. L., Berardo, F. M., Vera, H., \& Carley, S. M. (1991). Women in age-discrepant marriages. Journal of Family Issues, 12, 291-305.

Snell, J. G. (1993). The gendered construction of elderly marriage, 1900-1950. Canadian Journal on Aging 12, 509-523.

Snyder, D. K., Velasquez, J. M., Clark, B. L., \& Means-Christensen, A. J. (1997). Parental influence on gender and marital role attitudes: Implications for intervention. Journal of Marriage and the Family, 23, 191-201.

Spanier, G. B. (1976). Measuring dyadic adjustment: New scales for assessing the quality of marriage and similar dyads. Journal of Marriage and the Family, 38, 15-28.

Stokes, J. P., \& Wilson, D.G. (1984). The Inventory of Socially Supportive Behaviors: Dimensionality, prediction, and gender differences. American Journal of Community Psychology, 12,_53-69.

Strough, J., Patrick, J. H., Swenson, L. M., Cheng, S., \& Barnes, K. A. (2003). Collaborative everyday problem solving: Interpersonal relationships and problem dimensions. The International Journal of Aging and Human Development, 56, 43-66.

Szinovacz, M. (1996). Couples' employment/retirement patterns and perceptions of marital quality. Research On Aging, 18, 243-268.

Thompson, L., \& Walker, A. J. (1989). Gender in families: Women and men in marriage, work, and parenthood. Journal of Marriage and the Family, 51, 845-871. 
Ward, R. A. (1993). Marital happiness and household equity in later life. Journal of Marriage \& Family, 55, 427-438.

Ware, J. F., Sherbourne, L. D., \& Daviees, A. R. (1992). Developing and testing the MOS 20item short-form health survey: A general population application. In A. L. Stewart \& J. F. Ware (Eds.) Measuring functioning and well-being: The Medical Outcomes Study Approach (pp. 277-290), Durham, N. C. : Duke University Press.

Winston, N. A., \& Klepfer, G. J. Patterns of mate selection among the elderly: Do the homogamous norms apply? (Fall, 2000). Perspectives: Electronic Journal of the American Association of Behavioral and Social Sciences [On-line]. Available: http://www.aabss.org/journal2000/f26winston.jmm.html

Wright, D. L., \& Aquilino, W. S. (1998). Influence of emotional support exchange in marriage on caregiving wives' burden and marital satisfaction. Family Relations, 47, 195-204. 


\section{Interview Dialogue}

\section{RID}

1. A. Have you received the informed consent form?

a Yes

a No

B. Do you have any questions?

a Yes

a No

C. So, you do agree to participate in this study?

a Yes

№

D. Great, so I hope to receive your signed consent form in the mail within the next couple of days.

\section{Demographics Questionnaire}

1. What is your date of birth? (Month/Day/Year)

2. When did you marry your spouse (Mo/Day/Yr.)

3. Please indicate whether this is your first, second, third, other (please specify)

4. What is your religion, are you:
A.Protestant,
B. Catholic,
C. Jewish,
D. Other, Specify:
E. None? , or

5. In what state is your current residence?

6. How long have you lived in this state? (Years) 
7. How long have you lived in your current home? (Years)

\begin{tabular}{|l|l|l|l|}
\hline & 8. A.) Person & 8. B.) Age & 8. C.) Relation \\
\hline $\begin{array}{l}\text { 8. a) Are there any } \\
\text { individuals who live with } \\
\text { you and your spouse }\end{array}$ & & & \\
\hline 8. b) What is their age? & & & \\
\hline 8. c) What is their relation? & & & \\
\hline & & & \\
\hline & & & \\
\hline & & & \\
\hline
\end{tabular}

9. To which racial group do you belong:
A. African American/Black (1),
B. Caucasian/White (2), or
C. Other (3)?
(Please specify)

10. Are you:
A. Male, or (1)
B. Female? (2)

11. What kind of work have you done most of your life?

12. For what kind of business, company, or agency is that?

13. What is your current work status? Are you:
A. Employed full time (1)
B. Employed part-time (2)
C. Retired (3)
D. Unemployed (4)
E. Homemaker (5)
F. Other (6)
(Please specify)

14. What is the highest grade or level of education that you've completed?

15. How much difficulty do you have paying your bills? Would you say:
A. A great deal of difficulty (1)
B. Some difficulty (2)
C. A little difficulty (3), or
D. No difficulty (4)? 
16. Compared with other people your age, are your finances:
A. Better (1)
B. About the same (2), or
C. Not as good (3)?

17. Please indicate which category best describes your total income last year that you ( \& household members) received from all sources. Be sure to include Social Security, pensions, bank interest, reparations, annuities, and so forth:

\begin{tabular}{|ll|l|}
\hline A. & Under $\$ 10,000$ & I. $\$ 45,000-\$ 49,999$ \\
\hline B. $\quad \$ 10,000-\$ 14,999$ & J. $\$ 50,000-\$ 54,999$ \\
\hline C. $\quad \$ 15,000-\$ 19,999$ & K. \$55,000-\$59,999 \\
\hline D. $\quad \$ 20,000-\$ 24,999$ & L. \$60,000-\$64,999 \\
\hline E. & $\$ 25,000-\$ 29,999$ & M. \$65,000-\$69,999 \\
\hline F. & $\$ 30,000-\$ 34,999$ & N. \$70,000-\$74,999 \\
\hline G. & $\$ 35,000-\$ 39,999$ & O. \$75,000 and over \\
\hline H. & $\$ 40,000-\$ 44,999$ & P. I do not know/ do not \\
& & \\
\hline
\end{tabular}


The Philadelphia Geriatric Center (PGC; Lawton et al., 1992)

Positive and Negative Affect Scales

18.) Please indicate how often (Never, Rarely, Sometimes, Frequently, Very Frequently) you have felt the following emotions during the past week:

\begin{tabular}{|l|c|c|c|c|c|}
\hline & Never & Rarely & Sometimes & Frequently & Very Frequently \\
\hline A.) Happy & 1 & 2 & 3 & 4 & 5 \\
\hline B.) Interested & 1 & 2 & 3 & 4 & 5 \\
\hline C.) Energetic & 1 & 2 & 3 & 4 & 5 \\
\hline D.) Content & 1 & 2 & 3 & 4 & 5 \\
\hline E.) Warm-hearted & 1 & 2 & 3 & 4 & 5 \\
\hline F.) Sad & 1 & 2 & 3 & 4 & 5 \\
\hline G.) Annoyed & 1 & 2 & 3 & 4 & 5 \\
\hline H.) Worried & 1 & 2 & 3 & 4 & 5 \\
\hline I.) Irritated & 1 & 2 & 3 & 4 & 4 \\
\hline J.) Depressed & 1 & 2 & & 4 & 5 \\
\hline
\end{tabular}


Respondent's Functional Ability (Ware et al., 1992)

19.) How much difficulty do you have doing each of the following:

\begin{tabular}{|c|c|c|c|c|}
\hline & $\begin{array}{l}\underline{\text { No }} \\
\text { Difficulty }\end{array}$ & $\begin{array}{l}\text { Some } \\
\text { Difficulty }\end{array}$ & $\begin{array}{l}\text { Much } \\
\text { Difficulty }\end{array}$ & Unable \\
\hline $\begin{array}{l}\text { a. Walking for a quarter of a mile (which is } \\
\text { about } 2 \text { to } 3 \text { city blocks) without resting? }\end{array}$ & 0 & 1 & 2 & 3 \\
\hline $\begin{array}{l}\text { b. Walking up and down one flight of stairs } \\
\text { without resting? }\end{array}$ & 0 & 1 & 2 & 3 \\
\hline $\begin{array}{l}\text { c. Standing up for long periods (about } 2 \\
\text { hours)? }\end{array}$ & 0 & 1 & 2 & 3 \\
\hline d. Sitting for long periods (about 2 hours)? & 0 & 1 & 2 & 3 \\
\hline e. Stooping, crouching, or kneeling? & 0 & 1 & 2 & 3 \\
\hline $\begin{array}{l}\text { f. Reaching up (as if to get something from a } \\
\text { shelf)? }\end{array}$ & 0 & 1 & 2 & 3 \\
\hline $\begin{array}{l}\text { g. Reaching out (as if to shake someone's } \\
\text { hand)? }\end{array}$ & 0 & 1 & 2 & 3 \\
\hline h. Using fingers to grasp or handle? & 0 & 1 & 2 & 3 \\
\hline $\begin{array}{l}\text { i. Lifting or carrying something as heavy as } \\
25 \text { pounds (such as two full grocery bags)? }\end{array}$ & 0 & 1 & 2 & 3 \\
\hline $\begin{array}{l}\text { j. Lifting or carrying something as heavy as } \\
10 \text { pounds (such as a } 10 \text { pound sack of } \\
\text { potatoes)? }\end{array}$ & 0 & 1 & 2 & 3 \\
\hline
\end{tabular}




\section{Goals}

20.) Please indicate four goals that you would like to accomplish as an individual during the next five years.
A.)
B.)
C.)
D.)

21.) Please indicate four goals that you would like to accomplish as a couple during the next five years.
A.)
B.)
C.)
D.) 
Couple’s Questionnaire (Braiker \& Kelley, 1979)

This set of questions is about your experiences in your marriage during the past year. For these questions, please indicate the number (1-9) that best applies to your relationship.

\begin{tabular}{|c|c|c|c|c|c|c|c|c|c|}
\hline & $\begin{array}{c}\text { Not at } \\
\text { all } \\
1\end{array}$ & 2 & 3 & 4 & 5 & 6 & 7 & 8 & $\begin{array}{c}\text { Very } \\
\text { Much } \\
9 \\
\end{array}$ \\
\hline $\begin{array}{l}\text { 22.) To what extent do you reveal or disclose very } \\
\text { intimate things about yourself or personal feelings } \\
\text { to your spouse? }\end{array}$ & 1 & 2 & 3 & 4 & 5 & 6 & 7 & 8 & 9 \\
\hline $\begin{array}{l}\text { 23.) To what extent do you try to change things } \\
\text { about your spouse that bother you (e.g., behaviors, } \\
\text { attitudes, etc.)? }\end{array}$ & 1 & 2 & 3 & 4 & 5 & 6 & 7 & 8 & 9 \\
\hline $\begin{array}{l}\text { 24.) How confused are you about your feelings } \\
\text { toward your spouse? }\end{array}$ & 1 & 2 & 3 & 4 & 5 & 6 & 7 & 8 & 9 \\
\hline $\begin{array}{l}\text { 25.) How much do you think or worry about losing } \\
\text { some of your independence by being involved with } \\
\text { your spouse? }\end{array}$ & 1 & 2 & 3 & 4 & 5 & 6 & 7 & 8 & 9 \\
\hline $\begin{array}{l}\text { 26.) To what extent do you try to change your } \\
\text { behavior to help solve certain problems between } \\
\text { you and your spouse? }\end{array}$ & 1 & 2 & 3 & 4 & 5 & 6 & 7 & 8 & 9 \\
\hline $\begin{array}{l}\text { 27.) How ambivalent or unsure are you about } \\
\text { continuing in the relationship with your spouse? }\end{array}$ & 1 & 2 & 3 & 4 & 5 & 6 & 7 & 8 & 9 \\
\hline $\begin{array}{l}\text { 28.) To what extent do you feel that your spouse } \\
\text { demands or requires too much of your time and } \\
\text { attention? }\end{array}$ & 1 & 2 & 3 & 4 & 5 & 6 & 7 & 8 & 9 \\
\hline $\begin{array}{l}\text { 29.) To what extent do you feel "trapped" or } \\
\text { pressured to continue in the relationship? }\end{array}$ & 1 & 2 & 3 & 4 & 5 & 6 & 7 & 8 & 9 \\
\hline $\begin{array}{l}\text { 30.) How much do you tell your spouse what you } \\
\text { want or need from the relationship? }\end{array}$ & 1 & 2 & 3 & 4 & 5 & 6 & 7 & 8 & 9 \\
\hline $\begin{array}{l}\text { 31.) To what extent do you communicate negative } \\
\text { feelings toward your spouse (e.g., anger, } \\
\text { dissatisfaction, frustration, etc...)? }\end{array}$ & 1 & 2 & 3 & 4 & 5 & 6 & 7 & 8 & 9 \\
\hline
\end{tabular}


NOTE: RESPONSE SCALE CHANGES

\begin{tabular}{|c|c|c|c|c|c|c|c|c|c|}
\hline & $\begin{array}{l}\text { Never } \\
1\end{array}$ & 2 & 3 & 4 & 5 & 6 & 7 & 8 & $\begin{array}{l}\text { Very } \\
\text { Often } \\
9\end{array}$ \\
\hline $\begin{array}{l}\text { 32.) How much time do you and your spouse spend } \\
\text { discussing and trying to work out problems between } \\
\text { you? }\end{array}$ & 1 & 2 & 3 & 4 & 5 & 6 & 7 & 8 & 9 \\
\hline $\begin{array}{l}\text { 34.) How often do you feel angry or resentful toward } \\
\text { your spouse? }\end{array}$ & 1 & 2 & 3 & 4 & 5 & 6 & 7 & 8 & 9 \\
\hline
\end{tabular}

NOTE: RESPONSE SCALE CHANGES

\begin{tabular}{|c|c|c|c|c|c|c|c|c|c|}
\hline & \multicolumn{2}{|c|}{$\begin{array}{l}\text { Very } \\
\text { Infrequently }\end{array}$} & & & & & & \multicolumn{2}{|c|}{$\begin{array}{r}\text { Very } \\
\text { Frequently } \\
\end{array}$} \\
\hline $\begin{array}{l}\text { 35.) How often do you and your spouse argue with } \\
\text { each other? }\end{array}$ & 1 & 2 & 3 & 4 & 5 & 6 & 7 & 8 & 9 \\
\hline
\end{tabular}

NOTE: RESPONSE SCALE CHANGES

\begin{tabular}{|c|c|c|c|c|c|c|c|c|c|}
\hline & \multicolumn{2}{|c|}{$\begin{array}{l}\text { Not Serious } \\
\text { at all }\end{array}$} & \multirow[b]{2}{*}{3} & \multirow[b]{2}{*}{4} & \multirow[b]{2}{*}{5} & \multirow[b]{2}{*}{6} & \multirow[b]{2}{*}{7} & \multicolumn{2}{|c|}{ Very Serious } \\
\hline $\begin{array}{l}\text { 36.) When you and your spouse argue, how serious are } \\
\text { the problems or arguments? }\end{array}$ & 1 & 2 & & & & & & 8 & 9 \\
\hline
\end{tabular}


Division of Household Tasks (Based on Kulik, 2001; Lawton et al., 1982)

Please indicate who is responsible for each of the following tasks in your household (i.e., "Me, Him/Her, Both"). Then indicate how often you help or receive help from your spouse on each of the tasks: Never, Rarely, Sometimes, Frequently, or Very Frequently. You will also be asked how satisfied you are with the division of each task.

\begin{tabular}{|l|c|c|c|}
\hline & Me & Other & Both \\
\hline $\begin{array}{l}\text { 37.) } \\
\text { a. Housework }\end{array}$ & 1 & 2 & 3 \\
\hline
\end{tabular}

\begin{tabular}{|l|c|c|c|c|c|}
\hline & Never & Rarely & Sometimes & Frequently & Very Frequently \\
\hline $\begin{array}{l}\text { 37.) } \\
\begin{array}{l}\text { b. How often do you } \\
\text { help/receive help from } \\
\text { your spouse? }\end{array}\end{array}$ & 1 & 2 & 3 & 4 & 5 \\
\hline
\end{tabular}

\begin{tabular}{|l|c|c|c|}
\hline & Less & The Same & More \\
\hline $\begin{array}{l}\text { 37.) } \\
\text { c. Would you like to give/receive: }\end{array}$ & 0 & 1 & 2 \\
\hline
\end{tabular}

\begin{tabular}{|l|c|c|c|}
\hline & Me & Other & Both \\
\hline $\begin{array}{l}\text { 38.) } \\
\text { a. Laundry }\end{array}$ & 1 & 2 & 3 \\
\hline
\end{tabular}

\begin{tabular}{|l|c|c|c|c|c|}
\hline & Never & Rarely & Sometimes & Frequently & Very Frequently \\
\hline $\begin{array}{l}\text { 38.) } \\
\begin{array}{l}\text { b. How often do you } \\
\text { help/receive help from } \\
\text { your spouse? }\end{array}\end{array}$ & 1 & 2 & 3 & 4 & 5 \\
\hline
\end{tabular}

\begin{tabular}{|l|c|c|c|}
\hline & Less & The Same & More \\
\hline $\begin{array}{l}\text { 38.) } \\
\text { c. Would you like to give/receive: }\end{array}$ & 0 & 1 & 2 \\
\hline
\end{tabular}

\begin{tabular}{|l|c|c|c|}
\hline & Me & Other & Both \\
\hline $\begin{array}{l}\text { 39.) } \\
\text { a. Meal Preparation }\end{array}$ & 1 & 2 & 3 \\
\hline
\end{tabular}




\begin{tabular}{|l|c|c|c|c|c|}
\hline & Never & Rarely & Sometimes & Frequently & Very Frequently \\
\hline $\begin{array}{l}\text { 39.) } \\
\text { b. How often do you } \\
\text { help/receive help from } \\
\text { your spouse? }\end{array}$ & 1 & 2 & 3 & 4 & 5 \\
\hline
\end{tabular}

\begin{tabular}{|l|c|c|c|}
\hline & Less & The Same & More \\
\hline $\begin{array}{l}\text { 39.) } \\
\text { c. Would you like to give/receive: }\end{array}$ & 0 & 1 & 2 \\
\hline
\end{tabular}

\begin{tabular}{|l|c|c|c|}
\hline & Me & Other & Both \\
\hline 40.) & 1 & 2 & 3 \\
\hline a. Grocery shopping & 1 & 2 & \\
\hline
\end{tabular}

\begin{tabular}{|l|c|c|c|c|c|}
\hline & Never & Rarely & Sometimes & Frequently & Very Frequently \\
\hline $\begin{array}{l}\text { 40.) } \\
\text { b. How often do you } \\
\text { help/receive help from } \\
\text { your spouse? }\end{array}$ & 1 & 2 & 3 & 4 & 5 \\
\hline
\end{tabular}

\begin{tabular}{|l|c|c|c|}
\hline & Less & The Same & More \\
\hline $\begin{array}{l}\text { 40.) } \\
\text { c. Would you like to give/receive: }\end{array}$ & 0 & 1 & 2 \\
\hline
\end{tabular}

\begin{tabular}{|l|c|c|c|}
\hline & Me & Other & Both \\
\hline $\begin{array}{l}\text { 41.) } \\
\text { a. Paying bills }\end{array}$ & 1 & 2 & 3 \\
\hline
\end{tabular}

\begin{tabular}{|l|c|c|c|c|c|}
\hline & Never & Rarely & Sometimes & Frequently & Very Frequently \\
\hline $\begin{array}{l}\text { 41.) } \\
\text { b. How often do you } \\
\text { help/receive help from } \\
\text { your spouse? }\end{array}$ & 1 & 2 & 3 & 4 & 5 \\
\hline
\end{tabular}

\begin{tabular}{|l|c|c|c|}
\hline & Less & The Same & More \\
\hline $\begin{array}{l}\text { 41.) } \\
\text { c. Would you like to give/receive: }\end{array}$ & 0 & 1 & 2 \\
\hline
\end{tabular}




\begin{tabular}{|l|c|c|c|}
\hline & Me & Other & Both \\
\hline $\begin{array}{l}\text { 42.) } \\
\text { a. Telephone solicitors }\end{array}$ & 1 & 2 & 3 \\
\hline
\end{tabular}

\begin{tabular}{|l|c|c|c|c|c|}
\hline & Never & Rarely & Sometimes & Frequently & Very Frequently \\
\hline $\begin{array}{l}\text { 42.) } \\
\begin{array}{l}\text { b. How often do you } \\
\text { help/receive help from } \\
\text { your spouse? }\end{array}\end{array}$ & 1 & 2 & 3 & 4 & 5 \\
\hline
\end{tabular}

\begin{tabular}{|l|c|c|c|}
\hline & Less & The Same & More \\
\hline $\begin{array}{l}\text { 42.) } \\
\text { c. Would you like to give/receive: }\end{array}$ & 0 & 1 & 2 \\
\hline
\end{tabular}

\begin{tabular}{|c|c|c|c|c|c|c|}
\hline & Never & Rarely & Sometimes & Frequently & Very Frequently & N/A \\
\hline $\begin{array}{l}\text { 43.) } \\
\text { b. How often do you help } \\
\text { your spouse with } \\
\text { medications? }\end{array}$ & 1 & 2 & 3 & 4 & 5 & 6 \\
\hline
\end{tabular}

\begin{tabular}{|l|c|c|c|}
\hline & Less & The Same & More \\
\hline $\begin{array}{l}\text { 43.) } \\
\text { c. Would you like to give/receive: }\end{array}$ & 0 & 1 & 2 \\
\hline
\end{tabular}

\begin{tabular}{|l|c|c|c|c|c|c|}
\hline & Never & Rarely & Sometimes & Frequently & Very Frequently & N/A \\
\hline $\begin{array}{l}\text { 44.) } \\
\begin{array}{l}\text { b. How often do you } \\
\text { receive help from your } \\
\text { spouse with medications? }\end{array}\end{array}$ & 1 & 2 & 3 & 4 & 5 & 6 \\
\hline
\end{tabular}

\begin{tabular}{|l|c|c|c|}
\hline & Less & The Same & More \\
\hline $\begin{array}{l}\text { 44.) } \\
\text { c. Would you like to give/receive: }\end{array}$ & 0 & 1 & 2 \\
\hline
\end{tabular}




\begin{tabular}{|l|c|c|c|}
\hline & $M e$ & Other & Both \\
\hline $\begin{array}{l}\text { 45.) } \\
\text { a. Travel }\end{array}$ & 1 & 2 & 3 \\
\hline
\end{tabular}

\begin{tabular}{|l|c|c|c|c|c|}
\hline & Never & Rarely & Sometimes & Frequently & Very Frequently \\
\hline $\begin{array}{l}\text { 45.) } \\
\begin{array}{l}\text { b. How often do you } \\
\text { help/receive help from } \\
\text { your spouse? }\end{array}\end{array}$ & 1 & 2 & 3 & 4 & 5 \\
\hline
\end{tabular}

\begin{tabular}{|l|c|c|c|}
\hline & Less & The Same & More \\
\hline $\begin{array}{l}\text { 45.) } \\
\text { c. Would you like to give/receive: }\end{array}$ & 0 & 1 & 2 \\
\hline
\end{tabular}

\begin{tabular}{|l|c|c|c|}
\hline & $M e$ & Other & Both \\
\hline $\begin{array}{l}\text { 46.) } \\
\text { a. Daily transportation }\end{array}$ & 1 & 2 & 3 \\
\hline
\end{tabular}

\begin{tabular}{|l|c|c|c|c|c|}
\hline & Never & Rarely & Sometimes & Frequently & Very Frequently \\
\hline $\begin{array}{l}\text { 46.) } \\
\begin{array}{l}\text { b. How often do you } \\
\text { help/receive help from } \\
\text { your spouse? }\end{array}\end{array}$ & 1 & 2 & 3 & 4 & 5 \\
\hline
\end{tabular}

\begin{tabular}{|l|c|c|c|}
\hline & Less & The Same & More \\
\hline $\begin{array}{l}\text { 46.) } \\
\text { c. Would you like to give/receive: }\end{array}$ & 0 & 1 & 2 \\
\hline
\end{tabular}

\begin{tabular}{|l|c|c|c|}
\hline & Me & Other & Both \\
\hline $\begin{array}{l}\text { 47.) } \\
\text { a. Yardwork }\end{array}$ & 1 & 2 & 3 \\
\hline
\end{tabular}

\begin{tabular}{|l|c|c|c|c|c|}
\hline & Never & Rarely & Sometimes & Frequently & Very Frequently \\
\hline $\begin{array}{l}\text { 47.) } \\
\begin{array}{l}\text { b. How often do you } \\
\text { help/receive help from } \\
\text { your spouse? }\end{array}\end{array}$ & 1 & 2 & 3 & 4 & 5 \\
\hline
\end{tabular}




\begin{tabular}{|l|c|c|c|}
\hline & Less & The Same & More \\
\hline $\begin{array}{l}\text { 47.) } \\
\text { c. Would you like to give/receive: }\end{array}$ & 0 & 1 & 2 \\
\hline
\end{tabular}

\begin{tabular}{|l|c|c|c|}
\hline & Me & Other & Both \\
\hline $\begin{array}{l}\text { 48.) } \\
\text { a. Household repairs and } \\
\text { maintenance }\end{array}$ & 1 & 2 & 3 \\
\hline
\end{tabular}

\begin{tabular}{|l|c|c|c|c|c|}
\hline & Never & Rarely & Sometimes & Frequently & Very Frequently \\
\hline $\begin{array}{l}\text { 48.) } \\
\text { b. How often do you } \\
\text { help/receive help from } \\
\text { your spouse? }\end{array}$ & 1 & 2 & 3 & 4 & 5 \\
\hline
\end{tabular}

\begin{tabular}{|l|c|c|c|}
\hline & Less & The Same & More \\
\hline $\begin{array}{l}\text { 48.) } \\
\text { c. Would you like to give/receive: }\end{array}$ & 0 & 1 & 2 \\
\hline
\end{tabular}

\begin{tabular}{|l|c|c|c|c|}
\hline & $M e$ & Other & Both & N/A \\
\hline $\begin{array}{l}\text { 49.) } \\
\text { a. Financial assistance for children }\end{array}$ & 1 & 2 & 3 & 4 \\
\hline
\end{tabular}

\begin{tabular}{|l|c|c|c|c|c|}
\hline & Never & Rarely & Sometimes & Frequently & Very Frequently \\
\hline $\begin{array}{l}\text { 49.) } \\
\text { b. How often do you } \\
\text { help/receive help from } \\
\text { your spouse? }\end{array}$ & 1 & 2 & 3 & 4 & 5 \\
\hline
\end{tabular}

\begin{tabular}{|l|c|c|c|}
\hline & Less & The Same & More \\
\hline $\begin{array}{l}\text { 49.) } \\
\text { c. Would you like to give/receive: }\end{array}$ & 0 & 1 & 2 \\
\hline
\end{tabular}

\begin{tabular}{|l|c|c|c|c|}
\hline & $M e$ & Other & Both & N/A \\
\hline $\begin{array}{l}\text { 50.) } \\
\text { a. Gifts for children and grandchildren }\end{array}$ & 1 & 2 & 3 & 4 \\
\hline
\end{tabular}


Marital Satisfaction 108

\begin{tabular}{|l|c|c|c|c|c|}
\hline & Never & Rarely & Sometimes & Frequently & Very Frequently \\
\hline $\begin{array}{l}\text { 50.) } \\
\begin{array}{l}\text { b. How often do you } \\
\text { help/receive help from } \\
\text { your spouse? }\end{array}\end{array}$ & 1 & 2 & 3 & 4 & 5 \\
\hline
\end{tabular}

\begin{tabular}{|l|c|c|c|}
\hline & Less & The Same & More \\
\hline $\begin{array}{l}\text { 50.) } \\
\text { c. Would you like to give/receive: }\end{array}$ & 0 & 1 & 2 \\
\hline
\end{tabular}

\begin{tabular}{|l|c|c|c|c|}
\hline & Me & Other & Both & N/A \\
\hline $\begin{array}{l}\text { 51.) } \\
\text { a. Non-financial assistance for children }\end{array}$ & 1 & 2 & 3 & 4 \\
\hline
\end{tabular}

\begin{tabular}{|l|c|c|c|c|c|}
\hline & Never & Rarely & Sometimes & Frequently & Very Frequently \\
\hline $\begin{array}{l}\text { 51.) } \\
\begin{array}{l}\text { b. How often do you } \\
\text { help/receive help from } \\
\text { your spouse? }\end{array}\end{array}$ & 1 & 2 & 3 & 4 & 5 \\
\hline
\end{tabular}

\begin{tabular}{|l|c|c|c|}
\hline & Less & The Same & More \\
\hline $\begin{array}{l}\text { 51.) } \\
\text { c. Would you like to give/receive: }\end{array}$ & 0 & 1 & 2 \\
\hline
\end{tabular}

\begin{tabular}{|l|c|c|c|}
\hline & Me & Other & Both \\
\hline $\begin{array}{l}\text { 52.) } \\
\text { a. Entertainment }\end{array}$ & 1 & 2 & 3 \\
\hline
\end{tabular}

\begin{tabular}{|l|c|c|c|c|c|}
\hline & Never & Rarely & Sometimes & Frequently & Very Frequently \\
\hline $\begin{array}{l}\text { 52.) } \\
\begin{array}{l}\text { b. How often do you } \\
\text { help/receive help from } \\
\text { your spouse? }\end{array}\end{array}$ & 1 & 2 & 3 & 4 & 5 \\
\hline
\end{tabular}

\begin{tabular}{|l|c|c|c|}
\hline & Less & The Same & More \\
\hline $\begin{array}{l}\text { 52.) } \\
\text { c. Would you like to give/receive: }\end{array}$ & 0 & 1 & 2 \\
\hline
\end{tabular}




\begin{tabular}{|l|c|c|c|}
\hline & Me & Other & Both \\
\hline $\begin{array}{l}\text { 53.) } \\
\text { a. Inviting friends and guests }\end{array}$ & 1 & 2 & 3 \\
\hline
\end{tabular}

\begin{tabular}{|l|c|c|c|c|c|}
\hline & Never & Rarely & Sometimes & Frequently & Very Frequently \\
\hline $\begin{array}{l}\text { 53.) } \\
\text { b. How often do you } \\
\text { help/receive help from } \\
\text { your spouse? }\end{array}$ & 1 & 2 & 3 & 4 & 5 \\
\hline
\end{tabular}

\begin{tabular}{|l|c|c|c|}
\hline & Less & The Same & More \\
\hline $\begin{array}{l}\text { 53.) } \\
\text { c. Would you like to give/receive: }\end{array}$ & 0 & 1 & 2 \\
\hline
\end{tabular}

\begin{tabular}{|l|c|c|c|}
\hline & $M e$ & Other & Both \\
\hline $\begin{array}{l}\text { 54.) } \\
\text { a. Matters of the estate (for e.g., writing a will) }\end{array}$ & 1 & 2 & 3 \\
\hline
\end{tabular}

\begin{tabular}{|l|c|c|c|c|c|}
\hline & Never & Rarely & Sometimes & Frequently & Very Frequently \\
\hline $\begin{array}{l}\text { 54.) } \\
\begin{array}{l}\text { b. How often do you } \\
\text { help/receive help from } \\
\text { your spouse? }\end{array}\end{array}$ & 1 & 2 & 3 & 4 & 5 \\
\hline
\end{tabular}

\begin{tabular}{|l|c|c|c|}
\hline & Less & The Same & More \\
\hline $\begin{array}{l}\text { 54.) } \\
\text { c. Would you like to give/receive: }\end{array}$ & 0 & 1 & 2 \\
\hline
\end{tabular}

\begin{tabular}{|l|c|c|c|}
\hline & Me & Other & Both \\
\hline $\begin{array}{l}\text { 55.) } \\
\text { a. Requests for outside assistance }\end{array}$ & 1 & 2 & 3 \\
\hline
\end{tabular}

\begin{tabular}{|l|c|c|c|c|c|}
\hline & Never & Rarely & Sometimes & Frequently & Very Frequently \\
\hline $\begin{array}{l}\text { 55.) } \\
\text { b. How often do you } \\
\text { help/receive help from } \\
\text { your spouse? }\end{array}$ & 1 & 2 & 3 & 4 & 5 \\
\hline
\end{tabular}


Marital Satisfaction 110

\begin{tabular}{|l|c|c|c|}
\hline & Less & The Same & More \\
\hline $\begin{array}{l}\text { 55.) } \\
\text { c. Would you like to give/receive: }\end{array}$ & 0 & 1 & 2 \\
\hline
\end{tabular}


56.) FMSS Instructions (As indicated by Magana et al., 1986)

Read:

We've been talking a lot/a little about [SPOUSE], now...

"I'd like to hear your thoughts about him/her, in your own words, and without my interrupting you with questions or comments. When I ask you to begin, I'd like you to speak for 5 minutes, telling me what kind of person [SPOUSE] is, and how you get along together. After you've begun to speak, I'd prefer not to answer any questions until the 5 minutes are over. Do you have any questions you'd like to ask before we begin? $\mathrm{OK}$, please begin" (Start timing).

Standard reply to questions at this point:

"Anything you think would be important for me to understand [SPOUSE], and how you get along together."

Respondent stops talking; After 30 seconds, prompt with:

"Please tell me anything about [SPOUSE] for a few more minutes. Just tell me anything at all; you have a few minutes remaining." 


\section{Instructions Corresponding to Circle Diagram Social Networks}

(Refer to Antonucci, 2001)

\section{(Interviewer reads instructions to respondent. Respondent has a copy of the circle diagram).}

"I will be asking you some questions about all the people who are important in your life right now. I will ask you to think about the ways they make your life easier, as well as how they may make your life harder. To get it straight, I'm going to ask you to look at the circle diagram. It is the piece of paper labeled "Personal Network". This is you in the middle.

The first circle would include only the one person or persons that you feel so close to that it's hard to imagine life without them. People you don't feel quite that close to, but who are still important to you, would go in the second circle. People whom you feel less close, but who are still important to you, would go in the third circle. Circles can be empty, full, or anywhere in between.

Now, I'd like you to think about the people in your life and, as you do, please focus on people who are important to you--not just people you happen to know or who may be related to you."

57. A. Beginning with people you feel closest to, is there any one person to whom you feel so close that it's hard to imagine life without them? \{If no, skip to 58\}

B. First name and last initial?

C. Relationship to you?

D. Age?

E. Do they live in your home?

F. Is there anyone else feel so close to that it's hard to imagine life without them? (if yes, return to top; if NO, skip to next circle)

\{Enter first name and last initial at the 12 o'clock position in the circle closest to "You" (i.e., respondent's) circle in the diagram. Label each person the respondent identifies using sequential numbers.\}

58. A. Is there anyone to whom you may not feel quite that close, but who is still very important to you?

\{If no, skip to question 59\}

B. First name and last initial?

C. Relationship to you?

D. Age?

E. Do they live in your home?

F. Is there anyone else you feel that close to? (if yes, continue; if NO, go to next circle) 
\{Enter first name and last initial at the 12 o'clock position in the circle second closest to the "You" (i.e., respondent's circle in the diagram. Label each person the respondent identifies using sequential numbers.)\}

59. A. Is there anyone (whom you haven't already mentioned) who is close enough and important enough in your life that he or she should (also) be placed in your network? \{If no, go to question 60$\}$

B. First name and last initial?

C. Relationship to you?

D. Age?

E. Do they live in your home?

F. Is there anyone else you feel that close to? (If yes, continue; if no, go to 63) 


\section{ondent ID}

\section{PERSONAL NETWORK ·}

For each person, ask: name, relationship, gender, age, and in tousehold?

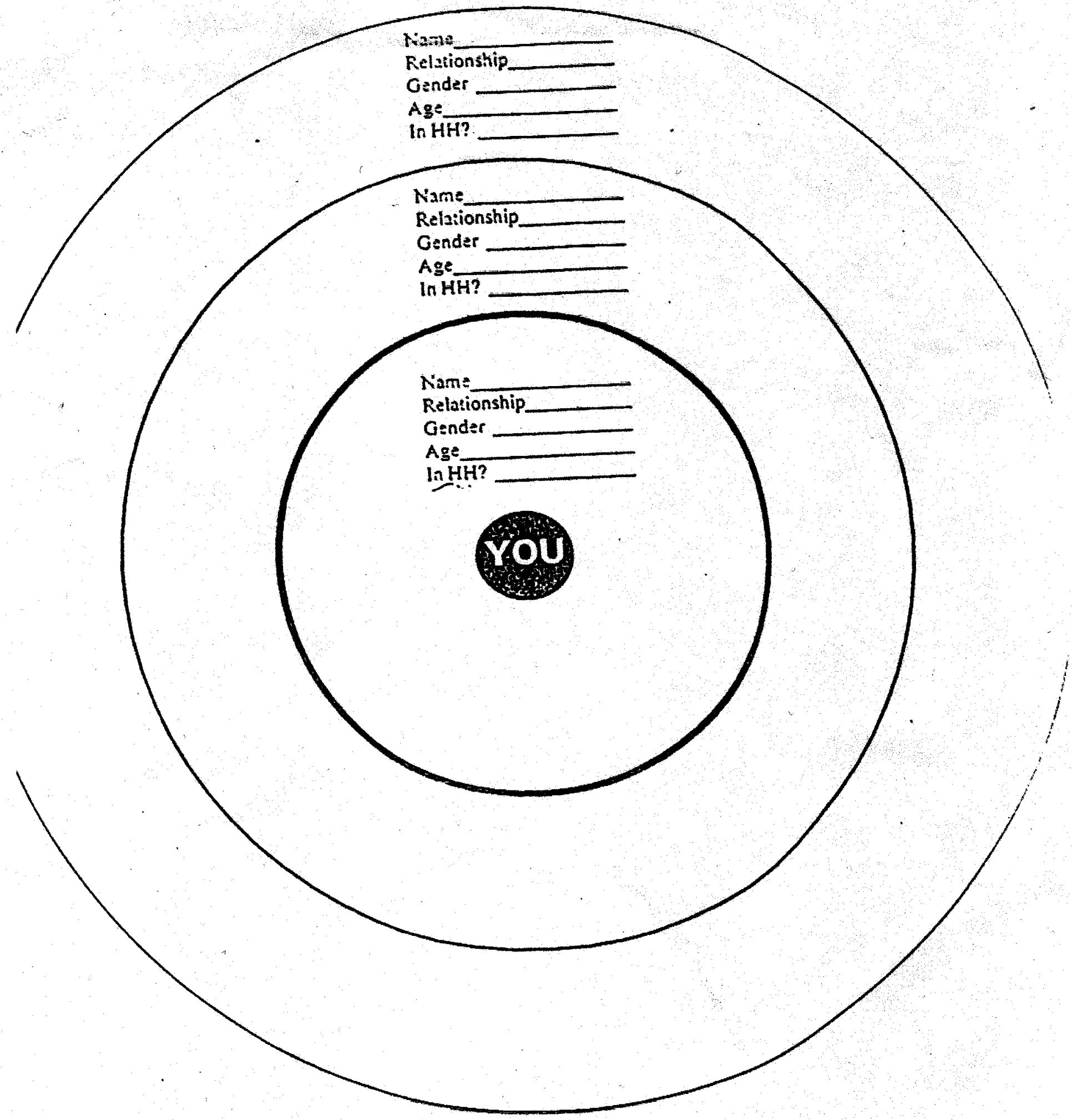


"Now I'd like to ask you some questions about your relationships with the people you know. Please refer to the sheet marked, 'Personal Networks'. As I ask each question, please tell me the name of each person who does each particular thing for you. They can include people in your circle or not. If no one does it, just say 'nobody.'"

\{If respondent answers "Nobody" to any question, circle code 00$\}$ If respondent answers "Don't know" or "Not sure" to any question, probe "What do you think?"\}

\begin{tabular}{|c|c|c|}
\hline & $\begin{array}{l}\text { Circle numbers corresponding to all persons } \\
\text { mentioned \& shown in the diagram. If someone } \\
\text { else is mentioned, record under "other(s)" }\end{array}$ & Others \\
\hline $\begin{array}{l}\text { 60. Are there people you } \\
\text { confide in about things that } \\
\text { are important to you? } \\
\text { Probe: Who else?\} }\end{array}$ & 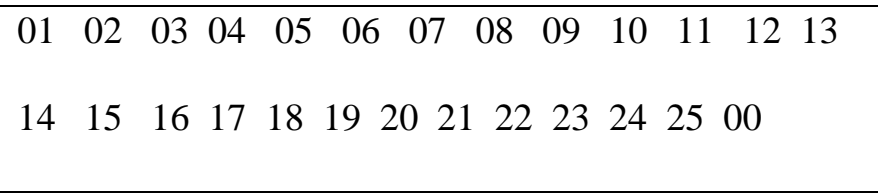 & \\
\hline $\begin{array}{l}\text { 61. Are there people who } \\
\text { expect you to do things that } \\
\text { you don't think are your } \\
\text { responsibility? \{Probe: Who } \\
\text { else?\} }\end{array}$ & 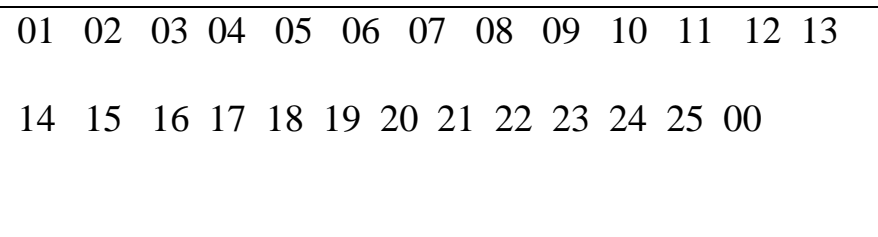 & \\
\hline $\begin{array}{l}\text { 62. Are there people who } \\
\text { give you good advice or } \\
\text { have a positive influence } \\
\text { on you? \{Probe: Who else?\} }\end{array}$ & 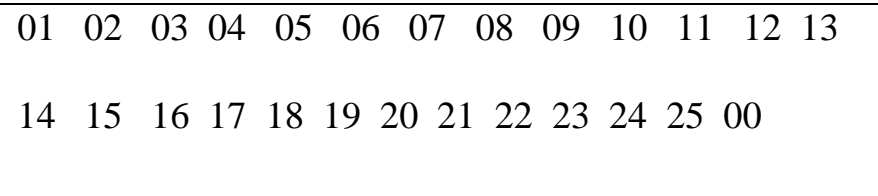 & \\
\hline $\begin{array}{l}\text { 63. Are there people who } \\
\text { give you bad advice or } \\
\text { have a negative influence } \\
\text { on you? \{Probe: Who else\} }\end{array}$ & 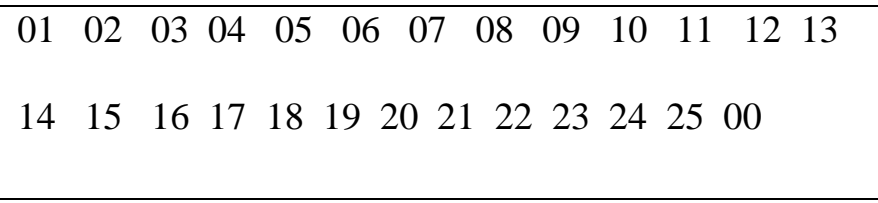 & \\
\hline $\begin{array}{l}\text { 64. Are there people who } \\
\text { are aware of your needs } \\
\text { and wishes? \{Probe: Who } \\
\text { else?\} }\end{array}$ & 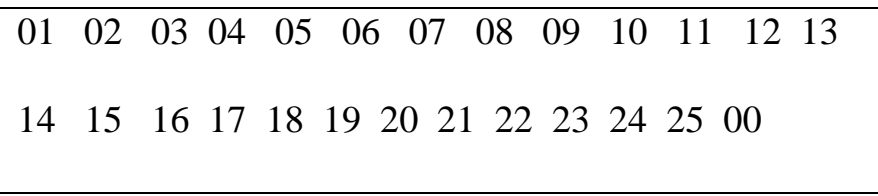 & \\
\hline $\begin{array}{l}\text { 65. Are there people who } \\
\text { don't pay attention to you } \\
\text { or take you seriously? } \\
\text { \{Probe: Who else?\} }\end{array}$ & 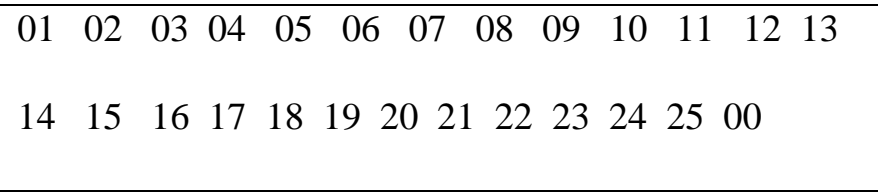 & \\
\hline $\begin{array}{l}\text { 66. Are there people who } \\
\text { are fun to be around? } \\
\text { \{Probe: Who else?\} }\end{array}$ & 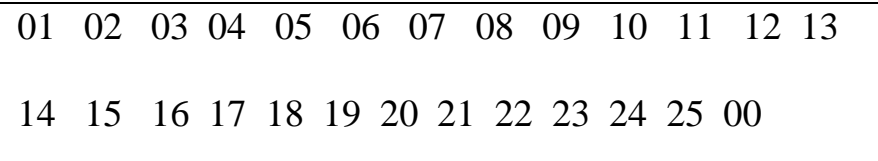 & \\
\hline $\begin{array}{l}\text { 67. Are there people who } \\
\text { you sometimes wish you } \\
\text { could avoid? } \text { \{robe: Who } \\
\text { else?\} }\end{array}$ & 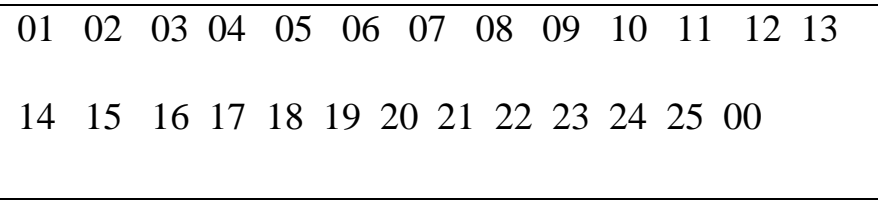 & \\
\hline
\end{tabular}




\begin{tabular}{|l|lllllllllllll|l|}
$\begin{array}{l}\text { 68. Are there people who } \\
\text { value your opinion? } \\
\text { \{Probe: Who else?\} }\end{array}$ & 01 & 02 & 03 & 04 & 05 & 06 & 07 & 08 & 09 & 10 & 11 & 12 & 13 & \\
\hline $\begin{array}{l}\text { 69. Are there people who } \\
\text { criticize you or are hostile } \\
\text { to you [?] } \\
\text { else?\} }\end{array}$ & 14 & 15 & 16 & 17 & 18 & 19 & 20 & 21 & 22 & 23 & 24 & 25 & 00 & \\
\hline
\end{tabular}

70. How satisfied are you with the amount of emotional support your receive from the people in your network?

$\begin{array}{llll}\text { Very Satisfied } & 3 & \text { Somewhat Satisfied } & 2\end{array}$

\section{Suggested Exit Interview}

Thank you \{Name\}, for agreeing to participate in this study. We really appreciate your time.

Do you have any questions for me?

I'd like to remind you that there is a lottery drawing for three $\$ 25.00$ cash prizes. If your name is selected we will give you a call. We will also be sending you an update of the findings in the mail in the next couple of months.

[Name] is there anyone else that you think might also want to participate in this study?

\{If yes\} What would be the best way to get in touch with you to get their contact information? Can we use your name as a referral when we contact them? Thank you again for your time. 